U.S. Department

of Transportation

National Highway

Traffic Safety

Administration

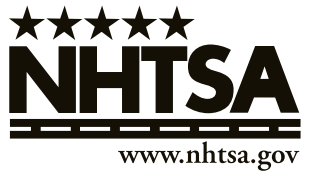

DOT HS 811614

June 2012

\title{
Review of Studies on Pedestrian and Bicyclist Safety, 1991-2007
}




\section{DISCLAIMER}

This publication is distributed by the U.S. Department of Transportation, National Highway Traffic Safety Administration, in the interest of information exchange. The opinions, findings, and conclusions expressed in this publication are those of the authors and not necessarily those of the Department of Transportation or the National Highway Traffic Safety Administration. The United States Government assumes no liability for its contents or use thereof. If trade names, manufacturers' names, or specific products are mentioned, it is because they are considered essential

to the object of the publication and should not be construed as an endorsement. The United States Government does not endorse products or manufacturers.

Suggested APA Citation:

Karsch, H. M., Hedlund, J. H., Tison, J., \& Leaf, W. A. (2012, June). Review of Studies on Pedestrian and Bicyclist Safety, 1991-2007. (Report No. DOT HS 811 614). Washington, DC: National Highway Traffic Safety Administration. 
Technical Report Documentation Page

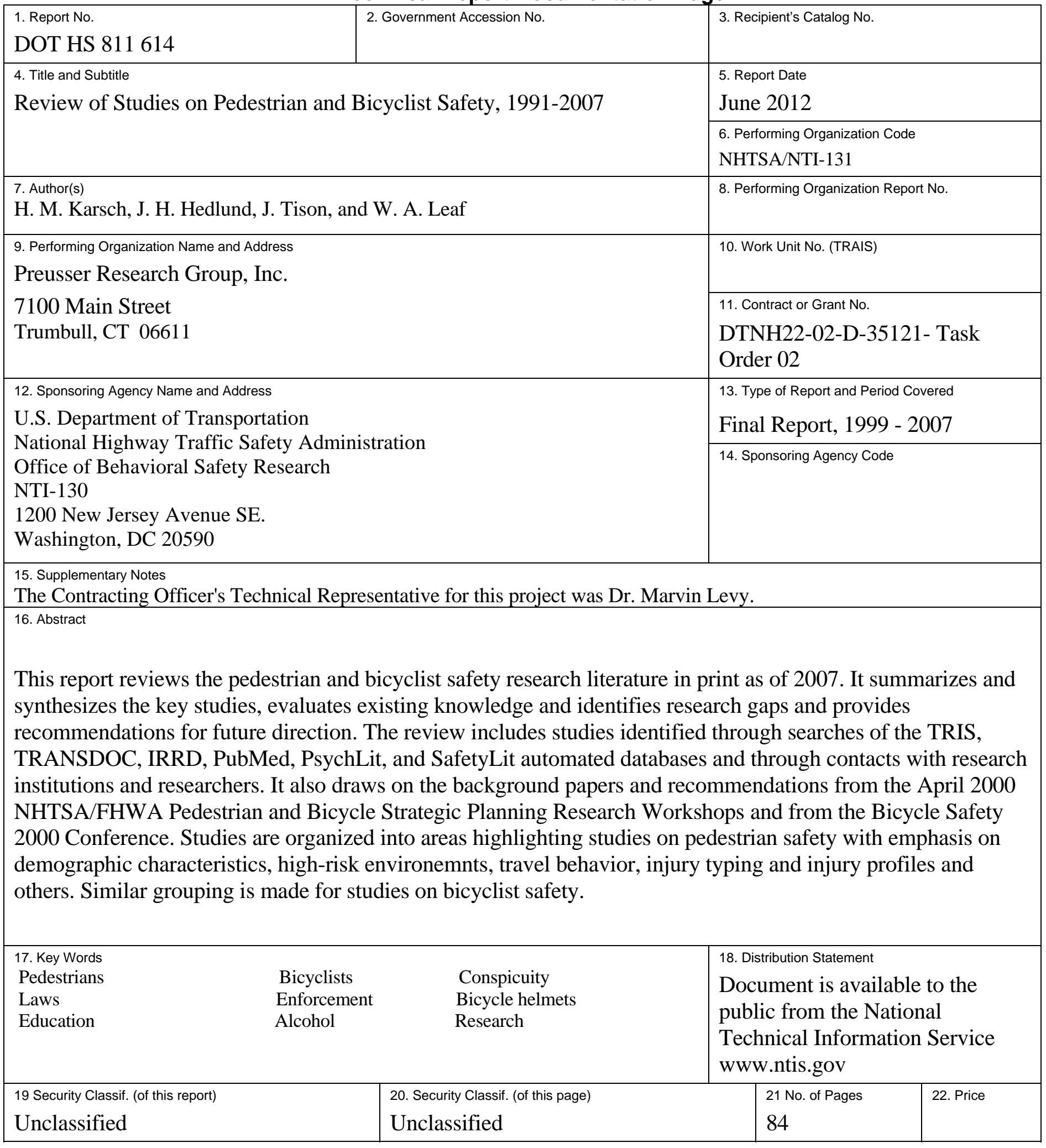

Form DOT F 1700.7 (8-72) 


\section{TECHNICAL SUMMARY}

\section{Background}

In 2009, 4,092 pedestrians and 630 bicyclists were killed in traffic crashes in the United States, representing a decrease of $7 \%$ and $12 \%$, respectively, compared to 2008 , and a decrease of $14 \%$ and $9 \%$, respectively compared to 2000 figures. Additionally, an estimated 59,000 pedestrians and 51,000 bicyclists were also injured in 2009. In the same year, pedestrians and bicyclists combined accounted for 14\% of traffic fatalities and 5\% of traffic injuries, as reported by the National Highway Traffic Safety Administration. These figures describe only traffic injuries and fatalities, and exclude injuries and fatalities from crashes occurring in private roadways, such as parking lots, bicycle and pedestrian trails, driveways, and similar locations. Additionally, pedestrian and bicycle injuries, especially lower-severity injuries, frequently are not reported to the police as traffic crashes, thus not counted towards the official traffic crash statistics.

\section{Objectives and methods}

This report reviews the pedestrian and bicyclist safety research literature from 1991 to 2007, highlighting key studies. The pedestrian and bicyclist research study review included studies that emphasize behavioral approaches to pedestrian and bicyclist safety published within this time frame. Foreign studies, directly relevant to pedestrian and bicyclist safety in the United States are included and previous literature reviews are summarized by highlighting their findings.

The studies included in the review were identified through a series of searches of a number of publication databases, which included TRIS, TRANSDOC, IRRD, PubMed, PsychLit, and SafetyLit. Additional reports and studies were identified through contacts with research institutions and researchers. Approximately 460 research articles, reports, reviews and other documents were identified through these search means and are summarized in this review. 


\section{Results}

General. Substantial pedestrian and bicycle safety research has been conducted recently. But while some topics have been studied extensively, others have not; while some issues are well understood, others are not.

Epidemiology. Further epidemiological data and studies on pedestrian and bicycle crashes and injuries are needed at two levels: To estimate the overall problem size more accurately and to provide a better understanding of crash causation.

Problem size. Published estimates of the number of injured pedestrians and bicyclists vary considerably. Methods should be sought to link or combine data from police reports, hospitals, emergency rooms, and other medical sources. If necessary, surveys or other sampling methods could be used to estimate crashes and injuries that do not appear on official records. Another critical lack is exposure data. Available exposure data for both pedestrians and bicyclists are limited and sporadic. Better exposure data will improve understanding of pedestrian and bicycle safety trends and causal factors.

Crash and injury causation. The police report provides the best data source, but the police report often doesn't record critical pieces of information. The rapid automation of State crash reporting systems provides an opportunity to collect and report additional useful data. States are designing their crash reporting systems so that police officers in the field can enter data through laptop or hand-held computers. A laptop system could include separate pedestrian and bicycle modules that are used only if a pedestrian or bicycle is involved in the crash.

Research is needed to define the crash data needs and determine how they can best be met, so the necessary data can be incorporated into State automated crash reporting systems.

Laws and enforcement. Research shows that many traffic laws regulating the interaction among drivers, bicyclists, and pedestrians are ignored regularly. Some laws may not be known or understood. Others may be ignored because they appear unnecessary. Enforcement is sporadic and ineffective in improving behavior.

The most obvious need is to establish a strategy regarding these laws and their enforcement. One possibility is to accept the current situation and recognize that these laws describe ideal behavior but will not be obeyed regularly. This strategy accepts that laws and enforcement have little role in improving pedestrian and bicycle safety.

A second possibility is to attempt to raise traffic law compliance substantially by pedestrians, bicyclists, and motorists alike. To do this, the laws must be generally accepted as sensible and reasonable. The appropriate first step is to review all traffic laws applying to pedestrians and bicyclists and all laws applying to drivers when they interact with pedestrians and bicyclists. If the laws are not sensible and reasonable, they should be changed. Only then can enforcement, combined with education, hope to be effective.

A final possibility, intermediate between these extremes, is to concentrate on situations where conflicts are frequent, risks are high, and the public supports action, such as school zones 
and red light running. Education and enforcement, aided by technology as appropriate, can be used to increase compliance. Research in these areas would be most useful to support action.

Public information and education. Pedestrian and bicycle safety education is absolutely essential for children. Many of the basic facts and concepts seem to be common sense but require education and guidance, usually by parents, and maturation and experience. Research shows clearly that formal pedestrian safety programs for children have been successful. Additional research should develop improved programs appropriate for children at different developmental ages and should determine effective ways to deliver this information to children. The evidence is far less clear for children's bicycle safety education programs, where basic research and evaluation are needed.

Most adults receive little or no pedestrian or bicycle safety information or education, even though many adults lack basic safety information (such as an understanding of the traffic laws applying to bicyclists or the meaning of the various phases of a WALK - DON'T WALK sign). Basic research is needed to investigate what information is useful and how it best can be transmitted.

Facilities and infrastructure. Extensive research has been conducted on facilities used by pedestrians and bicyclists. As this research continues, it should seek methods to accommodate and balance the sometimes conflicting needs and desires of pedestrians, bicyclists, and vehicle drivers. It also should consider how technology may be used to improve safety; for example, by automatically detecting pedestrians and bicyclists at controlled intersections and adjusting traffic signals accordingly.

Alcohol. Epidemiological studies have shown that many pedestrians and bicyclists in crashes are impaired by alcohol. A few studies have investigated the pedestrian alcohol problem but virtually nothing is known about alcohol-impaired bicyclists. Considerable research is needed in both areas to understand the problem and to recommend and test countermeasures. New studies are beginning for pedestrian alcohol safety efforts.

Conspicuity. Research on technical aspects of pedestrian and bicycle conspicuity driver visual capabilities, recognition distances under different lighting conditions, retroreflective materials, pedestrian and bicyclist awareness of their actual visibility, and the like - is quite extensive. One critical open area is to investigate how research findings on clothing conspicuity can be implemented into a wide variety of outer clothing for everyday use, much as retro-reflective materials are now used in many running shoes.

Older pedestrians. As the United States population ages, many aspects of society are being designed to accommodate older people. Pedestrian (and, in some instances, bicycle) facilities and programs should do the same. Some needs are obvious: longer WALK cycles to cross a street; public education directed at older people. Others may not be. Research on all pedestrian areas should keep the older pedestrian firmly in mind.

Bicycle helmets. Research has demonstrated conclusively that bicycle helmets substantially reduce head injuries in crashes. The important issue is how to convince more 
bicyclists to wear helmets. Research should continue to evaluate the effects of helmet use laws in the United States and around the world. Research also should continue to evaluate the effectiveness of various helmet use promotion programs. Research may be useful to develop more sophisticated methods of marketing helmet use to different cyclist audiences. 


\section{CONTENTS}

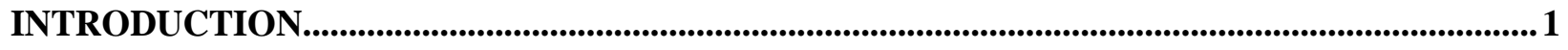

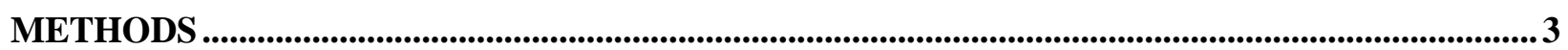

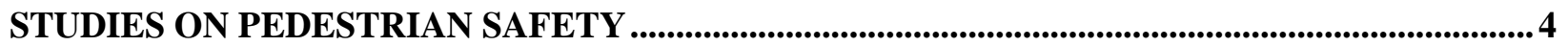

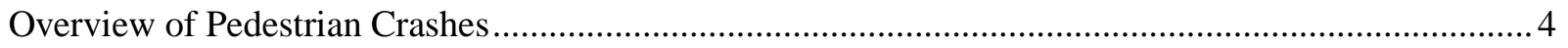

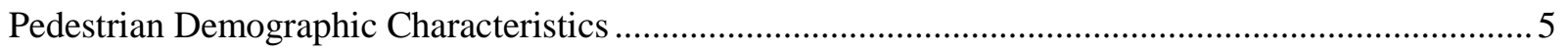

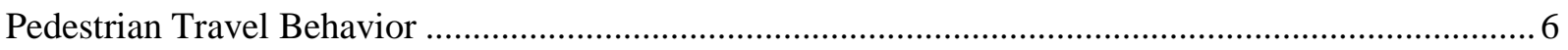

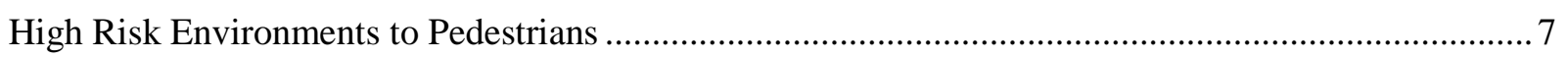

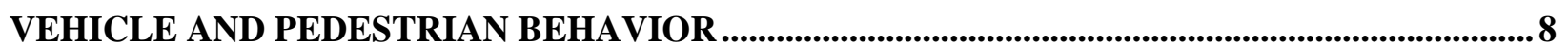

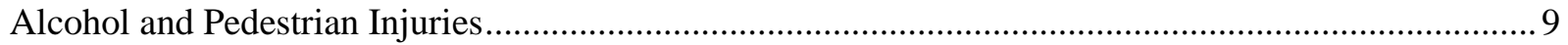

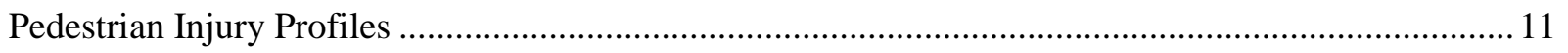

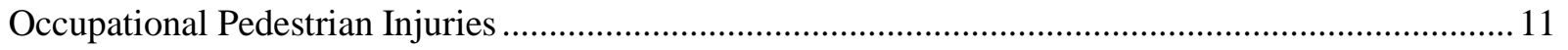

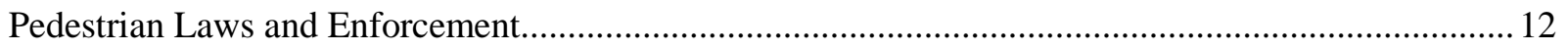

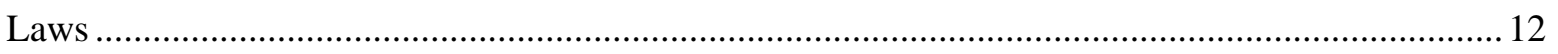

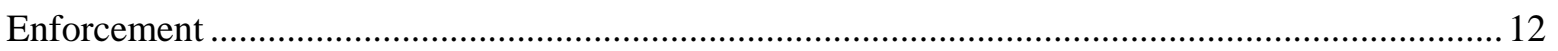

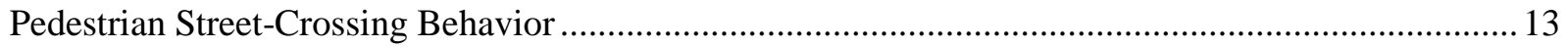

Pedestrian Conspicuity and Visibility ........................................................................................... 14

SPECIAL PEDESTRIAN TOPICS............................................................................................................... 15

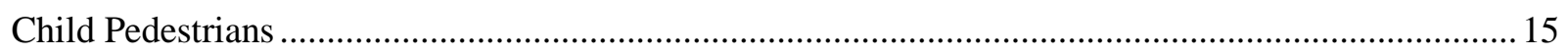

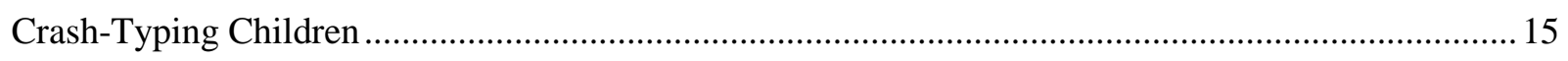

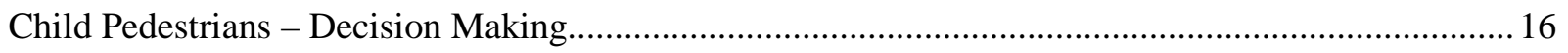

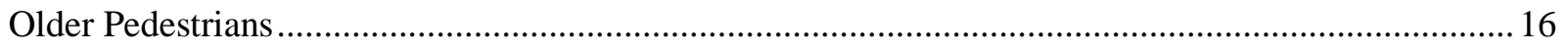

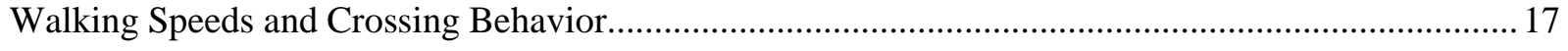

COUNTERMEAUSURES TO IMPROVE PEDESTRIAN SAFETY ................................................ 18

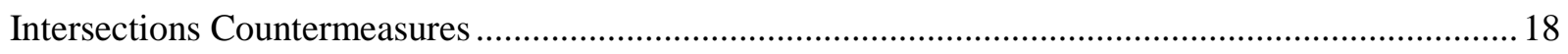

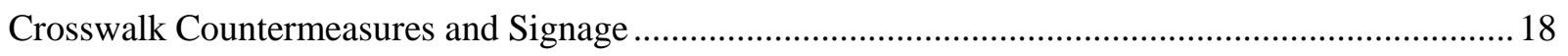

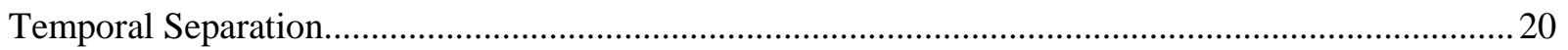

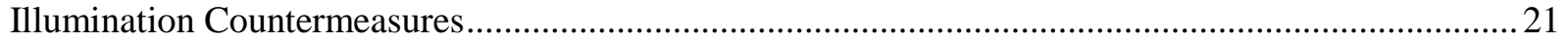

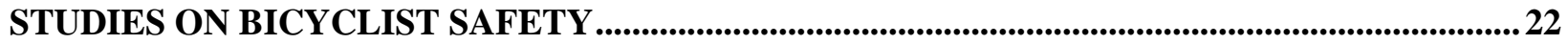

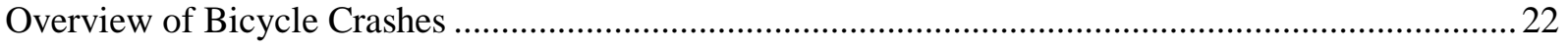

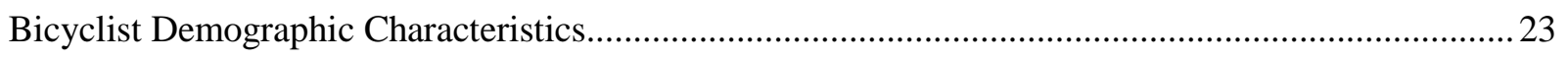

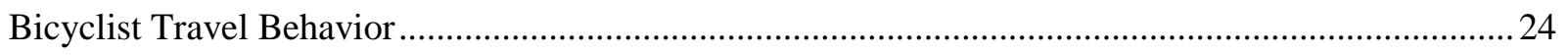

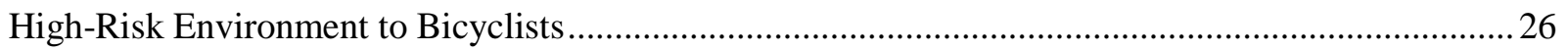

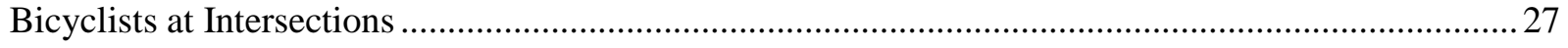

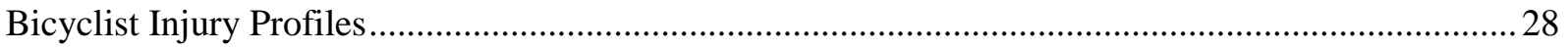




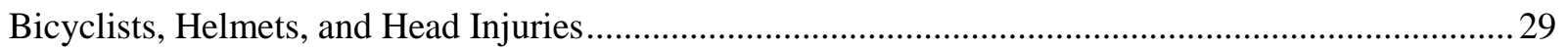

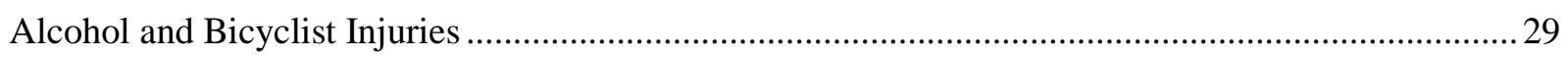

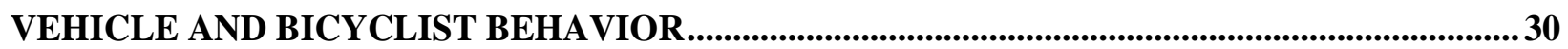

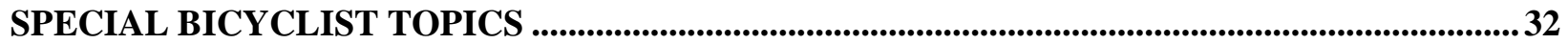

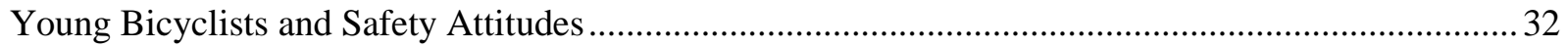

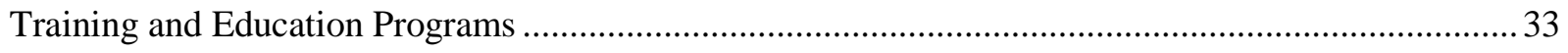

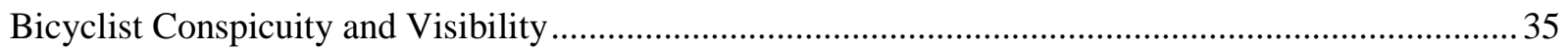

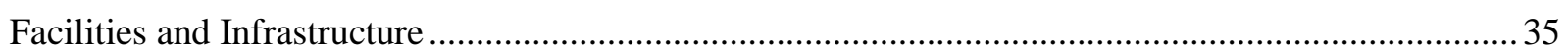

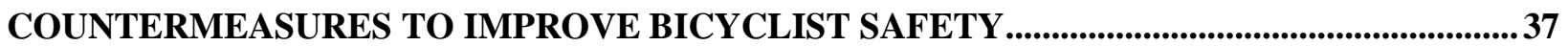

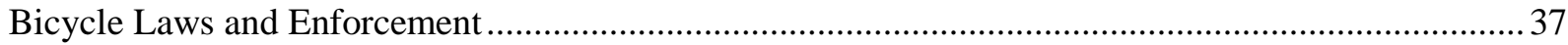

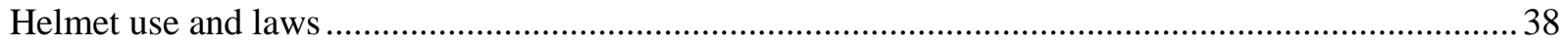

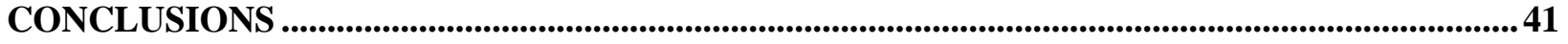

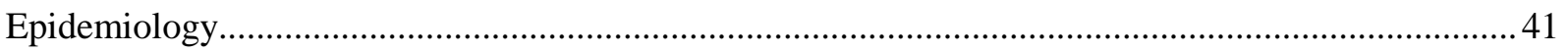

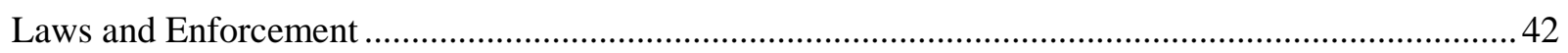

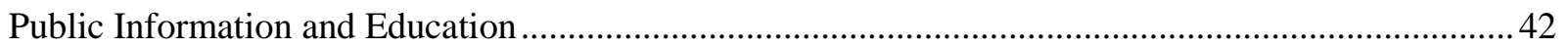

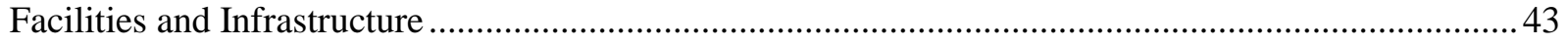

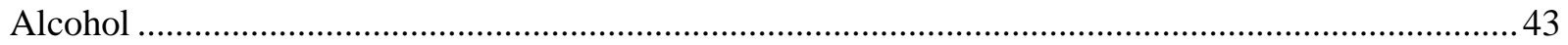

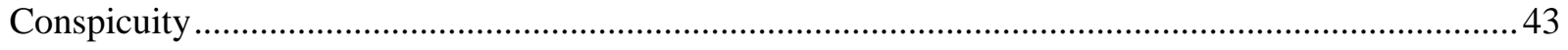

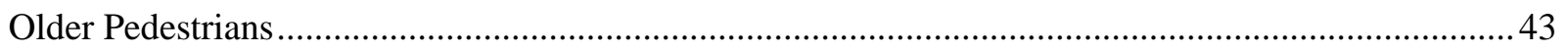

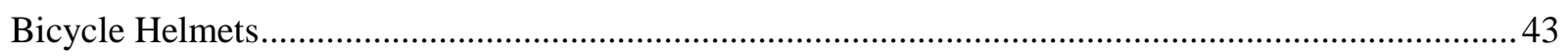

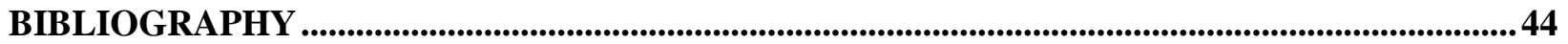




\section{INTRODUCTION}

In 2009, 4,092 pedestrians and 630 bicyclists were killed in traffic crashes in the United States, representing a decrease of $14 \%$ and $9 \%$, respectively, compared to 2000 . In the same year, approximately 59,000 pedestrians and 51,000 bicyclists were injured. Pedestrians and bicyclists accounted for $14 \%$ of traffic fatalities and 5\% of traffic injuries (NHTSA, 2010a; 2011b). These figures describe only traffic injuries and fatalities, and exclude injuries and fatalities from crashes occurring in private roadways, parking lots, bicycle and pedestrian trails, driveways, and similar locations. Furthermore, pedestrian and bicycle injuries, especially lowerseverity injuries, are frequently not reported to police as traffic crashes, thus not counted towards official traffic crash statistics.

While lagging behind other areas of safety research, pedestrian and bicyclist research has received considerable research support in recent years. Starting with the Intermodal Surface Transportation Efficiency Act of 1991 (ISTEA) that provided funding for pedestrian and bicycle facilities, there was also a call for a national bicycling and walking study (Zegeer \& Feske, 1994). The TEA-21 highway authorization bill included bicycling and walking as integral parts of the nation's transportation system and made all major funding sources for Federal aid transportation programs available to support bicycling and walking. Spending on bicycle facilities grew from a few million dollars annually in 1990 to about \$260 million annually in 2000 (Clarke, 2000a). Another contribution was the passage of the Americans With Disabilities Act in 1990 that led to dramatic changes in the physical environment for pedestrians and wheelchair users (Blomberg, 2000c).

- This report highlights research on behavioral issues of pedestrian and bicyclist safety, excluding studies on issues of highway design. It emphasizes research on the use of roads, sidewalks, intersections, and paths and includes studies on laws, enforcement, and education as they pertain to roadway uses by pedestrian and bicyclists.

- This report makes use of 12 previously conducted comprehensive reviews of specific pedestrian and bicycle areas, which together included over 1,150 studies: Campbell, Zegeer, Huang, and Cynecki, 2004; Clarke and Tracy, 1995; Karkhaneh, Kalenga, Hagel, and Rowe, 2006; Leaf and Preusser, 1999; Preusser Research Group, 2000; Retting, 1999; Retting, Ferguson, and McCartt, 2003; Steinberg, Freedman, and Fogash, 2000; Stutts, Hunter, Tracy, and Wilkinson, 1992; Taylor and Davis, 1999; Towner, Dowswell, Burkes, Dickinson, Towner, and Hayes, 2002; and Zegeer, 1991.

- This report emphasizes research conducted between 1991 and 2007 and other relevant studies.

- This report includes research conducted outside of the United States deemed relevant to pedestrian and bicyclist safety in the United States. 
The remainder of this report uses the terms bicycle and bicyclist in place of the more cumbersome terms pedalcycle and pedalcyclist. Most percentages and other numerical data have been rounded. 


\section{METHODS}

This report reviews scientific literature on pedestrian and bicycle safety issues that emphasize behavioral issues to pedestrian safety and were published between 1991 and 2007. Studies with a focus on highway or infrastructure design were omitted. Furthermore, this review presents results from previous literature reviews and notes studies conducted outside of the United States when directly relevant to pedestrian safety issues in the United States.

This review of studies on pedestrian and bicycle safety began with searches of automated transportation reference databases available through the Transportation Research Board (TRB). Three databases were used: TRIS (Transportation Research Information Services), with 310,000 records covering transportation-related publications from the United States; TRANSDOC, with 40,000 records on the social sciences of transportation published in European and associated countries; and IRRD (International Road Research Documentation), with 285,000 records covering all aspects of road research internationally. The search criteria were references to pedestrian and bicycle safety in general, from 1991 to 2007. The searches produced over 500 references of potential interest. Additional searches of the PubMed, PsychLit and SafetyLit databases were conducted and yielded over 350 additional references. Furthermore, studies from previously conducted comprehensive reviews of specific pedestrian and bicycle areas were included. 


\section{STUDIES ON PEDESTRIAN SAFETY}

\section{Overview of Pedestrian Crashes}

In 2009, 4,092 pedestrians were killed and an estimated 59,000 were injured in United States traffic crashes. This is equivalent to roughly one pedestrian killed in a traffic crash every 129 minutes and one injured in a traffic crash every 9 minutes. Overall, pedestrians accounted for 12\% of all traffic fatalities and 3\% of all traffic injuries in 2009 (NHTSA, 2010a).

NHTSA Traffic Safety Facts defines a pedestrian as "any person on foot, walking, running, jogging, hiking, sitting, or lying down who is involved in a motor vehicle traffic crash" where a traffic crash was defined as "an incident that involves one or more vehicles where at least one vehicle is in transport and the crash originates on a public traffic way."

Source: NHTSA Traffic Safety Facts 2009 Data-Pedestrians, DOT HS 811394

The most recent data from NHTSA show that, in 2009, those over the age of 20 account for $87 \%$ of pedestrian fatalities. Children 15 and younger accounted for $7 \%$ of the pedestrian fatalities and $25 \%$ of all pedestrians injured in traffic crashes (NTHSA, 2010a). Additionally, pedestrians 65 and older accounted for $19 \%$ of all pedestrian fatalities and $8 \%$ of all pedestrian injuries in 2009 (NTHSA, 2010a). These data also point out that $69 \%$ of pedestrians killed in 2009 were males, resulting in a male pedestrian fatality rate of 1.86 fatalities per 100,000 people, which is higher than the 0.82 fatalities per 100,000 people for female pedestrians. The male pedestrian injury rate in 2009 was 21 injuries per 100,000 people, which is slightly higher than the rate of 18 female pedestrian injuries for 100,000 people (NTHSA, 2010a).

Most national data on national pedestrian fatalities and injuries are from NHTSA's Fatality Analysis Reporting System (FARS) and General Estimates System (GES). While these sources provide an accurate account of pedestrian fatalities and injured occurring in public roadways, they exclude pedestrian injuries that do not involve a motor vehicle or injuries that did not occur in public roadways. Studies show that a substantial number of injuries are pedestrianonly injuries, where injury cause did not involve a motor vehicle and that may have occurred on a roadway, sidewalk, trail, or other public transportation-related facility (Stutts, 1997; Stutts \& Hunter, 1999). Some 66\% of pedestrians admitted to hospital emergency departments (ED) in California, New York, and North Carolina did not involve motor vehicles and some $80 \%$ of these pedestrian-only events occurred on non-roadway locations. In contrast, only $25 \%$ of pedestrian injury ED visits were due to pedestrian-motor vehicle crashes, and $88 \%$ of such visits resulted from incidents that occurred on the roadway (Stutts, 1997; Stutts \& Hunter, 1999).

Notable differences in the types of injuries and outcomes between injuries due to pedestrian-motor vehicle crashes and pedestrian-only injuries also exist. For example, 
pedestrian-motor vehicle crashes resulted in more severe injuries than pedestrian-only events. In motor vehicle crashes, $3 \%$ of victims died and approximately $36 \%$ were hospitalized, while in pedestrian-only crashes, none of those injured died and 7\% were hospitalized (Stutts, 1997; Stutts \& Hunter, 1999). Similarly, the types of injuries were also different, depending on the types of crashes. Pedestrians struck by motor vehicles were more likely to sustain lower limb, head and torso injuries and less likely to sustain injuries to the upper limb, face, and neck when compared to the injuries of those in pedestrian-only events (Stutts, 1997; Stutts \& Hunter, 1999).

\section{Pedestrian Demographic Characteristics}

In 2009, the most recent data available, 775 pedestrians 65 and older were killed in traffic crashes, accounting for $19 \%$ of all pedestrian fatalities. In the same year, an additional 5000 adults 65 and older were injured, accounting for 8\% of pedestrian injuries (NHTSA, 2010a). Based on NHTSA data for 2009, the fatality rate for pedestrians older than 75 was 2.28 per 100,000 population, higher than the fatality rate of any other age group (NHTSA, 2010a). NHTSA data also show that in 2009 for children 5 to 9 years old, fatalities as pedestrian accounted for $19 \%$ of all traffic crash fatalities. Children under age 16 accounted for $7 \%$ of the pedestrian fatalities in 2009 and 25\% of all pedestrians injured in traffic crashes (NHTSA, 2010a). For this age group, the fatality rate was 0.35 fatalities per 100,000 , considerably lower than the 23 injuries per 100,000 for the age group (NHTSA, 2010a).

Other studies examining demographic characteristics of pedestrian fatalities and injuries showed that $32 \%$ of pedestrian fatalities were adults 24 to 44, with twice as many pedestrian males being fatally struck compared to female pedestrians. Male pedestrian fatalities were shown to outnumber female fatalities in every age group (Campbell el. al, 2004). Similarly, a study by Harruff, Avery, and Alter-Pandya (1998) that analyzed pedestrian traffic fatalities in Seattle between 1990 and 1995, showed that the average age of pedestrians involved in traffic fatalities was 49 years old.

Reviews also point out that ethnic and racial minority pedestrians may be at increased risk for pedestrian related fatalities and injuries. For instance, among those States with available racial and ethnic information, FARS data showed that, in 2009, 61\% of pedestrians killed were classified as White, 17\% were African-American, and 2\% were Native Americans (FARS, 2011). One study reported that $75 \%$ of pedestrian fatalities were Caucasian-American, $19 \%$ are African-American and 16\% were Hispanic-Americans ${ }^{1}$ (Ernst, 2004). The larger proportion of walking trips made by Latino-Americans and African-Americans may contribute to that difference. For Caucasian-Americans, about 9\% of all trips are made on foot, compared to $12 \%$ and 13\% for Latino and African-Americans, respectively (Ernst, 2004). A 1998 study conducted in Seattle, Washington, showed that while Caucasian-Americans comprised $85 \%$ of the population, they accounted for $74 \%$ of fatalities. Asian-Americans and African Americans comprised $8 \%$ and $5 \%$ of the population, respectively, but accounted for $12 \%$ and $8 \%$ of fatalities (Harruff et al. 1998).

\footnotetext{
${ }^{1}$ Figures do not add up to $100 \%$ as values for Caucasian-American and African-American may include Hispanic ethnicity.
} 
A review of pedestrian fatalities in four counties in Georgia showed that pedestrian death rates for minority populations were significantly higher than those for whites. The pedestrian death rate for Non-Hispanic blacks and Hispanics was estimated to be between two and six times greater, respectively, than the rate for non-Hispanic whites (CDC, 1999). Additionally, other studies have shown that pedestrian crashes are positively correlated with the proportion of elderly residents, public transportation passengers, and the proportion of renters in census tracks, and negatively correlated with population size, household income, and population density (Kim \& Ortega, 1999).

\section{Pedestrian Travel Behavior}

Few studies have investigated U.S. pedestrian travel patterns and characteristics. While everyone can be considered a pedestrian, pedestrian trips are generally short and often are combined with other travel modes (Schwartz, 2000b). DaSilva, Smith, and Najm (2003) used data from the Statewide Traffic Accident Management Information System (STAMIS), the U.S. Census, and the Nationwide Personal Transportation Survey (NPTS) to examine walking and injury patterns across the United States. They showed that pedestrians 65 to 74 years old had the highest crash, injury, and fatality rates per miles walked, whereas pedestrians age 5 to 18 had the highest crash and injury rates per capita. Pedestrians over 75 were found to have the highest fatality rate on a per capita basis. Pedestrian travel as measured by pedestrian volume has also been shown to differ geographically. For example, a study in Washington State showed that pedestrian volumes, as measures by the number of pedestrians observed on a per hour basis, differed significantly between urban and suburban areas. All urban locations had higher number of pedestrians per hour and per 1,000 residents. Urban locations had higher pedestrian volumes on a per 500 acres basis when compared to suburban areas (Moudon, Hess, Snyder, \& Stanilov, 1997).

Street design, location of services and facilities, and the person's income has been shown to influence pedestrian travel behavior. Shriver (1997) compared pedestrian travel in "traditional" neighborhoods characterized by streets in a rectangular grid, short blocks, and numerous intersections to "modern" neighborhoods with irregular street designs and a hierarchical layout that discouraged vehicle traffic on residential streets. Results showed that in both types of neighborhood designs, $25 \%$ of walking trips were made for exercise and approximately 33\% were made for shopping and other similar activities. Pedestrians in modern neighborhood designs reported longer walking distances and durations for exercise, walking the dog, and socializing than those reported in traditional neighborhoods. Furthermore, regardless of neighborhood design, pedestrians with higher annual income, more dependents, and more cars made fewer walking trips and reported that long distances and lack of time were the greatest obstacles to walking. Older adults, students, and those with lower annual household incomes were found to walk longer distances. Larger household size and lower annual income were correlated with shorter walking trips (Shriver, 1997). In a similar study of pedestrian travel behavior, O’Sullivan and Morrall (1996) showed that the average walking distance to bus stops in Calgary, Canada, was 0.2 miles; walking distances to light rail train (LRT) stations were slightly longer, at an average of 0.4 miles, with lower walking distances to LRT stations in the central business district (O’Sullivan \& Morrall, 1996). 


\section{High Risk Environments to Pedestrians}

In an effort to develop countermeasures that best address pedestrian fatalities and injuries, a number of studies have been commissioned to identify high-risk areas for pedestrians and to characterize most frequent pedestrian crashes, known as crash types. According to the 2004 report, PEDSAFE: Pedestrian Safety Guide and Countermeasure Selection System, most pedestrian crashes occur in urban areas, due to the high pedestrian activity and traffic volumes (Harkey \& Zeeger, 2004; DaSilva, 2003). This is supported by the most recent NHTSA reports that estimate that $72 \%$ of pedestrian fatalities occurred in urban areas versus rural settings in 2009. Additionally, NHTSA reports show that $76 \%$ of pedestrian fatalities occurred at nonintersection locations, $70 \%$ occurred at night and 90\% occurred during non-inclement weather days (NHTSA, 2010a).

A report by Ernst (2004) suggests that high-speed arterials roads pose the most risk to pedestrians. Based on NHTSA's FARS data, this report shows that principal arterial roads accounted for $31 \%$ of pedestrian fatalities, followed by local roads and expressways, which accounted for 22 and 15\% of pedestrian fatalities, respectively. Furthermore, over $40 \%$ of pedestrian fatalities occurred in locations lacking crosswalks and the most risky areas were lower density neighborhoods with large arterial streets and few crosswalks or sidewalks (Ernst, 2004). A similar study conducted in San Francisco, California showed that pedestrian injuries were more likely to occur in areas with greater traffic flow and greater population densities. This study also showed that lower proportions of children in the population and higher unemployment, as well as lower education levels were also associated with higher risk for pedestrian injuries (LaScala, Gerber, \& Gruenewald, 2000). Past studies have also shown that, in cities with a population of 1 million or more, pedestrians account for about 35\% of motor-vehicle-related fatalities (Retting, Ferguson, \& McCartt, 2003).

In addition to heightened death and injury risks presented to pedestrians by various roadway configurations, studies have also examined the increased risk at different times of the day. A review of pedestrian safety research by Campbell et al. in 2004, showed that the highest proportion of crashes involving pedestrians occurred between 3 p.m. and 6 p.m. Contrary to pedestrian injuries, most pedestrian fatalities tend to occur at night, with the majority of fatal crashes occurring between 5 p.m. and 11 p.m. (Campbell et al., 2004; Harkey \& Zeeger, 2004). Crashes involving older pedestrians occurred more frequently during fall and winter months, whereas younger pedestrian crashes occurred more frequently during the spring and summer months (Campbell el al., 2004). A separate study showed that in 2003, approximately half of all pedestrian fatalities occurred during the last three days of the week, highlighting the clustering of pedestrian fatalities on weekend days (Harkey \& Zeeger, 2004).

A different approach to crosswalk safety argues that marked crosswalks give pedestrians a false sense of security, so that they may enter the roadway without looking for vehicles or may assume that vehicles will provide safe passage. Studies comparing the safety effects of marked and unmarked crosswalks at non-signalized locations found that crash frequency was affected by many variables other than crosswalk markings, including pedestrian volume, traffic volume, and number of lanes (Zegeer, Stewar, \& Huang, 2000). Other results include that road speed limit did not affect the frequency of crashes with pedestrians but was positively related to crash severity 
and that raised medians, but not painted medians, increased pedestrian safety. Furthermore, pedestrian crash risk was not affected by whether it occurred in a residential or business area, or whether the crosswalk was located at an intersection or midblock. Also, the study showed that the direction of traffic flow, such as one-way traffic or two-way traffic, crosswalk condition, or type of crosswalk marking did not affect pedestrian crash risk (Zegeer et al., 2000). In a separate study, Gibby, Stites, Thurgood, et al., (1994) showed that no relationship existed between crosswalk markings and crash rates at signalized intersections; however, non-signalized intersections crosswalk markings were associated with higher crash rates (Richards, 1999).

In another approach to investigating risky environments to pedestrians, Harruff et al. (1998) showed that residential streets accounted for the highest proportion of pedestrian crashes, $66 \%$, followed by pedestrian crashes occurring at thoroughfares, which accounted for $29 \%$. Additionally, the study showed that roads with speed limits between 25 and $30 \mathrm{mph}$ accounted for $44 \%$ of crashes; roads with speed limits of 35 to 40 , which accounted for $31 \%$ of crashes. Furthermore, roads with speed limits between 45 and 50 accounted for $10 \%$ of crashes; $15 \%$ of crashes occurred on roads with speed limits above $55 \mathrm{mph}$. Results showed that $72 \%$ of pedestrians were crossing the roadway when they were hit; and 14\% were walking or standing in the roadway or shoulder at the time of the crash (Harruff et al., 1998).

\section{VEHICLE AND PEDESTRIAN BEHAVIOR}

In an effort to distinguish the various characteristics of pedestrian and vehicle crashes, crash-typing was introduced. Crash-typing is a method for classifying crashes into a number of meaningful categories based on common crash characteristics. The usefulness of such a system has been recognized since the early 1970s, when Snyder and Knoblauch (1971) first proposed it. They defined crash types by analyzing the behavioral sequence in a crash of search, detection, evaluation, decision, human action, and vehicle action. Each stage in this sequence may produce a crash due to predisposing factors (driver factors, pedestrian factors, vehicle factors, or environmental factors) or precipitating factors such as pedestrian risk-taking and inadequate search. Several studies described below categorized pedestrian-motor vehicle crashes into specific types in order to determine the most frequent crash scenarios. For example, Jordan (1998) coded 43 different pedestrian actions for child pedestrian crashes near schools. The pedestrian action codes were clustered based on the type of signal control at the intersection where the crash occurred. Johnson (1997) classified pedestrian actions into 13 different categories in his investigation of pedestrian fatalities on interstate highways. Snyder and Knoblauch defined 30 crash types in 9 broad categories. These crash types, supplemented with predisposing and precipitating factors, were used to develop countermeasures. The original crash-typing system has been modified into the crash-typing system used in NHTSA's General Estimates System, where it is applied to all pedestrian crashes in the GES (Safety Consulting Services, 1997b).

Others have developed different crash-typing categorizations based on that originally used in NHTSA's GES. An example is a study by Stutts, Hunter, and Pein, who developed pedestrian and vehicle crash types based on large sample of 5,000 pedestrian vehicle crashes from California, Florida, Maryland, Minnesota, North Carolina, and Utah. This crash study created 61 crash types in 9 categories. Results showed that the most common pedestrian factors were running into road 
and failure to yield, which accounted for 15 and $12 \%$ of pedestrian crashes, respectively. Alcohol impairment and stepping from between parked vehicles accounted for another 10 and $7 \%$ of examined pedestrian crashes, respectively. The most common driver factors were hit-and-run, accounting for $16 \%$ of crashes, followed by $15 \%$ of drivers failing to yield to pedestrians, and $6 \%$ of drivers traveling at speeds above the speed limit (Stutts et al. 1996).

Results using this new typing showed that children under 10 were over-involved in midblock and intersection dashes, bus-related crashes, crashes due to playing in the roadway, and vehicle-specific crashes, which include going to or coming from a vendor or ice cream truck and entering or exiting a vehicle. This new crash-typing showed that pedestrians 10 to 14 were overrepresented in intersection and midblock dashes and bus-related crashes. Older teenagers, those between 15 and 19, accounted for over 33\% of bus-related crashes and were likely to be involved in crashes when walking along the roadway (Stutts et al., 1996).

This modified crash-typing showed that adult pedestrians 20 to 24 were over-involved in crashes involving disabled vehicles, backing vehicles, or walking along the roadway. Those 25 to 44 were over-involved in crashes dealing with disabled vehicles or walking along the roadway. Pedestrians 45 to 64 were over-represented in crashes involving turning vehicles at intersections. Pedestrians 65 and older were over-involved in crashed involving backing vehicles and intersection-related crashes (Stutts et al., 1996).

Others have established new crash types by grouping driver and pedestrian behaviors into pre-crash scenarios. One such approach reported that the top ten crash scenarios identified accounted for $86 \%$ of all crashes analyzed. It showed that $26 \%$ of crashes involved a vehicle traveling straight and pedestrian crossing at a non-junction and $19 \%$ of crashes involved a vehicle traveling straight while the pedestrian crossed at an intersection. Another $16 \%$ of crashes involved a vehicle traveling straight and pedestrian darting into the roadway at a non-junction and 9\% involved a vehicle making a left turn and pedestrian crossing at an intersection (DaSilva, Smith, \& Najm, 2003). This approach also showed that the majority of the scenarios took place on straight roads (non-junction) with speed limits between 25 to $35 \mathrm{mph}$; and $45 \%$ of crashes occurred at intersections where a three-color traffic light was present. Hit-and-run crashes accounted for 15 to $19 \%$ of the crashes (DaSilva et al. 2003).

\section{Alcohol and Pedestrian Injuries}

Many pedestrians in motor vehicle crashes are impaired by alcohol. In 2009, 35\% of all U.S. fatally injured pedestrians had BACs above $.08 \mathrm{~g} / \mathrm{dL}$ whereas only $13 \%$ the drivers involved in fatal pedestrian crashes reached or exceeded this BAC level. In $6 \%$ of fatal crashes, both the driver and the pedestrian had BACs of $.08 \mathrm{~g} / \mathrm{dL}$ or higher (NHTSA, 2011a). Past studies have shown that between 1999 and 2002, 43\% of fatally injured male pedestrians and 21\% of fatally injured female pedestrians had BACs at or above $.08 \mathrm{~g} / \mathrm{dL}$ (Leaf, Shabanova, Northrup, \& Preusser, 2005).

This problem is not limited to the United States; fatality rates among pedestrians globally show a high percentage of alcohol involvement. For instance, in Great Britain and Sweden, over two-thirds of young adult pedestrians killed were reported to be impaired (Öström \& Eriksson, 
2001, Tunbridge \& Keigan, 2002). While using varying definitions for alcohol involvement studies show that in Canada in 2000, 38\% of fatally injured pedestrians had been drinking (Mayhew, Brown, \& Simpson, 2002), while in Australia, close to 45\% of pedestrians killed had positive BACs (Lang, Tay, Watson, Edmonston, \& O’Connor, 2003). Impaired pedestrians were predominantly male and tend to be 25 to 44 years old (Campbell et al., 2004; Leaf \& Preusser, 1997; Wilson \& Fang, 2000). Crashes involving impaired pedestrian were more likely to occur at non-intersections compared to non-impaired pedestrian collisions (Wilson \& Fang, 2000 as cited in Wilson, Fang, \& LeBrun, 2003) and studies showed that alcohol significantly increases the risk of dying as a result of being involved in a crash (Miles-Doan, 1996). Studies also showed that $16 \%$ of pedestrians or bicyclists involved in traffic crashes had current or past history of alcohol abuse or dependence (Weber, Maio, Blow, Barry, \& Waller, 2002).

In an effort to examine the degree of alcohol involvement among U.S. pedestrian fatalities involving different racial and ethnic groups, Leaf and Preusser (1997) conducted an analysis of recorded fatalities. Fatality data were obtained from various sources including FARS, the Centers of Disease Control's Multiple Causes of Death (MCOD) database, and sources from six States. Analysis of these data by age, gender, race, and BAC showed that certain subpopulations were consistently over-represented. For example, Native American males were about twice as likely to have BAC levels above $.10 \mathrm{~g} / \mathrm{dL}$ compared to all other males, and Native American females were about three times as likely to have BAC levels above $.10 \mathrm{~g} / \mathrm{dL}$ compared to all other females. Elevated BAC levels were uncommon among Asian/Pacific Islander victims, and Hispanic female pedestrians were less likely to have elevated BAC levels compared to Hispanic males. High levels of alcohol involvement were also found among Black adults over age 24, Hispanic males over age 20, and Native Americans (Leaf \& Preusser, 1997). Leaf et al. (2005) showed that Native Americans males and females had the highest rate of BACs at .15 $\mathrm{g} / \mathrm{dL}$ or above, followed by Hispanic males, African American males, and Caucasian males (Leaf, Shabanova, Northrup, \& Preusser, 2005).

Examining the prevalence of alcohol among pedestrians and vehicle drivers involved in pedestrian fatalities, Subramanian (2005) showed that among all crashes involving alcohol and categorized as alcohol-related in 2003, two-thirds of fatalities involved drivers/motorcycle operators and non-occupants who themselves had alcohol in their systems and 79\% of pedestrians killed in alcoholrelated crashes had positive BACs. One argument for the high rate of positive BACs among fatally injured pedestrians is the high risk of being struck as a pedestrian in locations with a high number of drinking establishments (LaScala, Gerber, \& Gruenewald, 2000) with the majority of injuries occurring on the weekend and during nighttime hours (Johnson, 1997; Kong et al., 1996). This argument is based on observations that the frequency of alcohol-related pedestrian injuries and fatalities increases with an increase in the density of licensed drinking establishments (LaScala, Gerber, \& Gruenewald, 2000).

Kong et al. (1996) reported that $17 \%$ of fatally injured pedestrians tested for alcohol concentration had BACs above $.10 \mathrm{~g} / \mathrm{dL}$, and a majority of fatally injured male pedestrians had BACs averaging $.16 \mathrm{~g} / \mathrm{dL}$. A similar study that examined pedestrian fatalities in the Texas interstate system showed the extent of variability in BAC levels among pedestrians (Johnson, 1997). Texas reported a significantly higher prevalence of alcohol among pedestrians than the study by Kong et al. (1996). Some 33\% of pedestrian fatalities were alcohol-positive, with an average BAC of $.20 \mathrm{~g} / \mathrm{dL}$ with over $95 \%$ of the fatally injured, alcohol-positive pedestrians being 
struck in the roadway, compared to $75 \%$ for non-alcohol related cases. Alcohol-positive pedestrians were more likely to be struck after dark than non-intoxicated pedestrians. The driver of the striking vehicle had a BAC of .10 g/dL or above in $8 \%$ of these fatal pedestrian crashes in Texas (Johnson, 1997).

\section{Pedestrian Injury Profiles}

Pedestrians are vulnerable road users and several studies have attempted to characterize the injuries of those involved in pedestrian-motor vehicle crashes. One study showed that 38\% of the hospitalized patients of pedestrian-motor vehicle crashes were younger than 15 and another $8 \%$ of patients were over 65 (Stutts \& Hunter, 1999). The most common injuries were musculoskeletal injuries (34\%), followed by head and neck injuries (30\%), external injuries (24\%), abdominal and pelvic injuries (4\%), chest-related injuries (2.4\%) and spinal injuries (1.8\%). Mortality rates for older pedestrians were 3 times those of adults (Peng \& Bongard, 1999). Similar findings were reported by Kong et al. (1996). This study also reported that $39 \%$ of pedestrian-motor-vehicle crash victims died within two hours of the crash, 59\% within 24 hours, and $78 \%$ within 48 hours.

\section{Occupational Pedestrian Injuries}

Injuries sustained by workers as pedestrians represent an important prevention and countermeasure area. One review of pedestrian injuries that occurred on New York State Department of Transportation highway and bridge construction projects between 1993 and 1997 showed that most injuries resulted from accidents at construction sites, and that traffic crashes accounted for $15 \%$ of all serious injuries and over $40 \%$ of all fatalities (Bryden \& Andrew, 1999). It was also shown that among traffic crashes involving workers, two-thirds of the motor vehicles involved had left the traffic lane and entered the work area. However, 29\% of the worker fatalities occurred when worker pedestrians were struck by motor vehicles outside the defined work area.

Risks posed to pedestrians by commercial vehicles and have also been studied. One study noted that pedestrian fatalities involving large trucks ${ }^{2}$ were more likely to occur at intersections, when traffic signals controlled traffic flow, and during daylight when compared to pedestrian fatalities due to other vehicle types. Results also showed that pedestrians fatally hit by large trucks tend to be older, with a median age of 60, compared to a median age of 40 for those hit by other types of vehicles (Retting et al., 1993). It was also shown that large trucks were most frequently moving forward when pedestrian crashes occurred, with the initial impact point being the front of the truck or undercarriage. The two most common crash scenarios, accounting for $47 \%$ of all crashes, involved large trucks proceeding forward either at intersections or nonintersection locations. Trucks turning and striking pedestrians with the front of the trucks, the rear wheels, or the trailers accounted for another 24\%. Trucks backing up fatally injured pedestrians in $10 \%$ of cases (Retting et al., 1993).

\footnotetext{
${ }^{2}$ Large Trucks were defined as trucks exceeding 10,000 lbs.
} 


\section{Pedestrian Laws and Enforcement}

\section{Laws}

The key laws and ordinances affecting pedestrian safety attempt to control pedestrian and driver behavior at intersections, crosswalks, and other locations. The Uniform Vehicle Code (UVC) regulates pedestrian travel and road-crossing behavior. The UVC requires pedestrians to obey traffic control devices, cross roadways in marked crosswalks, and not cross diagonally (“jay-walk"). Pedestrians in crosswalks are granted the right-of-way under these laws (or under the UVC). Pedestrians crossing outside of crosswalks must yield the right-of-way to vehicles. The UVC requires pedestrians to use sidewalks whenever possible and to walk on the left side of the roadway in the absence of sidewalks. A report from Preusser Research Group, (2000) reviews UVC regulations that control vehicle actions and affect pedestrians, such as prohibiting motorists on sidewalks.

Studies show that both the driver and the pedestrian do not have a complete understanding of transportation laws. Pedestrians do not completely understand pedestrian signals and both pedestrians and drivers do not obey laws and signals consistently. Anecdotal evidence suggests that pedestrian compliance with traffic laws may be decreasing and that “aggressive pedestrians” may be joining aggressive drivers as a contemporary traffic safety problem (Brown, 2000). Some of these problems may be due to ambiguity or misunderstanding of right-of-way laws at crosswalks (Britt et al., 1995). In standard law (as codified in the UVC), a pedestrian has the right-of-way when in a crosswalk but the driver is not required to yield to a pedestrian waiting to enter a crosswalk.

In a study of understanding of pedestrian rules and regulations, $88 \%$ of respondents reported being aware that in cities, they are required to cross the street at signals or crosswalks. The vast majority of respondents, 93\%, also were aware that a pedestrian already in the crosswalk had the right of way. However, 31\% responded that drivers are not required to stop and about $60 \%$ believed that the driver was expected to stop. About $80 \%$ correctly understood that a driver making a right turn on red must yield right-of-way to pedestrians. More people answered correctly to a similar question regarding left turns on green; 93\% responded that the driver must wait for the pedestrian to cross (Tidwell \& Doyle, 1995).

When asked about the use of the roadway by joggers, 58\% of respondents knew that joggers must use sidewalks when available, as required in all States except Rhode Island; however, $17 \%$ of respondents considered that joggers are allowed on the roadway. Almost 69\% recognized that on roadways with no sidewalks, walking on the right side with traffic is not permitted (Tidwell \& Doyle, 1995). Furthermore, many respondents did not understand pedestrian WALK and DON'T WALK signals. Almost half (43\%) believed a flashing DON'T WALK signal requires pedestrians to return to the curb. Almost half (47\%) believe that a WALK signal indicates that no cars will be turning into the crosswalk area (Tidwell \& Doyle, 1995).

\section{Enforcement}

Pedestrians as vulnerable road users face increased risks in large cities with high motor vehicle and pedestrian densities and challenging traffic environments, such as New York City. A 
study examining pedestrian fatalities in New York City reported that the driver was fully or partially responsible for $92 \%$ of crashes with pedestrians (Komanoff, 1999). The most common pedestrian crash causes included drivers turning into the crosswalk (17\%) and vehicles speeding (11\%). Driver red lights or stop sign violations and driver distraction each contributed to $10 \%$ of crashes.

Although the vehicle driver was deemed at fault in the vast majority of New York City pedestrian crashes and $26 \%$ of crashes were hit-and-run, only $25 \%$ of drivers received citations. Although $5 \%$ of pedestrians were killed on the sidewalk or other non-roadway locations, only $12 \%$ of the drivers in these crashes received citations (Komanoff, 1999). A study of vehiclepedestrian crashes at Florida intersections indicated that the drivers were cited for a moving violations in only $20 \%$ of vehicle-pedestrian crashes. Male drivers were more often the cause of pedestrian crashes than female drivers (Lee \& Abdel-Aty, 2005). A separate study reported that that targeting small areas may be as effective as citywide campaigns, that brief efforts may be as effective as longer programs, and that benefits to pedestrians from such enforcement in high-volume commuter corridors may be minimal (Britt, Bergman, \& Moffat, 1995).

\section{Pedestrian Street-Crossing Behavior}

Drivers and pedestrians commonly violate pedestrian travel rules. A study by Palamarthy, Mahmassani,and Machemehl (1994) that examined street-crossing behavior and compliance with crossing signalization showed that $96 \%$ of pedestrians who arrived at the intersection when the sign indicated "WALK" crossed during this signal phase. At signalized intersections, $74 \%$ of pedestrians who arrived when the sign was flashing "DON'T WALK" crossed during that signal phase, $18 \%$ crossed when the sign had turned steady "DON'T WALK," and only $9 \%$ waited for the next "WALK" signal. Over 35\% of pedestrians who arrived during the steady "DON'T WALK" phase crossed immediately, while 65\% waited for the next "WALK" phase. Other studies show that pedestrians may be tempted to violate rules by crossing during the flashing or solid DON'T WALK phases as this may reduce their wait time by 22\% (Virkler, 1998d). At signalized intersections without separate pedestrian signals, most pedestrians crossed with the green signal when they arrived at the intersection during this phase. If they arrived during the red phase, half of pedestrians waited for the green phase while others crossed as soon as traffic permitted during the red phase (Palamarthy et al. 1994).

One reason for the high number of pedestrian-motor-vehicle crashes that occur at intersections is the confusion as to who has the right of way when pedestrians cross the street with the WALK signal and motor vehicles turn into their path. In one study, drivers often didn't recognize that they must yield to pedestrians, particularly during left turns. Drivers over 75 were especially unaware of these rules (Abdulsattar \& McCoy, 1999). A separate study by Lord (1996) indicated that at locations with vehicle volumes above 100 vehicles per hour, 3-way or Tshaped-intersections were more dangerous for pedestrians than 4-way or X-shaped-intersections. Regardless of intersection type, the study concluded that higher vehicle flows, as measured by the number of vehicles per hour, posed higher risk for pedestrians, regardless of pedestrian volume. 


\section{Pedestrian Conspicuity and Visibility}

A variety of methods can be used to increase pedestrian conspicuity, including better vehicle headlights, better roadway lighting, and various environmental measures to improve sight distances and warn of pedestrian crossings. The simplest measures that pedestrians themselves can take are to wear conspicuous clothing and to avoid entering the roadway in places where vehicle drivers do not expect pedestrians. It is recommended that pedestrians wear some form of retro-reflective clothing when walking or jogging at night.

Many pedestrian crashes occur at night or during other low-visibility conditions due to the inability of the driver to see the pedestrian. Unfortunately, most clothing is not designed to enhance conspicuity and, currently, most retro-reflective clothing for adults is designed for specialty audiences such as joggers and bikers, law enforcement, fire fighters, or construction workers. Children's clothing occasionally incorporates conspicuity features, such as reflective strips or sneakers. Studies show that pedestrians frequently overestimate their own visibility and underestimate the benefits of retro-reflective materials or the difference between low-beam and high-beam illumination (Tyrrell \& Patton, 1998; Tyrrell, Wood, \& Carberry, 2004; Wood, Tyrrell, \& Carberry, 2005).

A review of issues related to pedestrian conspicuity indicates that increased roadway lighting is one of the most effective ways of reducing nighttime pedestrian crashes. Modifying parking patterns to allow diagonal parking in contrast to parallel parking is another effective approach at improving pedestrian visibility. Diagonal parking has been shown to reduce the risk of pedestrians crossing directly into traffic, by allowing pedestrians to more easily scan for incoming traffic. Another method that successfully increases visibility of pedestrian is to relocate bus stops to the far side of intersections. Having bus stops across from vehicles stopped at intersections allows motorists to more easily detect pedestrians entering the roadway (Retting et al., 2003).

In addition to roadway design issues, in a review of pedestrian and bicyclist conspicuity literature, Steinberg et al. (2000) recommend steps for pedestrians to increase visibility, such as wearing reflective clothing and attaching retro-reflective or LED lights. Recognition distance increases as the reflective surfaces outline the human form more clearly and show its motion (Steinberg et al., 2000). Studies also show that the positioning and color of retro-reflective material is important. One study reported that retro-reflective markings attached to arms or legs produced recognition distances 60 to $80 \%$ greater than markings attached to the torso, which in turn had twice the recognition distance than pedestrians without any markings at all (Luoma, Schumann, \& Traube, 1996). Examining the visibility of retro-reflective material, one study demonstrated that materials reflecting red, yellow, and green colors were detected at similar distances at night, and all at significantly greater distances than white materials of the same intensity (Sayer, Mefford, Flannagan, Sivak, Traube, \& Kojima, 1998). 


\section{SPECIAL PEDESTRIAN TOPICS}

\section{Child Pedestrians}

In 2009, 272 children 15 and younger were killed as pedestrians and another 15,000 were injured. In that same year, $19 \%$ of all children 5 to 9 who were killed in traffic crashes were pedestrians. Children 15 and younger accounted for 7\% of the pedestrian fatalities in 2009 and $25 \%$ of all pedestrians injured in traffic crashes (NHTSA, 2010a). NHTSA data show that male children are significantly more likely to be killed and injured as pedestrians than females (NHTSA, 2011). Studies show that child pedestrians are most likely to be involved in crashes on residential streets in urban areas, particularly in the late afternoon or early evening (KupferbergBen \& Rice, 1994; Schieber \& Vegega, 2002).

A study of pedestrian crashes of children younger than 11 in San Jose, California, reported that the most common behavior was the mid-block dart-out, which accounted for 30\% of all crashes. Approximately $20 \%$ of crashes involved an ice cream truck and $25 \%$ occurred at intersections. Most crashes occurred on roads with speed limits of $25 \mathrm{mph}$ or less and traffic laws or regulations were violated in $76 \%$ of all crashes. The young pedestrian was the violator $75 \%$ of the time (Aoki \& Moore, 1996). Similar results were found in a study by Kupfenberg-Ben and Rice (1994). They demonstrated that children under 5 were most likely to be hit when darting out from between parked cars and most crashes involving children less than 10 years old occurred on local streets (Kupferberg-Ben \& Rice, 1994).

Studies show that child pedestrian fatality rates are strongly influenced by traffic volume. Year-to-year changes in United States child pedestrian fatality rates (fatalities per 100,000 population) between 1970 and 1988 were strongly correlated with changes in vehicle-miles traveled. While child pedestrian fatality rates decreased throughout the period, they decreased more when traffic volume dropped and decreased less when traffic volume rose (Roberts \& Crombie, 1995). Similarly, studies show that children are 6 times more likely to be involved in crashes on streets with high traffic volumes ${ }^{3}$ compared to streets with low traffic volumes. Moreover, children were almost 4 times as likely to be involved in crashes when crossing highspeed roads (over $50 \mathrm{~km} /$ hour or $31 \mathrm{mph}$ ) than low-speed roads (Roberts et al., 1995). Similarly, a study by Kupfenberg-Ben and Rice (1994) reported that most crashes occurred within higher density residential areas and significantly more crashes occurred during the summer months (June to September) than any other month of the year. Crash rates were highest in the afternoon during after-school hours (3 p.m. to 7 p.m.) and additional peaks were observed around 8 a.m. and noon to 1 p.m. More crashes occurred on weekdays than weekend days (Kupferberg-Ben \& Rice 1994).

\section{Crash-Typing Children}

Patterns of exposure to traffic for urban children show that most pedestrian injuries occur while the child is at play or walking to a specific destination (Posner, Liao, Winston, Cnaan, Shaw, \& Durbin, 2002). Posner et al. (2002) identified the pre-crash events and the child's usual

\footnotetext{
${ }^{3}$ High volume is defined as areas with more than 1,000 vehicles per hour
} 
pattern of street play and pedestrian activities. Results show that $71 \%$ of the injured children were walking to a specific destination right before the crash. Even though walking to or from school accounted for $81 \%$ of street crossings, only $22 \%$ of those injured while walking to a destination were walking to or from school. The other destinations included walking home from a destination other than school, which accounted for $26 \%$ of crashes. Another $13 \%$ were hit while walking to the store, $12 \%$ were hit while walking to a neighbor's house, $2 \%$ were walking to a playground, and $18 \%$ were walking to some other destination. Some $29 \%$ of injured child pedestrians were playing right before the crashes and $28 \%$ of those were intentionally using the street for play. The injured children were mostly male with a mean age of 8.7 years, and most injuries were minor.

\section{Child Pedestrians - Decision Making}

Studies argue that children lack the experience and cognitive ability to make accurate judgments on various aspects of traffic safety, such as judging the speed of oncoming vehicles and assessing whether it is safe to cross (Muttart, 1995). Foot et al., (1999) revealed that as children age, they become more proficient in recognizing safety-relevant features in traffic scenarios. Child pedestrians are at heightened risk in traffic because they are not able to distinguish the sound and visual stimuli that are important to their safety (Foot, Tolmie, Thomson, McLaren, \& Whelan, 1999). Other studies show that children under age 6 may not understand the causal sequences that may result in a crash. A study by Thornton et al., 1999, comparing comprehension of drivers and passenger behavior by children at different ages, demonstrated that children 5 and younger were not able to understand the behaviors of drivers and passengers that may lead to a crash, whereas 15-year-olds were much more likely to identify both driver and pedestrian behaviors that might lead to a crash (Thornton, Pearson, Andree, \& Rodgers, 1999).

Studies further show that children make their decisions based on the distance of the vehicle without considering the vehicle's speed. Younger children (5 to 9 years old) were especially unable to make safe decisions regarding vehicle approach speeds above $37 \mathrm{mph}$ (Connelly, Conagle, Parsonson, \& Isler, 1998).

\section{Older Pedestrians}

In 2009, 775 pedestrians 65 and older were killed and another 5,000 injured in traffic (NHTSA, 2011a). This represents a decline from the 996 pedestrian fatalities for this age group in 2000 (NHTSA, 2011c) In 2009, based on NHTSA data, pedestrians 65 and older have a population-based fatality rate of 1.96, higher than that population-based fatality rate of 1.54 for adults 21 to 54 (NHTSA, 2010a), For older people, 64\% of pedestrian fatalities in 2009 occurred at non-intersection locations. For other pedestrians, $78 \%$ of fatalities occurred at non-intersection locations (NHTSA, 2011c).

Studies comparing fatal and non-fatal pedestrian crashes involving older and younger adults show that on a per capita basis, the crash rates for pedestrians 65 to 74 years old are lower than any other age group and there is only a small increase in the crash rate for individuals older than 74. However, in the event of a crash, fatality rates increase steadily with age, reaching a 
high of $25 \%$ for crash victims over 74 years old. Older pedestrians are more likely to be involved in a fatal crash in fall or winter than in spring or summer. Older pedestrians are less likely to be struck on the weekend than other age groups. Except for young children, a higher percentage of older pedestrians are involved in crashes during daylight hours than younger pedestrians of other ages (Zegeer et al., 1993).

Examining the role of age-related declines in physical performance on injuries of pedestrians, studies have shown that factors influencing severity of injury were the pedestrian's age, the speed of vehicle at impact and the type of vehicle. The height and weight of the pedestrians, and their genders were also shown to be related to injury severity. Males were shown to sustain more serious injuries, to be hit at higher average vehicle speeds and to have higher mortality rates than female pedestrians of the same ages. Older pedestrians tend to sustain more severe injuries and are more likely to die in motor vehicle-pedestrian crashes than younger pedestrians. When other factors such as vehicle type and vehicle speed were included, older adults had 2.7 times the risk of severe injury and 7 times the risk of death compared with younger adults (Henary, Ivarsson, \& Crandall, 2006).

\section{Walking Speeds and Crossing Behavior}

Due to age-related changes in physical performance, studies have found that older pedestrians walk more slowly than younger pedestrians when crossing streets, with walking speeds influenced by factors such as street width, vehicle traffic volume, weather, number of pedestrians crossing together, signal cycle length, curb cuts, pavement markings, and on-street parking (Knoblauch et al., 1996). Another study showed that even among adults 65 and older, there is substantial variability of walking speeds and mobility levels and the most frequent concerns for older pedestrians include difficulty crossing the curb, difficulty judging oncoming vehicle speeds, turning vehicles, and confusion about pedestrian signal phases (Coffin \& Morrall, 1995).

When compared to younger pedestrians, higher crash rates among older adults have also been attributed to older pedestrians being less aware of their traffic environment. One study examined the scanning behavior of older and younger pedestrians at signalized intersections. To the contrary, the study found that pedestrians older than 50 were more cautious than younger pedestrians. Results also indicated that older adults were less likely to follow other pedestrians into the crosswalk without scanning, but instead scanned for traffic themselves (Harrell, 1996). Others have argued that the higher crash rate among older adults may be due to other factors, such as difficulties crossing the street. In a study by Langlois et al. (1997), 11\% of pedestrians over 71 years old reported having difficulty crossing the street. Most of them were not able to cross a signalized intersection within the allotted time while walking at their normal walking speed (Langlois, Keyl, Guralnik, Foley, Marottoli, \& Wallace, 1997). Other studies have shown that

older pedestrians are involved in specific types of intersection crashes and in crashes involving backing vehicles. Higher crash rates in winter suggest conspicuity problems of pedestrians not detecting vehicles or drivers not seeing pedestrians (Blomberg et al., 1993). 


\section{COUNTERMEAUSURES TO IMPROVE PEDESTRIAN SAFETY}

\section{Intersections Countermeasures}

Methods for increasing pedestrian safety at intersections can be grouped into three broad categories: approaches that target vehicle drivers; approaches that target pedestrians and approaches that use technology. Approaches that target vehicle drivers include educational campaigns that increase awareness for yielding to pedestrians, repositioning of stop signage and ground markings at intersections, and changes to the signal timing to give pedestrians sufficient time to cross the street. Approaches that target pedestrians include use of visual cues, signs, or voice prompts to alert them to be more aware of their immediate environment. Approaches that use technology include automatic pedestrian detectors to assure sufficient crossing interval lengths, while minimizing vehicle delays.

\section{Crosswalk Countermeasures and Signage}

Safe places to cross the street are essential for pedestrian mobility. Traffic signals are not always appropriate at crosswalks. At locations with low pedestrian volumes, including a regular pedestrian phase in signal cycles imposes undue delays on vehicles. Therefore, a variety of alternative crosswalk treatments have been investigated that are appropriate in certain settings. For example, Campbell et al. (2004), among others, have suggested raised medians on multilane roads, the use of curb extensions to reduce crossing distance, raised pedestrians islands, raised crossings, street narrowing, etc. Others have suggested that signaling systems, such as pedestrian-actuated signals, may be an appropriate alternative at intersections and midblock locations with sporadic pedestrian traffic. The signal eliminates any guesswork as to who has the right of way and discourages forced rights-of-way by pedestrians and drivers alike. Otis et al. (1994) provide guidelines to suggest where pedestrian-actuated signals are appropriate.

Several studies examined the role of crosswalk markings on vehicle speeds. For example, Raymond and Knoblauch (2000) found that new crosswalk striping reduced average vehicle speeds significantly when no pedestrians were present. If a pedestrian was present, average speeds decreased significantly when the pedestrian was not looking and slightly when the pedestrian was looking. Eighty-fifth percentile speeds were not reduced significantly regardless of pedestrian presence or actions. A similar study by Knoblauch, Nitzburg, and Siefert (2000) examined the effect of crosswalk markings on pedestrian and driver behavior at signalized intersections. They found that markings produced slightly lower vehicle speeds but no change was observed in the proportion of cars yielding to pedestrians or pedestrian behavior, such as looking or aggressiveness. Additionally, this study found that crosswalk markings on signalized intersections did not impact crosswalk usage.

Several studies have investigated methods of increasing crosswalk visibility to encourage drivers to yield to pedestrians. One proposal is to replace the traditional yellow color of pedestrian crossing signs' background with a fluorescent, strong yellow-green (SYG) background. A controlled-environment evaluation showed that the SYG signs had significantly increased legibility distances in daylight, backlight, and complex environments (Dutt, Hummer, \& Clark, 1996). A survey determined that people perceived the signs to be more conspicuous, 
induced more alertness, and had a stronger association with caution (Dutt et al., 1997). A field evaluation of their effects on motor vehicle drivers concluded that the SYG signs produced only a marginal improvement in pedestrian safety. Although there was a significant increase in motorists slowing and stopping at some sites, the percentage of pedestrian-motor vehicle conflicts was largely unchanged (Clark, Hummer, \& Dutt, 1996).

Some researchers have examined whether pedestrian-vehicle conflicts could be reduced by placing signs reading TuRning TRAFFiC Must Yield To Pedestrians at intersections. Results show that the signs reduced conflicts during left turns by 20 to 65\%, depending on location (Abdulsattar, Tarawneh, McCoy, \& Kachman, 1996). Conflicts during right turns were reduced by 15 to 30\%. The percentage of conflicts decreased with increasing pedestrian group size, regardless of whether a sign was present Others have examined whether increasing the vehicle stop line distance from 4 to 20 feet from the crosswalk improved pedestrian safety (Retting \& Van Houten, 1997). Results demonstrate that the proportion of drivers who stopped at least 4 feet from the crosswalk increased from 74 to $92 \%$ after increasing the distance of stop lines, although only 57\% stopped at the 20 -foot stop line. Furthermore, the percentage of drivers stopping in the crosswalk dropped from 25 to 7\%. Another study by Huang, Zeeger, Nassi, and Fairfax (2000) as shown in Campbell et al., (2004) found that the use of pedestrian signs at nonsignalized sites increased the frequency of motorists stopping for pedestrians. They concluded that, in order to achieve consistent effectiveness, signs must be used in combination with education and enforcement.

Approaches that alert drivers and pedestrians in an effort to increase awareness and vigilance rely on a number of devices for visual and auditory stimuli. Studies have examined overhead "CROSSWALK" signs as used in Seattle, a pedestrian-activated overhead sign "STOP FOR PEDESTRIAN IN CROSSWALK" as used in Tucson, Arizona, and pedestrian safety cones ("STATE LAW - YIELD TO PEDESTRIANS IN CROSSWALK IN YOUR HALF OF ROAD”) as used in New York State and Portland, Oregon (Huang et al., 2000. Studies demonstrated that the Seattle signs and New York cones increased the percentage of motorists who stopped for pedestrians. The overhead signs in Seattle and Tucson reduced the number of pedestrians who had to run, hesitate, or abort the crossing. None of the devices increased the likelihood of pedestrians crossing in the crosswalk. The researchers concluded that the devices by themselves were not considered effective in increasing pedestrian safety, but could be useful in conjunction with education and enforcement (Huang et al., 2000).

Another approach to alert pedestrians to turning vehicles is with the use of special signs and pavement markings. Signs reading "PEDESTRIANS - LOOK FOR TURNING VEHICLES” and pavement markings reading "WATCH TURNING VEHICLES” were shown to significantly reduce the number of pedestrians not looking for any threats (Retting et al., 1996). Both types of signage when used together were shown to be slightly more effective than when used alone. The number of conflicts between pedestrians and motor vehicles declined substantially after the treatments and dropped to zero at all intersections when both treatments were in place.

When using both signs and symbols to increase the percentage of drivers yielding to pedestrians at crosswalks, in conjunction with pedestrian-activated flashing beacons, yielding behavior can be increased. Studies examining such use concluded that only the presence of a sign 
that specifically instructed motorists to yield when the beacons were flashing succeeded in reducing pedestrian-motor vehicle conflicts (Van Houten, Healey, Malenfant, \& Retting, 1998a). This finding confirmed results of a previous study that investigated the efficacy of supplemental plaques to increase driver comprehension of warning signs (Hawkins, 1994).

\section{Temporal Separation}

Another way to increase pedestrian safety at signalized intersections is to use auditory and visual alerts to warn pedestrians to potential conflicts with vehicles. One method to remind pedestrians to watch for turning vehicles is by including animated eyes in the pedestrian signal. The pedestrian WALK signals were modified to include eyes that scanned from side to side either just before the WALK phase, at the beginning of the WALK phase, or cyclically throughout the WALK phase. The animated eyes reduced pedestrian-motor vehicle conflicts (Van Houten \& Malenfant, 1999). People recognized the correct meaning of the eyes, and the percentage of individuals who failed to scan decreased significantly. These behavioral changes were sustained six months after the animated eyes were introduced. Others have examined whether a change in signal timing would reduce pedestrian-motor vehicle conflicts at signalized intersections. Results demonstrated that pedestrian signals that provided a three-second lead to pedestrians before motor vehicle traffic is allowed to proceed, significantly reduced conflicts between pedestrians and vehicles, and pedestrians were significantly less likely to yield to turning vehicles (Van Houten, Retting, Farmer, \& Van Houten, 1997b).

A third method of increasing pedestrian vigilance at signalized intersections is with audible messages. In one study, signals were equipped with loudspeakers that announced three different messages, which included "Please wait for walk signal," played at individual corners when a crosswalk button was pressed, and "Look for turning vehicles while crossing Cleveland Street" or “... while crossing Garden Avenue," played on all corners just before the onset of the WALK signal. Results show that these audible messages reduced the percentage of pedestrians who did not look for vehicles by 75\% (Van Houten et al., 1997a). Pedestrian-motor vehicle conflicts, defined as evasive action by either pedestrian or vehicle, dropped by $75 \%$. The audible messages were generally well-received by the public.

Automated pedestrian detectors have also shown promise in reducing pedestrian-vehicle conflicts. Studies report that infrared or microwave based detectors used in conjunction with standard pedestrian push buttons at signalized intersections detected pedestrians in the crosswalk and extended the WALK signal for up to 6 seconds to allow pedestrians to complete crossing. The automated detection system significantly improved signal compliance by reducing the number of pedestrians who began crossing the street during a steady DON'T WALK signal. In addition, there was a significant reduction in the percentage of pedestrians who experienced conflicts with motorists while crossing (Hughes, Huang, \& Zegeer, 1999a; Hughes, Huang, Zegeer, \& Cynecki, 1999b, 2000). Others have tested infrared, ultrasonic, and microwave radar based automated pedestrian detectors at un-signalized intersections that warned drivers of the presence of pedestrians in a crosswalk. The most promising results were obtained with the radar and infrared sensors (Beckwith \& Hunter-Zaworski, 1998). 


\section{Illumination Countermeasures}

Illumination based countermeasures to increase the safety of pedestrians are another important safety approach. As reviewed by Kannel and Jansen (2004), one approach is the introduction of in-pavement flashing lights to alert motorists of the presence of pedestrians in the crosswalk. Kannel and Jansen (2004) demonstrated that in-pavement flashing lights resulted in a statistically significant increase in vehicle speed after installation when pedestrians were not in the crosswalk, but no change when pedestrians were in the crosswalk. They also showed that a higher proportion of motorists yielded to pedestrians after the flashers were installed. Kannel and Jansen (2004) also highlighted a study by Huang et al., (1999), which reported a non-significant reduction in speed after the installation of flashing lights along the crosswalk. The study also showed a significant increase in the proportion of motorists slowing down or stopping for pedestrian from pre to post-installation. Kannel \& Jansen, 2004 also describe a project by the Hawaii Department of Transportation, which installed flashing lights at an uncontrolled location, which resulted in a $17 \%$ drop in maximum speed and a $26 \%$ reduction in average speed (Prevedouros et al., 2000 - in Kannel \& Jansen, 2004). Others have shown that illuminated overhead crosswalk signs, used in conjunction with high-visibility ladder-style crosswalk markings, significantly increased driver yielding behavior during the day, but not at night, and pedestrians were more likely to use high-visibility crosswalks than unmarked crosswalks or crosswalks with standard markings (Nitzburg and Knoblauch., 2000). 


\section{STUDIES ON BICYCLIST SAFETY}

\section{Overview of Bicycle Crashes}

Bicycling in the United States is both a popular recreational activity and a means of transportation; however, bicycling can be risky. In 2009, there were 630 bicyclist fatalities in the United States, a decline from the 786 fatalities reported fatalities in 2005. In 2009, bicyclist fatalities accounted for $2 \%$ of all traffic fatalities (NHTSA, 2011b). In that same year, another 51,000 bicyclists were injured in traffic crashes in the United States.

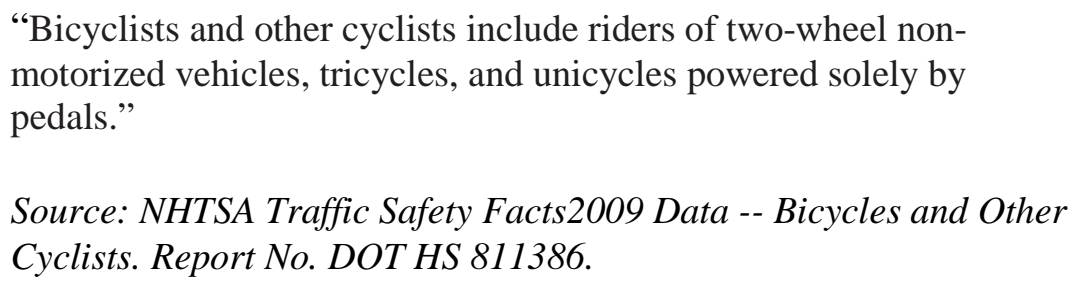

In 2009, young bicyclists, those under age 16, accounted for $13 \%$ of all bicyclists killed and $20 \%$ of all bicyclists injured in traffic crashes. By comparison, in 2000 this age group accounted for $28 \%$ of all those killed and $40 \%$ of those injured. The bicyclist fatality rate for those age 5 to 15 in 2009 was 1.8 fatalities per million people, lower than the 2.05 fatalities per million people among all bicyclists. In contrast, the injury rate for this age group was 223 per million people, compared to 165 per million people for bicyclists of all ages. Adult bicyclists, aged between 25 and 64, increasingly account for larger proportions of bicycle fatalities and injuries. For example, in 2009, adult bicyclists accounted for $64 \%$ of all bicyclist fatalities, in contrast to 52\% in 2000 (NHTSA, 2011b).

However, one concern regarding studies that rely on police reports is that they may represent only part of bicycling-related injuries that occur on non-public roadways, such as private roads, parking lots and bicycling trails. For example, in 2009, 200,478 people were treated for bicycle-related injuries occurring in traffic only, representing a rate of 66 injuries per 100000 population, but 518,750 people were transferred to hospital emergency rooms or hospitalized for bicycle-related injuries occurring in public and non-public roadways, representing a rate of 175 injuries per 100000 people (CDC, 2011).

In 2009, 70\% of bicyclist fatalities in motor vehicle crashes occurred in urban areas and $67 \%$ occurred at non-intersection locations. Almost $30 \%$ of bicyclist fatalities occur in late afternoons, between 4pm and 8pm, and the majority of fatalities (65\%) occur between noon and midnight (NHTSA, 2011b). More crashes involving a bicyclist occur during the fair weather months of April to October and on weekdays (Hunter \& Huang, 1995). Analyses show that the most common bicycle fatality road types are local streets, accounting for $34 \%$ of fatal crashes. County routes represent $28 \%$ of fatal crashes and State routes represent another $18 \%$. 
Further examination of the locations of bicyclist fatalities by Hunter et al. (1995) reported that crashes on two-lane roads accounted for $65 \%$ of crashes; another $25 \%$ occurred on four-lane roads. Over one-quarter of crashes are shown to have occurred on roads with speed limits of 25 mph or less. Approximately half of fatal crashes occurred on roads with speed limits between 30 and $35 \mathrm{mph}$. The majority of roads, 58\%, had no traffic control device. One-quarter had a stop sign and $16 \%$ had a flashing signal only.

National surveys have shown that bicyclists 18-24 years old reported significantly higher crash rates over the past 12 months than any other age group (Rodgers, 1997). Almost twice as many males reported having had a crash in the past year as females, even though there were about the same number of female and male cyclists. Although most bicyclists reported riding on roadways, the relative crash risk was highest on off-road trails. Bicyclists most commonly rode general purpose bicycles. Their relative crash risk was significantly lower than for bicyclists who rode racing and all-terrain bicycles. Bicyclists from the Pacific region were more likely to have crashed during the previous 12 months than those from any other part of the country. Bicyclists with the highest monthly mileage were also most likely to have crashed during the previous year.

\section{Bicyclist Demographic Characteristics}

One of the classical studies on bicycling safety, conducted by Rodgers (1995), examined gender differences in riding and reported injuries. The study concluded that female bicyclists accounted for almost half the estimated annual riding time, suggesting that the overrepresentation of male bicyclists in injuries and fatalities may be due to riding in more dangerous situations or engaging in riskier riding behaviors than females. However, a subsequent study by Li and Baker (1996) came to somewhat different conclusions. Analyzing data from the NCHS, NEISS and the Nationwide Personal Transportation Survey (NPTS), they reported that male bicyclist were overrepresented in bicycling fatalities due to their higher number of trips by bicycle. Furthermore, the study revealed that when in a crash, male bicyclists tended to sustain more severe injuries than female bicyclists.

On a per trip basis, men were found to be at slightly lower injury risk than women ( $\mathrm{Li}$, Baker 2006). Recent NHTSA data show that in 2009, 549 male bicyclists were killed and another 41,000 injured, resulting in a fatality rate of 3.62 fatalities per million population and an injury rate of 268 per million people. This compared to 81 female bicyclist fatalities and 10,000 injuries, with a fatality rate of 0.52 per million people and an injury rate of 65 per million people (NHTSA, 2011b).

Recent studies show that the average age of fatally injured bicyclists in traffic crashes has increased from 29.7 in 1995 to 38.5 in 2005 and 41 in 2009. A similar trend is seen for injured cyclists with the average age of an injured rider increasing from 22.7 in 1995 to 29 in 2005 and 31 in 2009 (NHTSA, 2011b). Changes in injury and fatality trends have also impacted younger bicyclists. The proportion of fatally injured child and young teen riders, under age 16, declined from 34\% in 1995 and 20\% in 2004, to 13\% in 2009 (NHTSA, 2004, 2011b). Analyses show that fatality risk increases steadily with age, with bicyclists over 65 years old significantly more likely to be fatally injured than bicyclists from other age groups (Rodgers, 1995). 
In a study of bicycle-motor vehicle crashes in Miami-Dade County, Florida examining demographic characteristics of crashes, results showed that African-American bicyclists were significantly overrepresented on a per population basis, among bicycling crash victims 5 to 15 years old and, to a lesser degree, among those 55 to 65 years old. Caucasian bicyclists were overrepresented among 15- to 25-year-old crash victims (Epperson, 1995). Results also pointed out that housing characteristics, such as low median rent, a high proportion of poor residents and, to a lesser degree, lower income, were correlated with higher crash rates. Furthermore, an increased proportion of Hispanics in the population, higher population density, and a higher proportion of children in the population were correlated with lower crash rates (Epperson, 1995). Results show that there was no difference in the race of crash-involved vehicle.

\section{Bicyclist Travel Behavior}

It is important to note that while each study adds unique information to the understanding of bicycle safety, there is considerable overlap among the study results. For example, the overrepresentation of young adolescent males among bicyclist fatalities and injuries, the heightened risk of bicycling at night, the high percentage of crashes that occur in the afternoon between 3 and 7 p.m., and the lower crash rates on weekends, particularly on Sunday, are examples of similar findings among studies. It should be noted, however, that studies may differ in their results when conducted in different regions or with different groups. For example, differences may occur due to differences in demographics, road infrastructure, weather conditions, or driving and bicycling behaviors.

A national survey of bicyclist attitudes and behavior, conducted in 2002, estimated that about 57 million people, or $27 \%$ of those over the age of 16 , rode a bike at least once during the year. This resulted in 91 million bicycle trips with an average trip of 3.9 miles. Close to half of those bicycle trips were on paved roads, about $14 \%$ were on sidewalks, $13 \%$ on bicycle or walking paths/trails, another $13 \%$ on the shoulders of paved roads, and about $7 \%$ on unpaved roads or other surfaces (NHTSA, 2003).

Survey results show that $34 \%$ of males rode bicycles, compared to $21 \%$ of females and that bicycling is most popular among 16 to 24-year-olds, with 39\% of that age group reporting riding a bicycle at least once in the last year (NHTSA, 2003). The group with the lowest reported bicycle use was people over 65 , with only $9 \%$ of respondents in this age group reporting use of a bicycle at the time of the survey. Although most respondents reported being satisfied with bike safety in their community, $75 \%$ of those surveyed also hoped for some changes in the form of more bike lanes, paths, trails or other bicycle amenities. Another $8 \%$ requested improvements to existing resources and $14 \%$ requested regulations and safety education. The remainder of respondents noted that safer bicycling areas and better law enforcement should be improved.

In an effort to characterize the bicyclist population, 2,374 North American bicycle commuters were surveyed in 1995 (Moritz, 1997). The survey reported that the average responding bicyclist was 39 years old; $82 \%$ of respondents were male; $58 \%$ reported being employed; they had an annual average income of more than $\$ 45,000$. Survey respondents were likely to own a vehicle, however $12 \%$ responded not owning a car by choice. Results indicated that mountain bikes and road bikes were similarly popular among bicyclists with $30 \%$ preferring 
mountain bikes and 28\% favoring road bikes. Hybrid bicycles were preferred by $18 \%$ of respondents and touring bikes were favored by $17 \%$. Results indicated that the average purchase price for a commuting bicycle was $\$ 687$. Thirty\% of respondents reported having a second bicycle for bad weather (Moritz, 1997).

When asked about the safety equipment on their bicycles, 80\% responded that their bicycles were equipped with reflectors and rear flashers; a pump and front lights were installed on the bicycles of $77 \%$ of respondents. Almost all respondents reported owning a helmet, though only 86\% reported always wearing it (Moritz, 1997). Respondents reported that commuting accounted for $61 \%$ of miles ridden and recreation for another 32\%; $70 \%$ responded using their bicycle as their most common means of commuting. Survey results revealed that $35 \%$ of miles were ridden on major streets and another 31\% were ridden on minor streets. Bicycle lanes and paths accounted for $18 \%$ and $14 \%$, respectively. Respondents reported that they averaged 8.1 commuting trips per week, with an average trip length of 7.5 miles and time of 31 minutes. Almost 54\% commuted by bicycle all year, with an average of 10.6 months.

When asked about bicycling related-crashes and injuries, approximately $10 \%$ of respondents reported having been in a crash during the previous 12 months (Moritz, 1997). The median costs for property damage and medical expenses were $\$ 100$ each and about 38\% of crashes were reported to the police. Doctors or emergency rooms were visited in $57 \%$ of crashes, and 5.5\% resulted in a hospital stay. Respondents reported that 58\% of the crashes involved motor vehicles (Moritz, 1997).

Antonakos (1994) investigated bicyclists' travel preferences and reported that most bicyclists preferred bicycle lanes, wide curb lanes or bicycle paths and trails. Un-paved roads or dirt roads and sidewalks were the least preferred travel preference. Bicyclists preferred that their routes for recreational trips be safe, and have low traffic volumes and smooth pavement. For commuting, bicyclists desired a safe, quick and direct route (Table 1). Bicyclists identified bicycle lanes, increased motorist awareness, child bicycle safety education, and surface quality as major areas for improvement in their communities. Adult bicycle safety education, bicycle paths, road markings, road signs, and slower traffic were also identified 
Table 1: Trip route preferences (from Antonakos, 1994)

\begin{tabular}{|c|l|}
\hline Recreational trips (by order of preference) & Commuting trips (by order of preference) \\
\hline 1. Safety & 1. Safety \\
\hline 2. Low traffic volume & 2. Quick route \\
\hline 3. Smooth pavement & 3. Direct route \\
\hline 4. Scenery & 4. Smooth pavement \\
\hline 5. Slow traffic & 5. Low traffic volume \\
\hline 6. Few stops & 6. Slow traffic \\
\hline 7. Few hills & 7. Convenient for errands and few hills \\
\hline
\end{tabular}

In a separate survey, members of the League of American Bicyclists were asked about their bicycling experiences during the previous year (Moritz, 1998). This 1996 survey showed that the average age of surveyed bicyclists was 48 years, $80 \%$ were male, and 66\% were married. Almost half were professionals (48\%), $80 \%$ had a college degree, and over half reported an annual household income above \$60,000. Among the surveyed League of American Bicyclists, only $4 \%$ did not own a motor vehicle. Some $49 \%$ of respondents preferred road bikes, $21 \%$ favored touring bikes, and $12 \%$ favored mountain bikes. Reported helmet use was $88 \%$. Bicyclists rode as much on weekends as on weekdays, $15 \%$ reported never riding in the rain, and 47\% reported never riding after dark. On average, respondents had been riding a bicycle continuously for 14.2 years (Moritz, 1998).

Among this group, almost all respondents bicycled for recreational purposes and 38\% reported bicycling for commuting purposes, such as work or school. Some $45 \%$ of miles were ridden on minor streets without bicycle facilities and 32\% were ridden on major streets without facilities. The average distance cycled during the year was 2,900 miles. Of those who reported commuting to work or school (53\%), 29\% did so by bicycle (Moritz, 1998). Similar to other surveys, about $9 \%$ reported having been in a crash during the previous year that resulted in at least $\$ 50$ of property damage or medical expense, with $72 \%$ of crashes not reported to the police. Falls were the most common crash, accounting for 59\% of crashes, followed by collisions with fixed objects, which represented another $14 \%$ of crashes, and collisions with moving motor vehicles and collisions with bicycles, which accounted for another $11 \%$ and $9 \%$, respectively (Moritz, 1998).

\section{High Risk Environment to Bicyclists}

Studies that have examined the factors that contribute to bicyclist crashes group these factors into those attributable to the bicyclists and those attributable to the vehicle driver. The studies show that the most common bicyclist contributing factors were failure to yield, which represented $21 \%$ of crashes, and riding against traffic, which represented another $15 \%$. Stop sign violations and safe movement violations represented another $7.8 \%$ and $6.1 \%$, respectively. The condition of the bicycle was found to be without defects in $91 \%$ of cases. Poor brakes or lack of lighting or reflectors accounted for $9 \%$ of the defects. Regarding driver contributing factors, the most common factors were failure to appropriately yield to bicyclists, which accounted for $24 \%$ of crashes, hit and run, which accounted for $14 \%$, and a driver's failure to note the bicyclist, which accounted for another 12\% (Hunter, Pein, \& Stutts, 1995, Hunter, Stutts, Pein, \& Cox, 1996, Hunter, Pein, \& Stutts, 1997a). 
Studies using data from hospital emergency room visits in California, New York, and North Carolina showed that $92 \%$ of bicycle-motor vehicle collisions occurred on the roadway. Non-roadway locations, such as sidewalks, parking lots, and off-road trails accounted for 7.6\% of crashes. The majority of bicycle-only crashes, 57\%, occurred on the roadway. Non-roadway locations, such as sidewalks, off-road trails, driveways, yards, and parking lots, accounted for $43 \%$. Of these off-road locations, sidewalks accounted for $21 \%$ of crashes and off-road trails accounted for another 12\% (Stutts, 1997; Stutts \& Hunter, 1998, 1999).

Results showed that children under 10 were most commonly involved in off-road bicycleonly crashes, followed by bicycle-only on-road. With increasing rider age, bicycle-only crashes decreased and bicycle-motor vehicle crashes increased. Among 25- to 44-year-olds, bicyclemotor vehicle crashes on road were most common, followed by bicycle-only on-road. Among 15- to 24-year-olds and those over 45, bicycle-only on-road was most common, followed by bicycle-motor vehicle crashes on-road. Motor vehicle involvement in off-road locations was rare in all age groups (Stutts, 1997; Stutts \& Hunter, 1998, 1999).

In a separate study using police reports from North Carolina for the years 1997-2002, Kim et al. (2007) examined bicycle-motor vehicle crashes that occurred on weekends. The age groups most commonly involved in these crashes were children under 16, which accounted for $32 \%$ of crashes, and those 25 to 54, who represented $42 \%$ of all crashes. Over $85 \%$ of bicycle crashes involved male riders. Some $94 \%$ of cyclists involved in crashes did not wear a helmet and about $6 \%$ of riders were intoxicated at the time of the crash, compared to $2.3 \%$ of drivers involved in bicycle-motor vehicle crashes.

\section{Bicyclists at Intersections}

Many intersection crashes appear to be due to bicyclists coming from unexpected directions. This may be due to the bicyclist riding against traffic or on a bicycle path that intersects the roadway. The limited research available suggests some methods to reduce intersection crashes without redesigning intersections. Riding against traffic could be addressed through public information and education campaigns and enforcement efforts. Bicycle paths crossing roadways need to be clearly visible to motorists. Stop signs or traffic lights both on the roadway and on the bicycle path may help bicyclists and motorists to see each other. Assuring good visibility by minimizing shrubbery and other visual obstacles near intersections is always beneficial. As an extreme measure, raising the bicycle crossing to create a form of speed hump effectively slows motor vehicles and thereby increases the safety of bicyclists.

Technological advances offer increasing possibilities to address both bicyclist and motorist needs. Loop or motion detectors may be able to distinguish bicycle and motor vehicle traffic and adjust traffic signals accordingly (NHTSA, 2000a, Recommendations C-4 and C-6).

Studies of bicycle-motor vehicle collisions at intersections demonstrated that bicyclists 18 and older were 1.8 times more likely to be involved in an intersection crash than bicyclists under 18 (Wachtel \& Lewiston, 1994). They offered several possible explanations for this unexpected result. One is that they calculated crash rates only within the bicycling community 
and not for the general population. Another is that younger bicyclists may ride more slowly or in groups that are more easily detected by motorists. Bicyclists riding against traffic were 3.6 times more likely to be involved in an intersection crash than those riding with traffic. Cyclists riding on the sidewalk were 1.8 times more likely to be involved in an intersection crash than those riding on the road.

At signalized intersections, a lag, also called a clearance interval, assures that all vehicles have cleared the intersection after the traffic lights turn red in one direction and before the lights turn green for the cross-traffic. This clearance interval is programmed to be sufficient for automobiles but may not be long enough for bicyclists traveling more slowly. Longer clearance intervals would delay motor vehicle traffic when bicycles are not present. Taylor (1993) developed a mathematical algorithm for calculating the safe clearance interval for bicycles. Another algorithm computes the probability of bicyclists getting caught in the intersection after the light turned red. There is no recent research on whether short clearance intervals at signalized intersections pose a problem to bicyclists.

\section{Bicyclist Injury Profiles}

Studies using data from hospital ER visits in California, New York and North Carolina reported that most bicyclists admitted to the ER were not further transferred to a hospital. Bicycle injuries from off-road crashes and crashes not involving a motor vehicle were generally less severe and $90 \%$ of these patients could be released after treatment. Bicycle-motor vehicle crashes on-road caused more serious injuries and most fatalities. Almost $25 \%$ of these patients had to be admitted to a hospital. The head, face, and neck were the most commonly injured areas, followed by the upper and lower limbs. The lower limbs were injured particularly often when the crash involved a motor vehicle. Only $48 \%$ of the emergency room cases involving a motor vehicle could be matched to State motor vehicle crash file cases (Stutts, 1997; Stutts \& Hunter, 1998, 1999). Crashes on roads with higher average annual daily traffic produced less severe injuries than crashes on lower-volume roads (Klop \& Khattak, 1999).

By examining hospital admissions for 1987 to 1992 for bicycle riders in Connecticut, Zavoski, Lapidus, Lerer, \& Banco (1995) found that, on average, one person per 400,000 population died each year in a bicycle crash and almost 9 per 100,000 were hospitalized. The study showed that bicycle mortality rates decreased during this period. The bicycle fatality rate per population was highest among males 10 to 14 years old, and $85 \%$ of all fatally injured bicyclists were male. Over two-thirds of bicycle fatalities died of head trauma and $75 \%$ involved collisions with motor vehicles. Approximately $70 \%$ of bicycle fatalities occurred in towns with populations under 50,000. Analysis of morbidity data yielded similar results. As with bicycle rider fatalities, between 1987 and 1992 injury rates decreased initially and then stabilized (Zavoski et al., 1995). The largest group of injured bicyclists was males 10 to 14 years old. Head injury was the most common diagnosis at $30 \%$. In contrast to fatalities, only $30 \%$ of bicycle injuries involved a motor vehicle. 


\section{Bicyclists, Helmets and Head Injuries}

Helmet use reduces the risk of head injury, brain trauma, and upper face injuries. Studies have shown that head injuries cause the majority of bicyclist fatalities and helmets are effective in preventing serious or fatal head injuries (Attewell, Glase, \& McFadden, 2001; Thomas et al., 1994; Thompson et al., 1990; Rivara et al., 1994). Between $31 \%$ and $65 \%$ of bicycle accidents involved head injuries, and 70 to $86 \%$ of bicyclist fatalities were due to head injuries (Finnoff, Laskowski, Altman, \& Diehl, 2001). The majority of cyclist fatalities and bicycling-related injury disabilities were caused by head injuries (Nagel, Hankenhof, Kimmel, \& Saxe, 2003). NHTSA has reported that helmets are $85 \%$ to $88 \%$ effective in reducing head and brain injuries (NHTSA, 2006c).

Studies analyzing National Center for Health Statistics data from the Multiple Cause of Death database from 1989 to 1992 and the National Electronic Injury Surveillance System database from 1989 to 1993 found that traumatic brain injury was the cause of death in approximately two-thirds of bicyclist fatalities in the United States. Head injuries ranged from $21 \%$ of non-fatal bicycling injuries in young adults (15 to 29 years old) to $48 \%$ in children under 5 (Sosin, Sacks, \& Webb, 1996). Other studies have reported similar results. For example, in Connecticut head injuries were the most common bicyclist injury and caused two-thirds of all bicyclist fatalities (Zavoski et al., 1995). Similarly, head injuries were the leading cause of death from bicycle crashes in Australia (Thomas et al., 1994).

\section{Alcohol and Bicyclist Injuries}

NHTSA data show that, in 2009, 28\% of the fatally injured bicyclists in motor vehicle crashes had BACs of $.01 \mathrm{~g} / \mathrm{dL}$ or higher; $24 \%$ had BACs of $.08 \mathrm{~g} / \mathrm{dL}$ or higher. In the same year, more than $33 \%$ of traffic crashes resulting in a bicyclist death involved a vehicle driver or bicyclist with a BAC of .08 g/dL or higher (NHTSA, 2011b). A study by Hunter at al., (1995) reported that alcohol or drug use is highest among 25- to 44-year-old bicyclists, and intoxicated bicyclists are more likely to suffer serious or fatal injuries than non-intoxicated bicyclists.

Operating a bicycle requires higher psychomotor skills than driving an automobile and bicycling performance is significantly impaired at a BAC of .08 (Schewe, Knöss, Ludwig, Schäufele, \& Schuster, 1984, cited in Li et al., 2000). FARS data for 1987-1992 showed that 32\% of bicycle crash fatalities over 15 years old were positive for alcohol and 23\% had BACs above $.10 \mathrm{~g} / \mathrm{dL}$ (Li \& Baker, 1994). Olkkonen and Honkanen (1990) estimate that intoxicated bicyclists with BACs exceeding .10 g/dL have ten times the injury risk of non-intoxicated bicyclists and intoxicated bicyclists were more likely to injure themselves by falling rather than by crashing.

Studies show that injuries sustained by intoxicated bicyclists are more severe when compared to injuries sustained by non-intoxicated cyclists (Yelon, Harrigan, \& Evans, 1995; Spaite, Criss, Weist, Valenzuela, Judkins, \& Meislin, 1995). Hospitalization and intensive care unit stays were significantly longer for BAC-positive bicyclists than non-intoxicated cyclists. Similar results were reached by a recent study by $\mathrm{Li}$, Baker, Smialek, and Soderstrom (2001) that showed that over a 12-year period, $24 \%$ of fatally injured bicyclists were intoxicated, compared to $9 \%$ of those with nonfatal injuries. 
Characteristics of intoxicated bicyclists differ from bicyclists who did not consume alcohol while riding. For example, a study showed that intoxicated bicyclists were significantly less likely to wear a helmet when compared to non-intoxicated bicyclist (6\% versus 31\%) (Li \& Baker, 1996). Li et al. (2000) also report that bicyclists involved in injury crashes who tested positive for alcohol were significantly more likely to have had their automobile driver's licenses revoked (52\% versus 14\%) and to have been convicted of alcohol impaired driving (30\% versus $3 \%$ ) than non-intoxicated bicyclists in injury crashes.

\section{VEHICLE AND BICYCLIST BEHAVIOR}

Crash typing provides a useful method for organizing and analyzing bicycle crashes. A crash-typing system is a method for assigning a crash to one of several categories based on common crash characteristics. Researchers can examine the relative frequencies of the different types to determine the bicycling situations that produce the most crashes and injuries. The similarities between crashes of a given type may suggest countermeasures. The crash types can be used to classify data from different samples, so that regional differences and trends over time can be studied.

The groundwork for the development of bicycle-motor vehicle crash types was first laid in the 1970s. Inspired by the earlier development of pedestrian-motor vehicle crash types, Cross and Fisher (1977) did the same for bicycles. Cross and Fisher's crash types, also known as "problem types," fell into 7 classes (A-G) that were subdivided into a total of 37 problem types. Suggested countermeasures were similar within each class. This system evolved into NHTSA's current crash-typing scheme, outlined in NHTSA's Manual Accident Typing (MAT) for Bicyclist Accidents Coder's Handbook. The MAT handbook identifies 45 distinct bicycle-motor vehicle crash types. Each type describes the physical circumstances and behavior that produced the crash. The initial classification is by vehicle movements: parallel paths, crossing paths, and special circumstances. Each of these is divided further into 15 groups. A report by Safety Consulting Services (1997a) discusses and illustrates the original crash types and their subsequent development.

Research shows that crossing-path crash types accounted for the highest proportion of all bicycle-motor-vehicle crashes, $58 \%$, followed by parallel path types, which accounted for $36 \%$ of bicycle to motor-vehicle crashes (Hunter et al., 1995). The most common crossing-path crash types were those where the motorist failed to yield to bicycle, representing $22 \%$ of all crashes. In $17 \%$ of cases, it was the cyclist that failed to yield to the motorist at an intersection and, in another $12 \%$ of cases, crashes occurred when a cyclist failed to yield to the motorist midblock. The most common parallel path types of bicycle to motor-vehicle crashes were when the motorist turned or merged into the cyclist's path. This type of crash accounted for $12 \%$ of cases. A motorist overtaking the cyclist accounted for $9 \%$ of cases, and a cyclist turning or merging into motorist's path was the cause of the crash in another $7 \%$ of reported cases. 
In another attempt to meaningfully categorize bicycle-motor-vehicle crashes, Räsänen and Summala (1998) developed a new crash-typing scheme for crashes where bicycle paths crossed roadways. Four major categories were defined, each with 3 or 4 subtypes (Table 2).

Table 2: Räsänen and Summala (1998) bicyclist crash-typing

\begin{tabular}{|l|l|}
\hline I & $\begin{array}{l}\text { Car turns, cycle path crosses street before road crossing - the bicycle may } \\
\text { approach from the left or the right and the car may be turning either left or } \\
\text { right (4 subtypes); }\end{array}$ \\
\hline II & $\begin{array}{l}\text { Car turns, cycle path crosses street after road crossing - the bicycle may be } \\
\text { appearing from in front of or behind the car and the car may be turning left or } \\
\text { right (4 subtypes); }\end{array}$ \\
\hline III & $\begin{array}{l}\text { Car drives straight ahead, cyclist comes from the left - the bicycle crossing is } \\
\text { on the far side of a 3-way (T type) or 4-way intersection or the bicycle } \\
\text { crossing is on the near side of a 3-way (T) intersection (3 subtypes) }\end{array}$ \\
\hline IV & $\begin{array}{l}\text { Car drives straight ahead, cyclist comes from the right - the bicycle crossing } \\
\text { is on the far side of a 3-way (T) intersection, on the near side of a 3-way (T) } \\
\text { intersection with one leg of the T going off to the right or to the left or the } \\
\text { bicycle crossing is on the far side of a 4-way intersection }\end{array}$ \\
\hline
\end{tabular}

The most common crash scenario fell into category I, where the driver turned right and the bicyclist appeared from the right (Räsänen \& Summala, 1998). While turning right, the driver scans to the left to find a gap in traffic in order to pull out. The driver may never look to the right for bicyclists. Another relatively frequent scenario in this category was where the driver turned left and the bicyclist appeared from the left. Here, the driver scans traffic to the right to find a gap. However, since the driver also needs to consider traffic coming from the left, he or she is much more likely to see an approaching bicyclist.

The second most common crash scenario fell into category III (Räsänen and Summala, 1998). Here, the driver was driving straight across a 4-way intersection and the bicyclist crossed from the left on the far side of the intersection. Since the bicyclist is traveling against traffic, the driver may simply not expect a bicyclist from this direction. However, it is also likely that drivers fail to scan for bicyclists on the far side of the intersection, since bicyclists appearing from the right also are struck fairly frequently.

The third most common crash scenario fell into category II where the vehicle turns right and the bicyclist appears from ahead or the left after the vehicle enters the turn (Räsänen and Summala, 1998). Again, the bicyclist rides against traffic and may not be anticipated by drivers. Moreover, drivers may be distracted by scanning left for passing traffic and may enter the turn without consideration for crossing bicyclists. Evidence for the latter is the fact that bicyclists approaching from behind, or from the right after the vehicle enters the turn, also are struck fairly frequently. Interestingly, for left-turning vehicles in this category, bicyclists riding with traffic are more commonly hit than those riding against traffic.

In 37\% of crashes, neither bicyclist nor driver saw the other or realized the danger in time for any avoidance reaction (Räsänen \& Summala, 1998). Sight obstacles were found to be a contributing factor to many crashes. In situations where the cyclist had the right of way, cyclists 
with a driver's license were more likely to be hit than those without. Most cyclists were very familiar with the accident site, with almost two-thirds passing it daily.

In a separate study, examining bicyclist's behavior, Kim, Kim, Ulfarsson, and Porello (2007) found that close to 70\% of accidents happened with bicycles riding with traffic. Bicycles turning or merging into traffic comprised $24 \%$ of crashes. Motorists overtaking or turning/merging were associated with $12 \%$ and $10 \%$ of crashes, respectively. Bicyclists were found to be solely at fault for the crash in $56 \%$ of cases; drivers were found solely at fault for $22 \%$ of the crashes.

\section{SPECIAL BICYCLIST TOPICS}

\section{Young Bicyclists and Safety Attitudes}

Bicycle helmets are considered to be crucial safety equipment for bicyclists, especially younger ones. Some of the major reasons for not wearing a helmet were that the helmets were too hot, uncomfortable, unnecessary, or unfashionable. In recent years, helmets have become much lighter; and they have many air vents, which make them more comfortable and cooler than older models. Making riders aware of these improvements in comfort and fashion may encourage helmet use.

Studies have consistently demonstrated the protective role of helmets on head injuries as they are designed to protect the cranium to minimize brain injuries (Attewell, Glase, \& McFadden, 2001; Finnoff, Laskowski, Altman, \& Diehl, 2001; Thomas et al., 1994; Thompson, Thompson, \& Rivara, 1990; Rivara, Thompson, Thompson, Rogers. Alexander, Felix et al., 1994). However, they do not prevent facial injuries, particularly to the lower part of the face (Thompson et al., 1996a). One study found that, among bicycle-related hospitalized patients, helmets reduced serious brain injuries by $74 \%$ and all types of brain and head injuries were reduced by $69 \%$ and $65 \%$, respectively (Thompson et al., 1996). Others have estimated a 60\% reduction in risk of head injuries associated with helmet use (Attewell el al., 2001). Bicycle helmets must be worn correctly to realize their full potential benefits, as those with poorly fitted helmets, especially children, have twice the risk of head injury compared to children whose helmets fit well (Rivara et al., 1999).

The 2002 national survey of bicyclist and pedestrian attitudes and behavior reported that $50 \%$ of bicyclists wear a helmet for at least some trips, with $35 \%$ using them for all or most trips, with male and female bicyclists being about equally likely to wear a helmet. Among younger bicycle riders, those 16 to 20, only 16\% report wearing helmets for all trips, compared to 30\% for bicyclists older than 30 (NHTSA, 2008). Other studies have shown similar trends. A study by Schlundt, Warren, \& Miller (2004) reported that approximately 20\% of children in the U.S. wear helmets and separately the rate of those who always wear a helmet when riding was found to vary between 13 to 65\% (Karkhaneh, Kalenga, Hagel, \& Rowe, 2006). Some studies show that, among children, the highest proportion of helmet use is by those 7 to 10 years old, with a use rate of $44 \%$ (Finnoff et al., 2001). 
To further examine barriers to bicycle helmet use, a survey of children, teens, and adults reported that for children, helmet comfort was the main reason for not wearing one. Twenty\% of children said they did not wear helmets because they were uncomfortable, and another 15\% reported that they did not need helmet, and 14\% considered helmets to be too hot to be worn comfortably (Finnoff et al., 2001). Loubeau (2000) reported similar findings. For teen bicyclists, top barriers to helmet use were somewhat different. Some $40 \%$ of teens said they find helmets annoying (Finnoff et al., 2001). Another 39\% said that helmets are uncomfortable. Only a quarter of teen respondents reported not wearing a helmet because they did not have access to one. Adults cited lack of access to a helmet and lack of comfort as the top reasons for not using one. Among school age children that wear helmets, it is estimated that only 30\% wear their helmets properly (Scuffham et al., 1997).

Studies show that helmet ownership and use of bicycle helmets tend to be higher in higher-income areas than in middle or lower income communities. A review by Towner et al. (2002) indicated that teenagers are less likely to own and wear helmets than children and/or adults. Some reports show that helmet use was greater in urban areas (23\%) than in rural areas ( $9 \%$ use) and was higher on main roads than on residential streets.

Parental attitudes and behavior with regard to helmet use are shown to be predictive of children's safety behavior. Surveys of parents and guardians and their children in grades 4 and 5 , showed that $88 \%$ of children that owned a bicycle also owned a helmet, and that most parents and children stated that helmets should be worn when riding. However, there were significant discrepancies between parents' beliefs about their children's helmet-wearing behavior. For example, while most parents believed their child always wore a helmet, only half of the surveyed children did so. Survey results also showed that children imitate their parent's behaviors. For example $88 \%$ of parents that reported not wearing helmets when riding had children who reported never wearing a helmet (Erlich, Helmkamp, Williams, Haque, \& Furbee, 2004). Finnoff et al. (2001) have shown similar results and also highlight the role of friends in helmet wearing behavior). In addition, children who rode with their parents were more likely to wear helmets than those who did not ride with their parents (Erlich et al., 2004).

\section{Training and Education Programs}

Often geared towards young bicyclists, schools and other institutions typically offer traffic education programs and workshops to promote bicycle safety. However, many programs offered are not standardized and their effect on bicycle safety is unknown. While a number of studies have examined training and educational programs, they often reach contradictory or inconclusive results (Bicycle Federation of America, 1993; Hart \& Daughtridge, 1998; Williams et al., 1993).

An evaluation of the effectiveness of a bicycle safety and skills training program by Van Schagen and Brookhuis (1994) demonstrated that for young children, knowledge could be increased and simple behavior sequences learned, but complex behaviors, such as priority rules, seemed to be beyond the children's cognitive capabilities. Other studies have similarly shown that brief safe bicycling skills training program for fourth graders were not effective (Macarthur 
et al., 1998) and that young, novice bicyclists are limited in their ability to accomplish complex cognitive tasks while cycling, compared to experienced bicyclists (Wierda \& Brookhuis, 1991).

Nagel et al. (2003) showed that training programs for children in grades 1 to 3 were successful in increasing awareness for bicycling rules, helmet use, and children's scanning of intersections when riding. A Dutch study showed that trainings delivered in a combination of teaching and modeling were successful in improving safe behavior among children; however, children showed no improvement with respect to making correct priority decisions (Van Schagen \& Brookhuis, 1994). In addition, Macarthur et al. (1998) found that safe bicycle handling skills training programs for fourth-graders was ineffective and safe bicycling behaviors, bicycling knowledge, and attitudes did not improve in the experimental group compared to a control group.

Bicycle helmet promotion is an effective means for increasing helmet use rates. Helmet use promotion can take many forms, including public information and education campaigns, helmet subsidies and distribution, and incentives for helmet use. Studies show that multi-faceted multi-year community-wide campaigns are an effective mode to increase helmet use among children (Rivara et al., 1994; Tracy, 1992). A study aimed at promoting helmet use by reducing financial barriers and use of print, electronic, and public media increased helmet use among school children from 5.5\% to 40\% over a 5-year period (Rivara et al., 1994).

A number of studies have attempted to increase helmet use rates among low-income families. Interventions to increase helmet use rates by providing discounted or free helmets coupled with education have shown success. One study increased rates from a $4 \%$ baseline to 18\% (Parkin et al., 1995), while another increased rates from 43\% to 89\% (Britt et al., 1998). Programs using community activities, coupons, group purchases, and helmet use reinforcement through rewards and regulations showed success in increasing helmet use rates from a 1\% baseline to 33\% (Farley et al., 1996). Those that combined education and parental involvement with free helmets doubled helmet use rates among low-income students (Hendrickson \& Becker, 1998).

Cushman et al. (1991) examined physician practice-based interventions and showed that helmet use rates were unaffected when interventions were delivered only as physician counseling and take-home pamphlets. A study by Lee et al. (2000) described a program conducted through the hospitals that also conducted talks on safety and helmet-use in schools, provided videos and demonstrations, and offered low-cost helmets. Following this program, self-reported helmet use increased from $11 \%$ at baseline to $31 \%$ over five years and bicycle-related head injuries decreased by $46 \%$. A similar study by Stevens et al. (2002) showed that pediatric practice-based programs designed to prevent high-risk behavior were successful in increasing use of bicycle helmets among those receiving safety promotion communication. 


\section{Bicyclist Conspicuity and Visibility}

Conspicuity, being easily seen by motorists, is critical to a bicyclist's safety. Improving daytime and nighttime conspicuity is an important part of bicycle safety. Bicyclists can increase their nighttime conspicuity with pedal reflectors, leg lamps, headlamps, fluorescent triangles, ankle bands, and fluorescent clothing. A Consumer Product Safety Commission study (Kiss et al., 1998) evaluated various types of bicycle reflectors, head- and taillights, and large area yellow or green fluorescent sheeting for their effectiveness in enhancing conspicuity. For parallel path conditions, a red blinking taillight was detected at the greatest distance. The detection distances for white pedal reflectors and red rear reflectors were virtually identical. Yellow or green fluorescent sheeting and an amber rear reflector had somewhat shorter detection and recognition distances. For crossing path conditions, yellow or green fluorescent sheeting, wheel circle reflectors, spoke reflectors, and headlights and tail lights with standard spoke reflectors were all detected and recognized at about the same distance. The authors concluded that there was no obvious way to improve current bicycle reflector requirements (Kiss et al., 1998).

Bicycle reflectors, particularly when supplemented with a headlight and flashing tail light, are effective for detecting bicyclists at night. Bicycle manufacturers must install reflectors on all new bicycles. These usually include a white front reflector, a red rear reflector, white spoke reflectors, and yellow pedal reflectors. In the United States, lights are not required and must be purchased and installed separately. Other countries require bicycles to be sold with lights (Osberg et al., 1998).

\section{Facilities and Infrastructure}

Wide curb lanes offer no physical or visual separation from motorists. This may produce inconsistent and sometimes erratic driver behavior when passing bicyclists, which may put the cyclists or other road users at risk. Bicycle lanes separated from motor vehicle traffic with pavement markings reduce erratic driver behavior. Shoulders are, in many respects, similar to bicycle lanes in that they are separated from the roadway through striping. The primary distinction is that bicycle paths usually are found in urban areas, while paved shoulders are often found on suburban and rural roads. The high motor vehicle travel speeds on many of these roads increase the risk to bicyclists. Moreover, distracted or drowsy drivers may drift off the road onto the shoulder. This danger may be reduced by installing rumble strips between roadway and shoulder.

Separate bicycle paths provide complete protection from motor vehicle traffic, but these paths often are shared by many users traveling in both directions at varying speeds. Crowded paths can increase bicyclist travel times and increase collision risks. Flow characteristics and level-of-service assessments provide a measure for evaluating these issues. Also, as noted earlier, purposive bicyclists, e.g., those commuting or running errands, often choose direct and swift routes, and those are rarely separate facilities. While most bicycle travel occurs on roads in traffic lanes shared with motor vehicles, some occurs on separate portions of the roadway and some on paths or sidewalks shared with pedestrians, skateboarders, roller-bladers, dogs, and various other obstacles to bicycle travel. These facilities present their own set of bicycle safety problems. 
Separate bicycling facilities tend to be safer for bicyclists than sharing the roadway with motor vehicles. Depending on the location, wide curb lanes, bicycle lanes, shoulders, or bicycle paths may be appropriate. Wilkinson et al. (1994) provide guidelines for selecting the best bicycle facility type for a given roadway. However, research is still needed to assess more accurately the relative safety of these various facilities in different situations and to incorporate these results into guidelines for their use (Harkey \& Hunter, 2000a).

Harkey and Stewart (1997) conducted an operational analysis of wide curb lanes, bicycle lanes, and paved shoulders. They found that bicycle-motor vehicle separation distance is significantly affected by these features. The separation distance between bicycle and motor vehicle during a passing maneuver was greatest for wide curb lanes $(1.95 \mathrm{~m})$, followed by paved shoulders $(1.89 \mathrm{~m})$, and least for bicycle lanes $(1.80 \mathrm{~m})$. The change in lateral displacement of the motor vehicle during a passing maneuver was greater for wide curb lanes than for paved shoulders and bicycle lanes $(0.73 \mathrm{~m}$ versus $0.30 \mathrm{~m})$. As may be expected, the percentage of vehicles that crossed the lane or center line with their left tire was greatest for wide curb lanes (22\%), compared to bicycle lanes (8.9\%) and paved shoulders (3.4\%).

Bicyclists rode farther from the roadway edge in bike lanes or on paved shoulders than in wide curb lanes. When riding farther from the edge, bicyclists are better able to avoid obstacles and debris on the roadway and have slightly more reaction time when motorists cross their path at intersections or driveways. In addition, bicyclists may be more visible to motorists and may have increased sight distance. A line painted on the roadway to delineate a bicycle path or a shoulder was observed to result in fewer erratic movements by motorists. A bicycle lane width of 3 feet was sufficient to ensure safe separation of bicyclists from motorists.

Hunter et al. (1999) conducted a comparative analysis of bicycle lanes and wide curb lanes. Bicyclists rode against traffic or on the sidewalk more frequently where there were wide curb lanes rather than bicycle lanes. More motor vehicles gave bicycles such a wide berth when passing at wide curb lane sites that they encroached on the adjacent traffic lane. There were no differences in bicycle-motor vehicle conflict severity by lane type, but wide curb lanes were associated with increased bicycle-pedestrian conflicts and bicycle lanes were associated with higher bicycle-bicycle conflicts. When bicyclists disobeyed stop signs, those on bicycle lanes were observed to engage in less safe movements than those in wide curb lanes. However, a larger proportion of bicyclists in bicycle lanes obeyed stop signs. Overall, both bicycle lanes and wide curb lanes were considered better for bicyclists than sharing travel lanes with motor vehicles.

Bicycling on paved highway shoulders is considered to be a safe and feasible alternative to sharing the roadway travel lanes. Others argue that policies and regulations concerning bicycling on highway shoulders differ substantially by highway category as well as between States (Kahn \& Bacchus, 1995). In particular, there is substantial disagreement regarding shoulder use along high speed and limited access highways. Some States prohibit bicycles on shoulders along any controlled access highway; other States prohibit bicycles on shoulders along interstate highways only. Some States allow bicycles on all State and interstate highways except in urban areas, some States only specify a minimum shoulder width, and others provide no clear guidelines or prohibitions. 
Bicycle paths and multi-use trails are costly to build and typically can be justified only if they are well-used. Hunter and Huang (1995) observed users on several bicycle and multi-use facilities across the United States User counts varied widely between locations and even at the same location at different times. Some trails were used by fewer than 100 people per day and others by 3,000 people per day or more. The user composition (bicyclists versus walkers and joggers) on multi-use trails also differed significantly.

Cyclists' beliefs and attitudes regarding their own safety parallel the crash information. People who ride bicycles in areas where they do not have access to bike paths or bike lanes feel two times less safe than those riding on paths/lanes (Bureau of Transportation Statistics [BTS], 2004). Furthermore, they are four times more likely to be dissatisfied with the safety efforts undertaken by their community. BTS reports that bike lanes and bike paths do not influence people's riding habits or likelihood to ride bicycles, but they are associated with a higher sense of personal safety. This desire for increased personal safety was illustrated in the results of NHTSA's survey of bicyclist attitudes and behavior (2003). Seventy-three\% of the nationwide sample desired bicycle facilities, such as bike paths, trails, or crosswalks. Ardekani et al. (1995) discussed improperly designed rumble strips as a bicycle hazard. Raised rumble strips, so-called “jiggle bars," pose a safety hazard to bicyclists. If raised rumble strips are used, bicyclists can be accommodated by leaving at least 4 feet of paved shoulder outside the strip. Grooved rumble strips were not considered hazardous to bicyclists. However, different designs resulted in different degrees of discomfort to the bicyclist.

\section{COUNTERMEASURES TO IMPROVE BICYCLIST SAFETY}

\section{Bicycle Laws and Enforcement}

Bicyclists are required to comply with laws and regulations that govern all vehicle operations and interactions on public roadways. In addition, bicyclists are subject to special laws and regulations. Most of these bicycle-specific laws are included in the Uniform Vehicle Code (UVC), but individual States may exclude or change specific rules to meet local needs and preferences. Therefore, considerable variation exists in bicycle-specific laws from State to State.

Statutes can vary considerably from State to State, beginning with the definition of a bicycle. The Uniform Vehicle Code (UVC) defines a bicycle as "Every vehicle propelled solely by human power upon which any person may ride, having two tandem wheels except scooters and similar devices.” (UVC § 1-105). Some States have adopted the UVC definition without modification and some States have chosen to modify the UVC definition. For example, some States specify that a bicycle must be propelled by pedals (Colorado, Delaware, North Carolina, Pennsylvania, Tennessee, Virginia, West Virginia) or a system of belts, chains or gears (California, New York). In Florida and Montana, bicycles may be propelled with the aid of a helper motor. The Delaware, Michigan, and Minnesota codes permit unicycles. Some States limit the number of wheels to no more than two, three, or four, and may exclude unicycles (Preusser Research Group, 2000; Scheib, 1998) 
States differ in whether bicyclists are permitted to ride abreast. The Uniform Vehicle Code (UVC) allows bicyclists to ride two abreast as long as traffic flow is not impeded. In Virginia, Alaska, Arkansas, California, Hawaii, Idaho, Kentucky. Massachusetts, Minnesota, Montana, Nebraska, and North Carolina, bicyclists must ride single file on a roadway. The UVC permits right turns to be signaled by extending the right arm horizontally to the right side of the bicycle. Only Arizona, California, Delaware, Idaho, Kentucky, Maine, Maryland, Massachusetts, Michigan, Minnesota, and Montana permit this signal, while all other States require that all signals be performed with the left arm. These variations in regulations between States are confusing, particularly since they are not well publicized (Preusser Research Group, 2000).

Within the last decade, a few studies have investigated bicyclist compliance with traffic laws. One such study observed bicyclist behavior on selected roadways in Phoenix, Arizona. In bicycle lanes, $18 \%$ of bicyclists rode in the wrong direction; on streets, $17 \%$ of men and $22 \%$ of women rode against traffic. The study also showed that, at signalized intersections, $20 \%$ of bicyclists crossed against the red signal. At intersections with a push-button actuated signal, onethird of cyclists who arrived on red pushed the button to request a green light. At intersections with stop signs, only $17 \%$ of bicyclists came to a complete stop (Cynecki, Perry, \& Frangos, 1993). Another study reported that helmeted bicyclists obey traffic laws more frequently than those not wearing a helmet (Farris, Spaite, Criss, Valenzuela, \& Meislin, 1997) and were more likely than non-helmeted cyclists to ride in parks, playgrounds, or on bicycle paths thus reducing their exposure to risk (DiGuisseppi et al., 1989 - in Robinson, 2007).

\section{Helmet use and laws}

According to a NHTSA report, about $70 \%$ of fatal bicycle crashes are due to head injury, and yet only 20 to $25 \%$ of bicyclists wear helmets. Estimates show that if every child 4 to 15 years old wore helmets, 39,000 to 45,000 head injuries and as many as 55,000 scalp injuries would be prevented (NHTSA, 2006c). As of January 2008, 21 U.S. States, the District of Columbia, and 149 municipalities had adopted age-specific helmet laws, most of which cover bicyclists under age 16. No States have adopted a universal helmet law, and fourteen States have no helmet law at all (NHTSA, 2008a).

Issues regarding bicycle helmet use laws in the United States are similar to those regarding motorcycle helmet or seat belt use laws. A law can be passed only if it has popular and political support. A helmet use law by itself has shown limited success in raising helmet use rates; however, publicized helmet use laws and their enforcement are shown to increase helmet use rates. Evidence suggests that current bicycle helmet laws covering children are rarely enforced and enforcement differs among States. For example, 15\% of motorists received citations for moving violations in crashes with bicycles in New York City (Komanoff, 1999). In crashes with bicyclists in Hawaii, fault was assigned to the driver in $84 \%$ of cases and to the bicyclist in $16 \%$ of cases (Kim \& Li, 1996), whereas in Maine, drivers were considered at fault in only $20 \%$ of cases and the bicyclist at least partially at fault in $80 \%$ (Gårder, 1994).

A study investigating the role of psychosocial factors in helmet use among children in counties in Maryland with different bicycle helmet policies showed that counties with helmet 
laws had higher helmet use rates (Gielen, Joffe, Dannenberg, Wilson, Beilenson, \& DeBoer, 1994). Furthermore, helmet wearers had more positive attitudes about helmet use and had higher scores for need and social consequences than non-helmet wearers. In counties with helmet laws, helmet wearers assessed their crash risk higher than non-helmet wearers. There was no difference in risk assessment in counties with no helmet laws. Helmet wearers reported to be less prone to risktaking than non-helmet wearers. Children were more likely to wear helmets if parents, siblings, and friends wore them.

A separate helmet law study compared helmet use rates for all cyclists among three adjacent counties in New York and Connecticut with different helmet use laws (Puder, Visintainer, Spitzer, \& Casal, 1999). The study found that Rockland County, New York, which had a helmet use law covering all ages, had the highest use rates, at 35\%. Westchester County, New York, which required helmet use by children under 14, had use rates of $24 \%$. Fairfield County, Connecticut, which had a helmet use law covering children under 12 years old, had use rates of $14 \%$. Teenagers were least likely to use helmets in all three counties.

An evaluation of comprehensive bicycle helmet programs that combined helmet giveaway, education, and enforcement showed an increase to $71 \%$ helmet use rates, from a baseline of $0 \%$ (Gilchrist, Schieber, Leadbetter, \& Davidson, 2000). The enforcement included bicycle impoundments. Overall, 167 bikes were impounded over the course of the program, the equivalent of one bicycle/day. No change in helmet use was observed for adult riders. A postmeasure conducted 2 years later revealed a $54 \%$ helmet use rate in children riders compared to $15 \%$ for teens and $0 \%$ for adults. However, once the giveaway program concluded, helmet use dropped to $5 \%$.

The lack of adequate enforcement is a common concern regarding bicycle helmet laws. In Georgia, the law allows for a citation to be sent to the child's parent in the event of noncompliance with the law. However, such citations are rare, and helmet use remains low (Gilchrist, Schieber, Leadbetter, \& Davidson, 2000). Similar results were found following Georgia's passage of a helmet use law in 1993, which required children under 16 to wear bicycle helmets. Helmet ownership and use surveys before and after passage of the law showed that the law increased helmet ownership from $39 \%$ to $57 \%$ of all cyclists and increased helmet use from $33 \%$ to $52 \%$ (Schieber et al., 1996).

Examining the effectiveness of a bicycle helmet law covering all riders under the age of sixteen in the State of Florida, Kinney \& McCloskey (1997 as cited in Kanny, Schieber, Pryor, \& Kresnow 2001) reported an increase in helmet use rates from a baseline of $13 \%$ to $73 \%$ in 16 months. In a similar study, Kanny et al. (2001) found that helmet use was $78 \%$ among all children observed as part of the study. There was a significant difference in use between counties covered by the law (79\% use) and the three counties that opted out (33\% use). Counties observing the law showed a difference in helmet use by race. A significantly higher proportion of Caucasian young riders were helmeted than African-American young riders (83\% and 62\%, respectively). This difference was also observed in the 3 counties exempt from the law (38\% of Caucasian children were helmeted compared to $12 \%$ of African-American children) (Kanny et al., 2001). 
A review of the impact of legislation on bicycle helmet use by Karkhaneh, Kalenga, Hagel, \& Rowe (2006) showed an increase in helmet use after the passage of a law. One study reported an increase of 10\%; 5 reported an increase of 10 to $30 \%$ and 7 studies showed an improvement greater than 30\%. The long term impact of legislation, defined as the impact between 2 and 11 years post-law, showed an increase in helmet use ranging from 10 to 40\% (Karkhaneh et al., 2006). Overall, helmet use was four times higher after legislation, with the largest effects found in communities with the lowest initial helmet use rates and where laws covered riders of all ages.

Studies have shown that legislation in conjunction with education is more effective in increasing helmet use rates than education alone (Dannenberg, Gielen, Beilenson, Wilson, \& Joffe, 1993). A study by Gilchrist et al. (2000) showed that a program delivered in Georgia that combined legislation, education, giveaways and enforcement had some success in increasing helmet use rates. However, while it succeeded in increasing helmet use from a baseline of $0 \%$ to an average of $45 \%$ after helmets were distributed, the programmatic effects were short-lived, as helmet use dropped to $5 \%$ once the giveaway program ended. 


\section{CONCLUSIONS}

This section comments on broader pedestrian and bicycle issues with general recommendations for both programs and research. Additional research recommendations as well as additional discussion on topics in the chapter may be found in the NHTSA/FHWA Pedestrian and Bicycle Strategic Planning Workshops report (NHTSA, 2000a).

It's clear that substantial pedestrian and bicycle safety research has been conducted recently. But while effort has been concentrated on a number of areas, others have remained understudied and are not well understood. The following discussion points out some areas where additional research is recommended.

\section{Epidemiology}

The literature contains many pedestrian and bicycle epidemiological studies that describe the overall safety problems with the available data. Additional similar studies would add little to the overall understanding of pedestrian and bicycle problems. Rather, epidemiological data and studies on pedestrian and bicycle crashes and injuries are needed, separated into two types. The first type would aim to accurately estimate the overall problem, which includes the number of pedestrian injuries and fatalities according to amount of walking and other exposure measures. The second type of studies would aim to provide a better understanding of crash causation.

Problem size: Published estimates of the number of injured pedestrians and bicyclists vary considerably. For example, NHTSA estimates 53,000 bicycle injuries were reported to police in 1998; CPSC estimates about 500,000 were treated in hospital emergency rooms annually and suspects that as many as 500,000 more may have been treated elsewhere. Part of this difference is due to inconsistency in defining the problems, i.e., whether or not motor vehicles are involved and whether or not the injuries occur on public roadways; this also affects countermeasure development and implementation. Stutts and Hunter (1999) estimate that as many as two-thirds of pedestrian injuries did not involve a motor vehicle and are not reported in official transportation statistics. When official sources consistently underestimate pedestrian and bicyclist injuries and fatalities, pedestrians and bicyclists fail to receive an appropriate share of societal attention and resources. As noted in the NHTSA/FHWA workshop report (NHTSA, 2000a), methods should be sought to link or combine data from police reports, hospitals, emergency rooms, and other medical sources. If necessary, surveys or other sampling methods could be used to estimate crashes and injuries that do not appear on official records. Epidemiological studies then can access these combined data sources to quantify and describe the pedestrian and bicycle safety problems more accurately and completely than can be done at present.

Another critical lack is exposure data. Available exposure data for both pedestrians and bicyclists are limited and sporadic. Better exposure data will help understand pedestrian and bicycle safety trends and causal factors.

Crash and injury causation: Pedestrian and bicycle safety countermeasures requires data of high quality that include information on crash causes and contributing factors. While 
police reports provide the best data source for pedestrian and bicycle safety research, they often lack critical pieces of information.

The rapid automation of State crash reporting systems provides an opportunity to collect and report additional useful data. States are designing their crash reporting systems so that police officers in the field can enter data through a laptop or hand-held computer, at the crash scene. A laptop system could include separate pedestrian and bicycle modules that are used only if a pedestrian or bicycle is involved in the crash. A computer-based system could include substantial explanations for unfamiliar data. Research is needed to define the crash data needs and determine how they can best be met, so that the necessary data can be incorporated into State automated crash reporting systems. See NHTSA (2000a) for additional detail.

\section{Laws and enforcement}

Many traffic laws attempt to regulate drivers, bicyclists, and pedestrians as they interact with each other on the roads. Research shows that many of these laws are ignored regularly: drivers do not yield to bicyclists or pedestrians; bicyclists fail to observe stop signs, pedestrians cross midblock and against signals. Some laws may not be known or understood. Others may be ignored because they appear unnecessary or silly or because compliance would be inconvenient. Enforcement is sporadic and ineffective in improving behavior.

The most obvious need is to establish a strategy regarding these laws and their enforcement. One possibility is to accept the current situation and recognize that these laws describe ideal behavior but will not be obeyed regularly. This strategy accepts that laws and enforcement have little role in improving pedestrian and bicycle safety. A second possibility would attempt to raise traffic law compliance by pedestrians, bicyclists, and motorists alike. To do this, the laws must be generally accepted as sensible and reasonable. The appropriate first step is to review all traffic laws applying to pedestrians and bicyclists and all laws applying to drivers when they interact with pedestrians and bicyclists.

A final possibility is to concentrate on situations where conflicts are frequent, risks are high, and the public supports action. School zones and red light running (by pedestrians, bicyclists, and motorists alike) may be examples. Education and enforcement, aided by technology as appropriate, can be used to increase public support and compliance. Preusser Research Group (2000) outlines a broad range of situations, laws, research findings, and recommended future research to support action.

\section{Public information and education}

Pedestrian and bicycle safety education is absolutely essential for children. Many of the basic facts and concepts are common sense, but poorly understood among children. Parents are the first source of facts, and guided practice. Research shows clearly that formal pedestrian safety programs for children have been successful. Additional research should develop improved programs appropriate for children at different developmental ages and should determine effective ways to deliver this information to children. The evidence is far less clear for children's bicycle safety education programs, where basic research and evaluation are needed. 
Most adults receive little or no pedestrian or bicycle safety information or education, even though many adults lack basic safety information (such as an understanding of the traffic laws applying to bicyclists or the meaning of the various phases of a WALK - DON'T WALK sign). Basic research is called for to investigate what information is needed and how it best can be transmitted.

\section{Facilities and infrastructure}

Extensive research has been conducted on facilities used by pedestrians and bicyclists. Much of this research lies outside the scope of this report, so that detailed discussion and recommendations are not appropriate. As this research continues, it should seek methods to accommodate and balance the sometimes conflicting needs and desires of pedestrians, bicyclists, and vehicle drivers. It also should consider how technology can be used to improve safety, for example by automatically detecting pedestrians and bicyclists at controlled intersections and adjusting traffic signals accordingly.

\section{Alcohol}

Epidemiological studies have shown that many pedestrians and bicyclists in crashes are impaired by alcohol. A few studies have investigated the pedestrian alcohol problem but little is known about alcohol-impaired bicyclists. Considerable research is needed in both areas to understand the problem and countermeasures.

\section{Conspicuity}

The research on technical aspects of pedestrian and bicycle conspicuity - driver visual capabilities, recognition distances under different lighting conditions, retro-reflective materials, and the like - is quite extensive. Freedman et al. (2000) document this research and suggest gaps that should be filled. One critical open area is to investigate through strategic and marketing research how research findings on clothing conspicuity can be implemented such that these materials can be incorporated into a wide variety of outer clothing for everyday use.

\section{Older pedestrians}

As the United States population ages, many aspects of society are being designed to accommodate older as well as younger people. Pedestrian (and, in some instances, bicycle) facilities and programs should do the same. Some needs are obvious such as longer WALK cycles to cross a street and public education directed at older people, with all future pedestrian researchers keeping the older pedestrian firmly in mind.

\section{Bicycle helmets}

Research has demonstrated conclusively that bicycle helmets can substantially reduce head injuries. The remaining issues include increasing rates of helmet use among riders. Research should continue to evaluate the effects of the various helmet use laws in the United States and around the world. Research also should continue to evaluate the effectiveness of various helmet use promotion programs. Research may be useful to develop more sophisticated methods of marketing helmet use to different cyclist audiences. 


\section{BIBLIOGRAPHY}

Abdulsattar, H. N., \& McCoy, P. T. (1999). Pedestrians’ right-of-way at signalized intersections. Paper presented at Transportation Research Board 78th Annual Meeting, January 10-14, 1999, Washington, DC.

Abdulsattar, H. N., Tarawneh, M. S., McCoy, P. T., \& Kachman, S. D. (1996). Effect of vehiclepedestrian conflicts of “turning traffic must yield to pedestrians" sign. Transportation Research Record, No. 1553, pp. 38-45.

Allen, D. P., Rouphail, N., Hummer, J. E., \& Milazzo II, J. S. (1998). Operational analysis of uninterrupted bicycle facilities. Transportation Research Record, No. 1636, pp. 29-36.

Allsbrook, L. E. Pedestrian signal countdown device. (1999). Enhancing Transportation Safety in the 21st Century, ITE International Conference, Kissimmee, Florida, March 28-31, 1999.

Al-Senan, S. H., Ergün, G., \& Al-Khabbaz, A. (1993). Characteristics of pedestrian accidents in selected cities of Audi Arabia. Transportation Research Record, No. 1405, pp. 49-55.

American Association of State Highway \& Transp. Off. (1998). Slower speeds' initiative launched in the U.K. AASHTO International Transportation Observer, p. 8.

Anderson, R. W. G., McLean, A. J., Farmer, M. J. B., Lee, B. H., \& Brooks, C. G. (1997). Vehicle travel speeds and the incidence of fatal pedestrian crashes. Accident Analysis and Prevention 29(5), pp. 667-674.

Antonakos, C. L. (1994). Environmental and travel preferences of cyclists. Transportation Research Record, No. 1438, pp. 25-33.

Antonakos, C. L. (1995). Nonmotor travel in the 1990 Nationwide Personal Transportation Survey. Transportation Research Record, No. 1502, pp. 75-82.

Aoki, M., \& Moore, L. (1996). KIDSAFE: a young pedestrian safety study. ITE Journal 66(9), p. 36.

Ardekani, S. A., Govind, S., Mattingly, S. P., Demers, A., Mahmassani, H. S., \& Taylor, D. (1995, December). Detection and mitigation of roadway hazards for bicyclists. Final report. Report No. FHWA/TXDOT-96/1394-2F Washington, DC: Federal Highway Administration, Athanaselis, S., Dona, A., Papadodima, S., Papoutsis, G., Maravelias, C., \& Koutselinis, A. (1999). The use of alcohol and other psychoactive substances by victims of traffic accidents in Greece. Forensic Sci Int 102(2-3), pp. 103-9.

Attewell, R. G., Glase, K., \& McFadden, M. (2001). Bicycle helmet efficacy: A meta-analysis. Accident Analysis and Prevention, 33, 345-352.

Aultman-Hall, L., \& Adams Jr., M. F. (1998). Sidewalk bicycling safety issues. Transportation Research Record, No. 1636, pp. 71-76.

Aultman-Hall, L., \& Hall, F. L. (1998a). Ottawa-Carleton commuter cyclist on- and off-road incident rates. Accident Analysis and Prevention 30(1), pp. 29-43.

Aultman-Hall, L., \& Hall, F. L. (1998b). Research design insights from a survey of urban bicycle commuters. Transportation Research Record, No. 1636, pp. 21-28. 
Aultman-Hall, L., \& Kaltenecker, M. G. (1999). Toronto bicycle commuter safety rates. Accident Analysis and Prevention 31(6), pp. 675-86.

Aultman-Hall, L., Hall, F. L., \& Beatz, B. B. (1997). Analysis of bicycle commuter routes using geographic information systems: implications for bicycle planning. Transportation Research Record, No. 1578, pp. 102-110.

Baltes, M. R. (1996). Factors influencing nondiscretionary work trips by bicycle determined from 1990 U. S. census metropolitan statistical area data. Transportation Research Record, No. 1538, pp. 96-101.

Baltes, M. R. (1998). Descriptive analysis of crashes involving pedestrians in Florida, 1990-1994. Transportation Research Record, No. 1636, pp. 138-145.

Bandara, S.., Wirasinghe, S. C., Gurofsky, D.., \& Chan, P.. (1994). Grade-separated pedestrian circulation systems. Transportation Research Record, No. 1438, pp. 59-66.

Beck, M. J. H., \& Immers, L. H. (1994). Bicycle ownership and use in Amsterdam. Transportation Research Record, No. 1441, pp. 141-146.

Beckwith, D. M., \& Hunter-Zaworski, K. M. (1998). Passive pedestrian detection at unsignalized crossings. Transportation Research Record, No. 1636, pp. 96-103.

Bergman, A. B. (2000). The case for a coordinated national bicycle helmet campaign. Paper presented at Bicycle Safety 2000 Conference, National Highway Traffic Safety Administration, Washington, DC.

Berry, D. S., \& Romo, C. V. (2006). Should 'Cyrus the Centipede’ take a hike? Effects of exposure to a pedestrian safety program on children's safety knowledge and self-reported behaviors. Journal of Safety Research, 37(4): 333-341..

Betz, J.., Dustrude, J.., \& Walker, J.. (1993).. Intelligent bicycle routing in the United States.. Transportation Research Record, No. 1405, pp.. 21-27.

Bicycle Federation of America (1992). Integrating bicycle and pedestrian considerations into state and local transportation planning, design, and operations. The national bicycling and walking studyCase Study No. 21. (Publication No. FHWA-PD-93-017,).Washington, DC: Federal Highway Administration.

Bicycle Federation of America (1993). Analysis of successful provincial, state, and local bicycle and pedestrian programs in Canada and the United States. The national bicycling and walking study - Case Study No. 18. (Publication No. FHWA-PD-93-010).Washington, DC: Federal Highway Administration,

Blomberg, R. D. (2000a). Bicycle countermeasures. In: National Highway Traffic Safety Administration: NHTSA/FHWA Pedestrian and Bicycle Strategic Planning Research Workshops. Draft report. Washington, DC: National Highway Traffic Safety Administration.

Blomberg, R. D. (2000b). Bicycle crash data needs. In: NHTSA/FHWA Pedestrian and Bicycle Strategic Planning Research Workshops. Draft report. Washington, DC: National Highway Traffic Safety Administration.

Blomberg, R. D. (2000c). Pedestrian countermeasures. In: NHTSA/FHWA Pedestrian and Bicycle Strategic Planning Research Workshops. Draft report. Washington, DC: National Highway Traffic Safety Administration. 
Blomberg, R. D., \& Cleven, A. M. (1998). Development, implementation and evaluation of a pedestrian safety zone for elderly pedestrians. (Report No. DOT HS 808 692). Washington, DC: National Highway Traffic Safety Administration. Available at http://ntl.bts.gov/lib/20000/20500/20521/PB98132442.pdf.

Blomberg, R. D., \& Cleven, A. M. (2000, July). Development, implementation and evaluation of a countermeasure program for alcohol-involved pedestrian crashes. (Report No. DOT HS 809 067).. Washington, DC: National Highway Traffic Safety Administration. Available at http://ntl.bts.gov/lib/25000/25900/25960/DOT-HS-809-067.pdf.

Blomberg, R. D., Cleven, A. M., \& Edwards, J. M. (1993, June). Development of safety information materials and media plans for elderly pedestrians. (Report No. DOT HS 808 132). Washington, DC: National Highway Traffic Safety Administration. Available at http://ntl.bts.gov/lib/25000/25800/25844/DOT-HS-808-132.pdf .

Blomberg, R. D., Jordan, G., Killingsworth, R., \& Konheim, C. (2000). Pedestrian transportation: A look forward. Transportation into the New Millenium, Washington, DC: Transportation Research Board, National Research Council. Available at http://onlinepubs.trb.org/onlinepubs/millennium/00088.pdf.

Borglund, S. T., Hayes, J. S., \& Eckes, J. M. (1999). Florida’s bicycle helmet law and a bicycle safety educational program: did they help? J Emerg Nurs 25(6), pp. 496-500.

Botma, H. (1995). Method to determine level of service for bicycle paths and pedestrian-bicycle paths. Transportation Research Record, No. 1502, pp. 38-44.

Bowman, B. L., \& Vecellio, R. L. (1994). Pedestrian walking speeds and conflicts at urban median locations. Transportation Research Record, No. 1438, pp. 67-73.

Bowman, B. L., Vecellio, R. L., \& Haynes, D. W. (1993). A synthesis of existing bicyclist and pedestrian related laws and enforcement programs. The national bicycling and walking study - Case Study No. 13. Publication No. FHWA-PD-93-018. Washington, DC: Federal Highway Administration,

Britt, J., Silver, I., \& Rivara, F. P. (1998). Bicycle helmet promotion among low income preschool children. Injury Prevention 4(4), pp. 280-3.

Britt, J. W., Bergman, A. B., \& Moffat, J. (1995). Law enforcement, pedestrian safety, and driver compliance with crosswalk laws: evaluation of a four-year campaign in Seattle (with discussion and closure). Transportation Research Record, No. 1485, pp. 160-167.

Brown, W. (2000). “Sidewalk selfishness means danger for all. ” Washington Post, August 4, 2000.

Bryan-Brown, K., Thomas, H., \& O’Reilly, D. (1998). Road safety education of children. Road Safety Research Series 1, 14p.

Bryden, J. E., \& Andrew, L. B. (1999). Serious and fatal injuries to workers on highway construction projects. Transportation Research Record, 1657, pp. 42-47.

Bunn, F., Collier, T., Frost, C., Ker, K., Roberts, I., Wentz, R. (2003) Traffic calming for the prevention of road traffic injuries: Systematic review and meta-analysis. Injury Prevention, 200-204.

Bureau of Transportation Statistics (2004). How bike paths and lanes make a difference. BTS Issue Brief, $11,4 \mathrm{p}$.

Cairney, P. (1999, December). Pedestrian safety in Australia. (Report No. FHWA-RD-99-093).

Washington, DC: Federal Highway Administration, Available at www.fhwa.dot.gov/publications/research/safety/99093/index.cfm. 
Cameron, M. H., Vulcan, A. P., Finch, C. F., \& Newstead, S. V. (1994). Mandatory bicycle helmet use following a decade of helmet promotion in Victoria, Australia - an evaluation. Accident Analysis and Prevention 26(3), pp. 325-337.

Campbell, B. J., Zegeer, C. V., Huang, J. J., \& Cynecki, M. J. (2004, January).. A Review of Pedestrian Safety Research in the United States and Abroad. (Report No. FHWA-RD-03-042). McLean, VA [now Washington, DC]: Federal Highway Administration. Available at http://katana.hsrc.unc.edu/cms/downloads/Pedestrian_Synthesis_Report2004.pdf.

Centers for Disease Control and Prevention (1999), Pedestrian Fatalities -- Cobb, DeKalb, Fulton, and Gwinnett Counties, Georgia, 1994-1998. Morbidity and Mortality Weekly Report. 48(28);601-605

Centers for Disease Control and Prevention. National Center for Injury Prevention and Control. Web-based Injury Statistics Query and Reporting System (WISQARS) (2011). Cited 2011, Dec, 29 Available at www.cdc.gov/ncipc/wisqars

Ching, R. P., Thompson, D. C., Thompson, R. S., Thomas, D. J., Chilcott, W. C., \& Rivara, F. P. (1997). Damage to bicycle helmets involved with crashes. Accident Analysis and Prevention 29(5), pp. 555-562.

Christie, N. (1995). Social, economic and environmental factors in child pedestrian accidents: a research review. TRL Project Report, No. PR 116, 21p.

Clark, K. L., Hummer, J. E., \& Dutt, N. (1996). Field evaluation of fluorescent strong yellow-green pedestrian warning signs. Transportation Research Record, No. 1538, pp. 39-46.

Clarke, A., \& Dornfeld, M. J. (1994, January). Traffic calming, auto-restricted zones and other traffic management techniques - their effect on bicycling and pedestrians. The national bicycling and walking study - Case Study No. 19.(Publication No. FHWA-PD-93-028). Washington, DC: Federal Highway Administration. Available at http://safety.fhwa.dot.gov/PED_BIKE/docs/case19.pdf.

Clarke, A., \& Tracy, L. (1995, April). Bicycle safety-related research synthesis. (Report No. FHWA-RD94-062). McLean, VA [now Washington, DC]: Federal Highway Administration. Available at www.hsrc.unc.edu/pdf/1995/Bike1995.pdf.

Clarke, A. (1992). Bicycle-friendly cities: key ingredients for success. Transportation Research Record, No. 1372, pp. 71-75.

Clarke, A. (2000a). Bicycling: pathway to the future. Transportation into the New Millenium, Washington, DC: Transportation Research Board, National Research Council.

Clarke, A. (2000b). Bicycle safety facilities and planning. Paper presented at Bicycle Safety 2000 Conference, National Highway Traffic Safety Administration, Washington, DC.

Cleven, A. M., \& Blomberg, R. D. (1992). Incorporating consideration of bicyclists and pedestrians into education programs. The national bicycling and walking study - Case Study No. 12. (Publication No. FHWA-PD-92-036). Washington, DC: Federal Highway Administration.

Cleven, A. M., \& Blomberg, R. D. (1994, December). Development and evaluation of a pedestrian safety training program for elementary school bus riders. (Report No. DOT HS 808 267).. Washington, DC: National Highway Traffic Safety Administration. Available at http://ntl.bts.gov/lib/25000/25800/25847/DOT-HS-808-267.pdf. 
Cleven, A. M., Blomberg, R. D., \& Levy, M. M. (1998). Field test of a pedestrian safety zone program for older pedestrians. 42nd Annual Conference of the Association for the Advancement of Automotive Medicine, Charlottesville, VA, October 5-7, 1998, pp. 321-334.

Coffin, A., \& Morrall, J. (1995). Walking speeds of elderly pedestrians at crosswalks. Transportation Research Record, No. 1487, pp. 63-67.

Connelly, M. L., \& Isler, R. (1996). Child pedestrians' judgments of safe crossing gaps at three different vehicle approach speeds: a preliminary study. Education and Treatment of Children 19(1), pp. 19-29.

Connelly, M. L., Conagle, H. M., Parsonson, B. S., \& Isler, R. B. (1998). Child pedestrians' crossing gap thresholds. Accident Analysis and Prevention 30(4), pp. 443-453.

Cooper, C. (1999). Evaluation of a bicycle skills training program for young children. Injury Prevention 5(1), p. 78.

Corben, B., Diamantopoulou, K., Mullan, N., \& Mainka, B. (1996, September). Environmental countermeasures for alcohol-related pedestrian crashes., Report No. 101.Melbourne, Australia: Monash University Accident Research Centre. Available at www.monash.edu.au/miri/research/reports/muarc101.pdf.

Cove, L. L., \& Clark, J. E. (1993). Modeling pedestrian volumes on college campuses. Transportation Research Record, No. 1405, pp. 43-48.

Cross, D., Stevenson, M., Hall, M., Burns, S., Laughlin, D., Officer, J., \& Howat, P. (2000). Child pedestrian injury prevention project: student results. Prev Med 30(3), pp. 179-87.

Cross, K. D., \& Fisher, G. (1977, September). A study of bicycle/motor-vehicle accidents: identification of problem types and countermeasure approaches. (Report No. DOT HS 803 315). Washington, DC: National Highway Traffic Safety Administration. Available at http://ntl.bts.gov/lib/25000/25400/25439/DOT-HS-803-315.pdf.

Cryer, P. C., Cole, J., Davidson, L. L., Rahman, M., Ching, V., \& Goodall, J. B. (1998). Rates of, and the factors affecting, cycle helmet use among secondary schoolchildren in East Sussex and Kent. Injury Prevention 4(2), pp. 106-10.

Curnow, W. J. (2005). The Cochrane Collaboration and bicycle helmets. Accident Analysis and Prevention, 37, 569-573.

Cushman, R., Down, J., MacMillan, N., \& Waclawik, H. (1991). Helmet promotion in the emergency room following a bicycle injury: a randomized trial. Pediatrics 88(1), pp. 43-7.

Cynecki, M. J., Perry, G., \& Frangos, G. (1993). Study of bicyclist characteristics in Phoenix, Arizona. Transportation Research Record, No. 1405, pp. 28-34.

Dannenberg, A. L., Gielen, A. C., Beilenson, P. L., Wilson, M. H., Joffe, A. (1993). Bicycle helmet laws and educational campaigns: an evaluation of strategies to increase children's helmet use. AJPH 83(5), pp. 667-74.

DaSilva, M. P., Smith, J. D., \& Najm, W. G. (2003, April) Analysis of Pedestrian Crashes. (Report No. DOT HS 809 585). Washington, DC: National Highway Traffic Safety Administration. Available at www.nhtsa.gov/DOT/NHTSA/NRD/Multimedia/PDFs/Crash\%20Avoidance/2003/DOTHS80958 5.pdf. 
David Evans and Associates, Inc. (1992). What needs to be done to promote bicycling and walking? The national bicycling and walking study - Case Study No. 3. (Publication No. FHWA-PD-93-039). Washington, DC: Federal Highway Administration.

Davies, D. G. (1999). Research, development, and implementation of pedestrian safety facilities in the United Kingdom. (Report No. FHWA-RD-99-089). Washington, DC: Federal Highway Administration. Available at http://www.fhwa.dot.gov/publications/research/safety/pedbike/99089/.

Davis, D. M., \& Wessels, R. L. (1999). Automated pedestrian collision typology in Washington State, 1990 to 1995. Washington State Department of Transportation. Paper presented at Transportation Research Board 78th Annual Meeting, January 10-14, 1999, Washington, DC.

Davis, G. A., \& Corkle, P. T. (1997). Probabilistic rating of safety on local streets. Traffic Congestion and Traffic Safety in the 21st Century: Challenges, Innovations, and Opportunities. Conference sponsored by: Urban Transportation Division, ASCE; Highway Division, ASCE; Federal Highway Administration, USDOT; and National Highway Traffic Safety Administration, USDOT. Chicago, IL, June 8-11, 1997, pp. 465-471.

Davis, G. A. (1998). Method for estimating effect of traffic volume and speed on pedestrian safety for residential streets. Transportation Research Record, No. 1636, pp. 110-115.

Davis, J. (1987). Bicycle safety evaluation. Auburn University, City of Chattanooga, and ChattanoogaHamilton County Regional Planning Commission, Chattanooga, TN.

Dawson, K. P. and Bener, A. (1999). Safer roads for children in the United Arab Emirates. East Mediterr Health J 5(2), pp. 277-81.

Demers, A., Suddarth, A., Mahmassani, H. A., Ardekani, S. A., \& Govind, S. (1995). Bicycle hazard mitigation manual. Interim report. Texas University Center for Transportation Research, Austin, Texas University Center for Transportation Studies, Arlington, Texas Department of Transportation, and Federal Highway Administration, Report No. FHWA/TXDOT-96/1394-1.

DeVeauuse, N., Kim, K., Peek-Asa, C., McArthur, D., \& Kraus, J. (1999). Driver compliance with stop signs at pedestrian crosswalks on a university campus. Journal of American College Health 47(6), pp. 269-274.

DiGuiseppi, C. G., Rivara, F. P., \& Koepsell, T. D. (1990). Attitudes toward bicycle helmet ownership and use by school-age children. Am J Dis Child 144(1), pp. 83-6.

DiGuiseppi, C. G., Rivara, F. P., Koepsell, T. D., \& Polissar, L. (1989). Bicycle helmet use by children. Evaluation of a community-wide helmet campaign. JAMA 262(16), pp. 2256-61.

Dijkstra, A., Levelt, P., Thomsen, J., Thorson, O., Van Severen, J., Vansevenant, P., Nilsson, P. K., Jørgensen, E., la Cour Lund, B., \& Laursen, J. G. (1998). Best practice to promote cycling and walking. (ADONIS - Analysis and Development Of New Insights into Substitution of short car trips by cycling and walking. ). SWOV Institute for Road Safety Research, The Netherlands, Ingeniería de Tráfico S. L., Spain, Langzaam Verkeer VZW, Belgium, Danish Road Directorate, Denmark, and Technical University of Denmark.

Dixon, L. B. (1996). Bicycle and pedestrian level-of-service performance measures and standards for congestion management systems. Transportation Research Record, No. 1538, pp. 1-9.

Dixon, M. A., \& Jacko, J. A. (1998). An investigation of tactile and visual stimuli in the roadway environment. Perceptual \& Motor Skills 87(2), pp. 387-394. 
Do, A. (1999). Studies shed light on bicycle and pedestrian crashes with vehicles. APWA Reporter 66 (7), $13 p$.

Dunbar, G., Lewis, V., \& Hill, R. (1999). Control processes and road-crossing skills. Psychologist 12(8), pp. 398-399.

Durkin, M. S., Laraque, D., Lubman, I., \& Barlow, B. (1999). Epidemiology and prevention of traffic injuries to urban children and adolescents. Pediatrics 103(6), pp. 1273-74.

Dutt, N., Hummer, J. E., \& Clark, K. L. (1997). User preference for fluorescent strong yellow-green pedestrian crossing signs. Transportation Research Record, No. 1605, pp. 17-21.

Dutt, N., Hummer, J. E., Clark, K. L., \& Blakely, S. (1996). Controlled-environment evaluation of fluorescent strong yellow-green pedestrian-crossing sign prototypes. Transportation Research Record, No. 1553, pp. 86-94.

Eck, R. W., \& Simpson, E. D. (1996). Using medical records in non-motor-vehicle pedestrian accident identification and countermeasure development. Transportation Research Record, No. 1538, pp. 54-60.

Ehrlich, P. F., Helmkamp, J. C., Williams, J. M., Haque, A., \& Furbee, P. M. (2004). Matched analysis of parent's and children's attitudes and practices towards motor vehicle and bicycle safety: an important information gap. Injury Control and Safety Promotion, 11, 23-28.

Eilert-Pettersson, E., \& Schelp, L. (1997). An epidemiological study of bicycle-related injuries. Accident Analysis and Prevention 29(3), pp. 363-372.

Ekman, L., \& Hyden, C. (1999). Pedestrian safety in Sweden.,(Report No. FHWA-RD-99-091). Lund University, University of North Carolina, Highway Safety Research Center, and Washington, DC: Federal Highway Administration. Available at http://www.fhwa.dot.gov/publications/research/safety/99091/index.cfm.

Ekman, R., Schelp, L., Welander, G., \& Svanstrom, L. (1997). Can a combination of local, regional and national information substantially increase bicycle-helmet wearing and reduce injuries? experiences from Sweden. Accident Analysis and Prevention 29(3), pp. 321-328.

Elbadrawi, H. R., Ospina, D. I., \& Shen, L. D. (2000). Pedestrian crossing locations at single lane roundabouts. Paper presented at Transportation Research Board 78th Annual Meeting, January 913, 2000, Washington, DC, 9p.

Elvik, R. (2000). Which are relevant costs and benefits of road safety measures designed for pedestrians and cyclists? Accident Analysis and Prevention 32(1), pp. 37-45.

Epperson, B. (1994). Evaluating suitability of roadways for bicycle use: toward a cycling level-of-service standard. Transportation Research Record, No. 1438, pp. 9-16.

Epperson, B. (1995). Demographic and economic characteristics of bicyclists involved in bicycle-motor vehicle accidents. Transportation Research Record, No. 1502, pp. 58-64.

Ercolano, J. (1998). New “yield to pedestrians” devices in New York, USA. ITE Journal 68(10), p. 71.

Ercolano, J. M., Olson, J. S., \& Spring, D. M. (1997). Sketch-plan method for estimating pedestrian traffic for central business districts and suburban growth corridors. Transportation Research Record, No. 1578, pp. 38-47.

Ernst, M. (2004). Mean Streets 2004 - How Far Have We Come? Pedestrian Safety, 1994-2003. Surface Transportation Policy Project, Report No. HS-043-734. 
Evans, D., \& Norman, P. (1998). Understanding pedestrians' road crossing decisions: An application of the theory of planned behaviour. Health Education Research 13(4), pp. 481-489.

Everett, S. A., Price, J. H., Bergin, D. A., and Groves, B. W. (1996). Personal goals as motivators: predicting bicycle helmet use in university students. Journal of Safety Research 27(1), pp. 43-53.

Ewing, R., King, M. R., \& Brown, S. Traffic calming main roads. (2000)Rutgers University/Surface Transportation Policy Project, Research Institute for Regional and Urban Development of North Rhine-Westphalia, and Fehr \& Peers Associates, Inc. Paper presented at Transportation Research Board 79th Annual Meeting, January 9-13, 2000, Washington, DC, 18pp.

Faghri, A., \& Egyháziová, E. (1999). Development of a computer simulation model of mixed motor vehicle and bicycle traffic on an urban road network. Transportation Research Record, No. 1674, pp. 86-93.

FARS (2011); Fatality Analysis Reporting System Encyclopedia Data Query. Accessed December29, 2011. Available at www-fars. nhtsa. dot. gov/

Farley, C., Haddad, S., \& Brown, B. (1996). The effects of a 4-year program promoting bicycle helmet use among children in Quebec. AJPH 86(1), pp. 46-51.

Farris, C., Spaite, D. W., Criss, E. A., Valenzuela, T. D., \& Meislin, H. W. (1997). Observational evaluation of compliance with traffic regulations among helmeted and nonhelmeted bicyclists. Annals of Emergency Medicine 29(5), pp. 625-9.

Fazio, J., \& Tiwari, G. (1995). Nonmotorized-motorized traffic accidents and conflicts in Dehli streets. Transportation Research Record, No. 1487, pp. 68-74.

Federal Highway Administration. (1998, January). Improving conditions for bicycling and walking. A best practices report. Washington, DC: Federal Highway Administration.

Ferguson, S. A., Preusser, D. F., Lund, A. K., Zador, P. L., \& Ulmer, R. G. (1995). Daylight saving time and motor vehicle crashes: the reduction in pedestrian and vehicle occupant fatalities. AJPH 85(1), pp. 92-95.

Finnoff, J. T., Laskowski, E. R., Altman, K. L., \& Diehl, N. N. (2001). Barriers to bicycle helmet use. Pediatrics, 108, e4. Available at www. pediatrics. org/cgi/content/full/108/1/e4

Fisher, N. L. (1999). Bicycle helmets: it’s the law. Med Health R I 82(8), pp. 302-3.

Floerchinger-Franks, G., Machala, M., Goodale, K., \& Gerberding, S. (2000). Evaluation of a pilot program in rural schools to increase bicycle and motor vehicle safety. $J$ Community Health 25(2), pp. 113-24.

Fontaine, H., \& Gourlet, Y. (1997). Fatal pedestrian accidents in France: a typological analysis. Accident Analysis and Prevention 29(3), pp. 303-312.

Fontaine, H. (1996). Alcohol in fatal pedestrian crashes in France. Proceedings of the conference Road Safety in Europe held in Birmingham, United Kingdom, September 9-11, 1996. (VTI Konferens), No. 7A:2, pp. 1-14.

Foot, H., Tolmie, A., Thomson, J., McLaren, B., \& Whelan, K. (1999). Recognizing the hazards. Psychologist 12(8), pp. 400-402.

Foss, R. D., \& Beirness, D. J. (2000). Bicycle helmet use in British Columbia: Effects of the helmet use law. Chapel Hill, NC: University of North Carolina, Highway Safety Research Center, and Ottawa, Ontario: Traffic Injury Research. 
Freedman M. (2000). Bicyclist conspicuity issues and topics for future research. In: National Highway Traffic Safety Administration: NHTSA/FHWA Pedestrian and Bicycle Strategic Planning Research Workshops. Draft report.

Gårder, P. (1994). Bicycle accidents in Maine: an analysis. Transportation Research Record, No. 1438, pp. 34-41.

Gårder, P. (1995). Rumble strips or not along wide shoulders designated for bicycle traffic. Transportation Research Record, No. 1502, pp. 1-7.

Gårder, P., Leden, L., \& Pulkkinen, U. (1998). Measuring the safety effect of raised bicycle crossings using a new research methodology. Transportation Research Record, No. 1636, pp. 64-70.

Gibby, A. R., Stites, J. L., Thurgood, G. S., \& Ferrara, T. C. (1994). Evaluation of marked and unmarked crosswalks at intersections in California. Final report. California Department of Transportation and Federal Highway Administration, Report No. FHWA/CA/TO-94/1 CPWS 94-02 4A5B1162.

Gielen, A. C., Joffe, A., Dannenberg, A. L., Wilson, M. E. H., Beilenson, P. L., \& DeBoer, M. (1994). Psychosocial factors associated with the use of bicycle helmets among children in counties with and without helmet use laws. Journal of Pediatrics, 124(2), pp. 204-210.

Gilchrist, J., Schieber, R. A., Leadbetter, S., \& Davidson, S. C. (2000). Police enforcement as part of a comprehensive bicycle helmet program. Pediatrics, 106, 6-9.

Gilleran, B. F., \& Pates, G. (1994). Bicycling \& walking in the nineties and beyond. Applying Scandinavian experience to America’s challenges. (Report No. FHWA-PL-95-007). Washington, DC: Federal Highway Administration.

Goldsmith, S. A. (1993). Reasons why bicycling and walking are not being used more extensively as travel modes. The national bicycling and walking study - Case Study No. 1. (Publication No. FHWA-PD-92-041). Washington, DC: Federal Highway Administration.

Grayson, B., \& Ward, H. (1996). Pedestrian activity and accident risk. TRL Published Article PA 3138/96, pp. 62-73. (1996).

Greenways Incorporated (1992a). Current planning guidelines and design standards being used by State and local agencies for bicycle and pedestrian facilities. The national bicycling and walking study - Case Study No. 24. (Publication No. FHWA-PD-93-006). Washington, DC: Federal Highway Administration.

Greenways Incorporated (1992b). Transportation potential and other benefits of off-road bicycle and pedestrian facilities. The national bicycling and walking study - Case Study No. 7. (Publication No. FHWA-PD-92-040). Washington, DC: Federal Highway Administration.

Gurrier, J. H., \& Jolibois, S. C., Jr. (1998). The safety of elderly pedestrians at five urban intersections in Miami. Human Factors and Ergonomics Society 42nd Annual Meeting, Chicago IL, October 5-9, 1998, Proceedings Volume 1, pp. 171-177.

Hagel, B. E., \& Pless, I. B. (2006). A critical examination of arguments against bicycle helmet use and legislation. Accident Analysis and Prevention, 38, 277-278.

Hagel, B. E., Lamy, A., Rizkallah, J. W., Belton, K. L., Jhangri, G. S., Cherry, N., \& Rowe, B. H. (2007). The prevalence and reliability of visibility aid and other risk factor data for uninjured cyclists and pedestrians in Edmonton, Alberta, Canada. Accident Analysis and Prevention, 39, 284-289. 
Harkey, D. L., \& Hunter, W. W. (2000a). Bicycle facilities research. In: National Highway Traffic Safety Administration: NHTSA/FHWA Pedestrian and Bicycle Strategic Planning Research Workshops. Draft report. 2000a.

Harkey, D. L., \& Hunter, W. W. (2000b). Engineering countermeasures research for bicycling. In: National Highway Traffic Safety Administration. NHTSA/FHWA Pedestrian and Bicycle Strategic Planning Research Workshops. Draft report.

Harkey, D. L., \& Stewart, J. R. (1997a). Bicycle and motor vehicle operations on wide curb lanes, bicycle lanes, and paved shoulders. Traffic Congestion and Traffic Safety in the 21st Century Challenges, Innovations, and Opportunities. Conference sponsored by: Urban Transportation Division, ASCE; Highway Division, ASCE; Federal Highway Administration, and National Highway Traffic Safety Administration. Chicago, IL, June 8-11, 1997, pp. 139-145.

Harkey, D. L., \& Stewart, J. R. (1997b). Evaluation of shared-use facilities for bicycle and motor vehicles. Transportation Research Record, No. 1578, pp. 111-118.

Harkey, D. L., \& Zeeger, C. V. (2004). PEDSAFE: Pedestrian Safety Guide and Countermeasure Selection System, Final Report 2001-2004. (Report No. FHWA-SA-04-003). Washington, DC: Federal Highway Administration.

Harkey, D. L., Reinfurt, D. W., \& Knuiman, M. (1998). Development of the bicycle compatibility index. Transportation Research Record, No. 1636, pp. 13-20.

Harland, D. G., Bryan-Brown, K., \& Christie, N. (1996a). The pedestrian casualty problem in Scotland. Why so many.Edinburgh: Her Majesty’s Stationery Office.

Harland, G., O’Reilly, D., \& Christie, N. (1996b). Planning for safer child pedestrians. Proceedings of the conference Road Safety in Europe held in Birmingham, United Kingdom, September 9-11, 1996. (VTI Konferens), No. 7A:1, pp. 77-93.

Harlos, S., Warda, L., Buchan, N., Klassen, T. P., Koop, V. L., \& Moffatt, M. E. (1999). Urban and rural patterns of bicycle helmet use: factors predicting usage. Injury Prevention 5(3), pp. 183-8.

Harrell, W. A. (1994). Effects of blind pedestrians on motorists. Journal of Social Psychology 134(4), pp. 529-39.

Harrell, W. A. (1996). The safety of older pedestrians at signal-controlled crossings. International Journal of Aging and Human Development 42(1), pp. 65-79.

Harruff, R. C., Avery, A., \& Alter-Pandya, A. S. (1998). Analysis of circumstances and injuries in 217 pedestrian traffic fatalities. Accident Analysis and Prevention 30(1), pp. 11-20.

Hart, K. M., \& Daughtridge, J. (1998). Implementing a bicycle safety workshop. Orthop Nurs 17(3), pp. 49-52.

Hatziandreu, E. J., Sacks, J. J., Brown, R., Taylor, W. R., Rosenberg, M. L., \& Graham, J. D. (1995). The cost effectiveness of three programs to increase use of bicycle helmets among children. Public Health Reports 110(3), pp. 251-259.

Hawkins, H. G. (1994). Use of supplemental plaques to improve effectiveness of warning signs. Transportation Research Record, No. 1456, pp. 20-26.

Henary, B. Y., Ivarsson, B. J., \& Crandall, J. R. (2006). The influence of age on the morbidity and mortality of pedestrian victims. Traffic Injury Prevention, 7, 182-190. 
Hendrickson, S. G., \& Becker, H. (1998). Impact of a theory based intervention to increase bicycle helmet use in low income children. Injury Prevention 4(2), pp. 126-31.

Hess, P. M., Moudon, A. V., Snyder, M. C., \& Stanilov, K. (1999). Site design and pedestrian travel. Transportation Research Record, No. 1674, pp. 9-19.

Holland, V. J. (1996). Fiber optic speed signs educate drivers in school speed zones. Conference Compendium of Technical Papers for the 66th ITE Annual Meeting. Sponsored by: Institute of Transportation Engineers, Minneapolis, Minnesota, September 15-18, 1996, pp. 346-350.

Holubowycz, O. T. (1995a). Age, sex, and blood alcohol concentration of killed and injured pedestrians. Accident Analysis and Prevention 27(3), pp. 417-422.

Holubowycz, O. T. (1995b). Alcohol-involved pedestrians: the Australian experience. Alcohol, Drugs and Traffic Safety, August 13-18, 1995; proceedings of the 13th International Conference on Alcohol, Drugs and Traffic Safety, Adelaide, Australia, volume 2, pp. 700-10.

Hook, W. (1994). Role of nonmotorized transportation and public transport in Japan's economic success. Transportation Research Record, No. 1441, pp. 68-74.

Hope, D. (1994). Nonrecreational cycling in Ottawa, Canada. Transportation Research Record, No. 1441, pp. 147-150.

Hotz, G. A., Cohn, S. M., Nelson, J., Mishkin, D., Castelbanco, A., Li, P., Duncan, R. (2004). Pediatric pedestrian trauma study: A pilot project. Traffic Injury Prevention, 5, 132-136.

Howe, J. (1995). Enhancing nonmotorized transportation use in Africa - changing the policy climate. Transportation Research Record, No. 1487, pp. 22-26.

Huang, H., Zegeer, C., \& Nassi, R. (2000). The effects of innovative pedestrian signs at unsignalized locations: a tale of three treatments. University of North Carolina, Highway Safety Research Center and City of Tuscon Department of Transportation. Paper presented at Transportation Research Board 79th Annual Meeting, January 9-13, 2000, Washington, DC.

Hughes, R., Huang, H., \& Zegeer, C. (1999a). ITS and pedestrian safety at signalized intersections. ITS Quarterly 7(2), pp. 37-45.

Hughes, R., Huang, H., Zegeer, C., \& Cynecki, M. (1999b). Automated pedestrian detection used in conjunction with standard pedestrian push buttons at signalized intersections. Enhancing Transportation Safety in the 21st Century, Institute of Transportation Engineers, ITE International Conference, Kissimmee, Florida, March 28- 31, 1999.

Hughes, R., Huang, H., Zegeer, C., \& Cynecki, M. (2000). Automated pedestrian detection used in conjunction with standard pedestrian push buttons at signalized intersections. Paper presented at Transportation Research Board 79th Annual Meeting, January 9-13, 2000, Washington, DC, 19p.

Hummel, T. (1998). Dutch pedestrian research review. A review of the main traffic safety research on pedestrians in the Netherlands, 1984-1997. No. R-98-7, 40p. The Netherlands: SWOV Institute for Road Safety Research.

Hummel, T. (1999). Dutch pedestrian safety research review. (Report No. FHWA-RD-99-092). Washington, DC: Federal Highway Administration.

Hunter, W. W., \& Huang, H. F. (1995). User counts on bicycle lanes and multiuse trails in the United States. Transportation Research Record, No. 1502, pp. 45-57. 
Hunter, W. W., Harkey, D. L., \& Stewart, J. R. (2000). Evaluation of Portland, Oregon's blue bike lane treatment. Paper presented at Transportation Research Board 79th Annual Meeting, January 9-13, 2000, Washington, DC.

Hunter, W. W., Pein, W. E., \& Stutts, J. C. (1995). Bicycle-motor vehicle crash types: the early 1990s. Transportation Research Record, No. 1502, pp. 65-74.

Hunter, W. W., Pein, W. E., \& Stutts, J. C. (1997a). Bicycle crash types: A 1990’s informational guide., (Report No. FHWA-RD-96-104, 3A4b, HS-042 610). Washington, DC: Federal Highway Administration.

Hunter, W. W., Stewart, J. R., \& Stutts, J. C. (1999). A study of bicycle lanes versus wide curb lanes. Transportation Research Record, No. 1674, pp. 70-77.

Hunter, W. W., Stutts, J. C., \& Pein, W. E. (1997). Pedestrian crash types: a 1990’s informational guide. (Report No. FHWA-RD-96-163, 3A4b, Research Report, HS-042 609). Washington, DC: Federal Highway Administration.

Hunter, W. W., Stutts, J. C., Pein, W. E., \& Cox, C. L. (1996). Pedestrian and bicycle crash types of the early 1990’s. (Report No. FHWA-RD-95-163), Washington, DC: Federal Highway Administration.

Hydén, C., \& Várhelyi, A. (2000). The effects on safety, time consumption and environment of large scale use of roundabouts in an urban area: a case study. Accident Analysis and Prevention 32(1), pp. 11-23.

Jackson, M. E., \& Ruehr, E. O. (1998). Let the people be heard: San Diego county bicycle use and attitude survey. Transportation Research Record, No. 1636, pp. 8-12.

Jensen, S. U. (1999). Pedestrian safety in Denmark. Transportation Research Record, No. 1674, pp. 6169.

Johnson, C. D. (1997). Pedestrian fatalities on interstate highways: characteristics and countermeasures. Transportation Research Record, No. 1578, pp. 23-29.

Jolibois, S., Guerrier, J., Ospina, D., Baker, T., \& Hermantin, L. (1997). Interventions to promote pedestrian safety at urban intersections. (Report No. WPI 0510760), . Washington, DC: Federal Highway Administration.

Jordan, G. (1998). Child pedestrian-car crashes near schools are a small percentage of total child pedestrian crashes in Philadelphia. Transportation Research Record, No. 1636, pp. 132-137.

Kannel, E. J., \& Jansen, W. (2004). In-Pavement Pedestrian Flasher Evaluation: Cedar Rapids, Iowa. (CTRE Project 03-145). Ames, IA: Center for Transportation Research and Education, Iowa State University.

Kanny, D., Schieber, R. A., Pryor, V., \& Kresnow, M. (2001). Effectiveness of a State law mandating use of bicycle helmets among children: An observational evaluation. American Journal of Epidemiology,154, 1072-1076.

Karkhaneh, M., Kalenga, J-C., Hagel, B. E., \& Rowe, B. H. (2006). Effectiveness of bicycle helmet legislation to increase helmet use: A systematic review. Injury Prevention, 12, 76-82.

Karsch, H. M., Leaf, W. A., \& Preusser, D. F. (2000). Pedestrian injuries in relation to vehicle speed. In: National Highway Traffic Safety Administration: NHTSA/FHWA Pedestrian and Bicycle Strategic Planning Research Workshops. Draft report. 
Keall, M. D. (1995). Pedestrian exposure to risk of road accident in New Zealand. Accident Analysis and Prevention 27(5), pp. 729-740.

Khan, A. M., \& Bacchus, A. (1995). Bicycle use of highway shoulders. Transportation Research Record, No. 1502, pp. 8-21.

Khan, F. M., Jawaid, M., Chotani, H., \& Luby, S. (1999). Pedestrian environment and behavior in Karachi, Pakistan. Accident Analysis and Prevention 31(4), pp. 335-9.

Khisty, C. J. (1994). Evaluation of pedestrian facilites: beyond the level of service concept. Transportation Research Record, No. 1438, pp. 45-50.

Kim, J., Kim, S., Ulfarsson, G. F., \& Porello, L. A. (2007). Bicyclist injury severities in bicycle-motor vehicle accidents. Accident Analysis and Prevention, 39, 238-251.

Kim, K., \& Li, L. (1996). Modeling fault among bicyclists and drivers involved in collisions in Hawaii, 1986-1991. Transportation Research Record, No. 1538, pp. 75-80.

Kim, K., \& Ortega, K. (1999). Modeling the relationships between pedestrian accidents and census block group characteristics in Hawaii. University of Hawaii, Dept. of Urban and Regional Planning, Honolulu, HI. Paper presented at Transportation Research Board 78th Annual Meeting, January 10-14, 1999, Washington, DC.

Kiss, C. T., Kumagai, M., Tinsworth, D. K., Cassidy, S. P., Inkster, S., Snyder, S., Murphy Jr., J. R., \& Schroeder, T. (1998). Bicycle reflector project. Washington, DC: Consumer Product Safety Commission.

Klop, J. R., \& Khattak, A. J. (1999). Factors influencing bicycle crash severity on two-lane undivided roadways in North Carolina. Transportation Research Record, No. 1674, pp. 78-85.

Knoblauch, R. L., Nitzburg, M. S., \& Seifert, R. F. (2000). Pedestrian crosswalk case studies. Center for Applied Research. Inc., Great Falls, VA, Paper No. 1598. Paper presented at Transportation Research Board 79th Annual Meeting, January 9-13, 2000, Washington, DC, 15p.

Knoblauch, R. L., Pietrucha, M. T., \& Nitzburg, M. (1996). Field studies of pedestrian walking speed and start-up time. Transportation Research Record, No. 1538, pp. 27-38.

Koenig, D. J., \& Wu, Z. (1994). The impact of a media campaign in the reduction of risk-taking behavior on the part of drivers. Accident Analysis and Prevention 26(5), pp. 625-633.

Komanoff, C., and Right of Way.org. (1999, March). Killed by automobile: Death in the streets of New York City 1994-1997. New York: Right of Way,.org. Available at www.rightofway.org/research/kba_text.pdf.

Komanoff, C. (2000). Getting motorists to share the road. Paper presented at Bicycle Safety 2000 Conference, National Highway Traffic Safety Administration, Washington, DC.

Kong, L. B., Lekawa, M., Navarro, R. A,. McGrath, J., Cohen, M., Margulies, D. R., \& Hiatt, J. R. (1996). Pedestrian-motor vehicle trauma: an analysis of injury profiles by age. Journal of the American College of Surgeons 182, pp. 17-23.

Kupferberg-Ben David, N., \& Rice, R. G. (1994). The role of the physical environment in child pedestrian accidents. Journal of Advanced Transportation 28(2), pp. 171-187.

Kwon, Y., Morichi, S., \& Yai, T. (1998). Analysis of pedestrian behavior and planning guidelines with mixed traffic for narrow urban streets. Transportation Research Record, No. 1636, pp. 116-123. 
Lam, W. H. K., Morrall, J. F., \& Ho, H. (1995). Pedestrian flow characteristics in Hong Kong. Transportation Research Record, No. 1487, pp. 56-62.

Landis, B. W. (1994). Bicycle interaction hazard score: a theoretical model. Transportation Research Record, No. 1438, pp. 3-8.

Landis, B. W., Vattikuti, V. R., \& Brannik, M. T. (1997). Real-time human perceptions: toward a bicycle level of service. Transportation Research Record, No. 1578, pp. 119-126.

Lang, C. Tay, R. Watson, B., Edmonston, C., \& O’Connor, E. (2003). Drink walking: An examination of the related behaviour and attitudes of young people. 2003 Road Safety Research, Policing and Education Conference - From Research to Action: Conference Proceedings (pp. 164-169). Sydney, NSW Roads and Traffic Authority.

Langlois, J. A., Keyl, P. M., Guralnik, J. M., Foley, D. J., Marottoli, R. A., \& Wallace, R. B. (1997). Characteristics of older pedestrians who have difficulty crossing the street. AJPH 87(3), pp. 393397.

LaScala E. A., Gerber, D., \& Gruenewald P. J. (2000). Demographic and environmental correlates of pedestrian injury collisions: a spatial analysis. Accident Analysis and Prevention 32(5), pp. 651658.

Lau, G., Seow, E., \& Lim, E. S. (1998). A review of pedestrian fatalities in Singapore from 1990 to 1994. Ann Acad Med Singapore 27(6), pp. 830-837.

Leaf, W. A., \& Preusser, D. F. (1997). Identification of alcohol-pedestrian crash problems among selected racial/ethnic groups. (Report No. DOT HS 808 641). Washington, DC: National Highway Traffic Safety Administration.

Leaf, W. A., \& Preusser, D. F. (1999, October). Literature review on vehicle travel speeds and pedestrian injuries. (Report No. DOT HS 809 021). Washington, DC: National Highway Traffic Safety Administration. Available at http://www.nhtsa.gov/people/injury/research/pub/hs809012.html.

Leaf, W. A., Preusser, D. F., \& Karsch, H. M. (2000). Race/ethnicity. In: National Highway Traffic Safety Administration: NHTSA/FHWA Pedestrian and Bicycle Strategic Planning Research Workshops. Draft report. 2000a.

Leaf, W. A., Shabanova Northrup, V., \& Preusser, D. F. (2005). Evaluation of Alternative Approaches for Reducing Alcohol-Related Crashes Among Pedestrian Targets of Opportunity. DTNH22-98-D45079, Draft Final Report. Washington, DC: National Highway Traffic Safety Administration.

Leden, L., Gårder, P., \& Pulkkinen, U. (2000). An expert judgment model applied to estimating the safety effect of a bicycle facility. Accident Analysis and Prevention 32(4), pp. 589-599.

Lee, A. J., Mann, N. P., \& Takriti R. (2000). A hospital led promotion campaign aimed to increase bicycle helmet wearing among children aged 11-15 living in West Berkshire 1992-1998. Injury Prevention 6(2), pp. 151-153.

Lee, C., \& Abdel-Aty, M (2005). Comprehensive analysis of vehicle-pedestrian crashes at intersections in Florida. Accident Analysis and Prevention, 37, 775-786.

Leonard, P. A., Beattie, T. F., \& Gorman, D. R. (1999). Under representation of morbidity from paediatric bicycle accidents by official statistics-a need for data collection in the accident and emergency department. Injury Prevention 5(4), pp. 303-4.

Li, G., \& Baker, S. P. (1994). Alcohol in fatally injured bicyclists. Accident Analysis \& Prevention 26(4), pp. 543-548. 
Li, G., \& Baker, S. P. (1996). Exploring the male-female discrepancy in death rates from bicycle injury: the decomposition method. Accident Analysis and Prevention 28(4), pp. 537-540.

Li, G., Baker, S. P., Smialek, J. E., \& Soderstrom, C. A. (2001). Use of alcohol as a risk factor for bicycling injury. Journal of the American Medical Association, 285, 893-896.

Li, G., Baker, S. P., Sterling, S., Smialek, J. E., Dischinger, P. C., Soderstrom, C. A. (1996). A comparative analysis of alcohol in fatal and nonfatal bicycling injuries. Alcoholism: Clinical \& Experimental Research 20(9), pp. 1553-9.

Li, G., Shahpar, C. Soderstrom, C. A., \& Baker, S. P. (2000). Alcohol use in relation to driving records among injured bicyclists. Accident Analysis and Prevention 32(4), pp. 583-587.

Liller, K. D., Morissette, B., Noland, V., \& McDermott, R. J. (1998). Middle school students and bicycle helmet use: knowledge, attitudes, beliefs, and behaviors. J Sch Health 68(8), pp. 325-8.

Linn, S., Smith, D., \& Sheps, S. (1998). Epidemiology of bicycle injury, head injury, and helmet use among children in British Columbia: A five-year descriptive study. Canadian Hospitals Injury, Reporting and Prevention Program. Injury Prevention 4(2), pp. 122-5.

Litman, T. (1994). Bicycling and transportation demand management. Transportation Research Record, No. 1441, pp. 134-140.

Litman, T. (1999). Evaluating traffic calming benefits, costs and equity impacts. Victoria, British Columbia, Canada: Victoria Transport Policy Institute.

Liu, X., Shen, L. D., \& Huang, J. (1995). Analysis of bicycle accidents and recommended countermeasures in Beijing, China. Transportation Research Record, No. 1487, pp. 75-83.

Lord, D. (1996). Analysis of pedestrian conflicts with left-turning traffic. Transportation Research Record, No. 1538, pp. 61-67.

Loubeau, P. R. (2000). Exploration of the barriers to bicycle helmet use among 12 and 13 year old children. Accident Analysis and Prevention 32(1), pp. 111-5.

Luoma, J., Schumann, J., \& Traube, E. C. (1996). Effects of retroreflector positioning on nighttime recognition of pedestrians. Accident Analysis and Prevention 28(3), pp. 377-383.

Lusk, A. (1993). Analysis of successful grassroots movements relating to pedestrians and bicycles and a guide on how to initiate a successful program. The national bicycling and walking study - Case Study No. 6.(Publication No. FHWA-PD-93-024). Washington, DC: Federal Highway Administration.

Macarthur, C., Parkin, P. C., Sidky, M., \& Wallace, W. (1998). Evaluation of a bicycle skills training program for young children: a randomized controlled trial. Injury Prevention 4(2), pp. 116-21.

Mace, D., Finkle, M., \& Pennak, S. (1997). Daytime photometric requirements for pedestrian signals. Transportation Research Record, No. 1605, pp. 41-48.

MacGregor, C., Smiley, A., \& Dunk, W. (1999). Identifying gaps in child pedestrian safety: comparing what children do with what parents teach. Transportation Research Record, No. 1674, pp. 32-40.

Macpherson, A., Roberts, \& I., Pless, I. B. (1998). Children's exposure to traffic and pedestrian injuries. AJPH 88(12), pp. 1840-3.

Macpherson, A. K., To, T. M., Macarthur, C., Chipman, M. L., Wright, J. G., \& Parkin, P. (2002). Impact of mandatory helmet legislation on bicycle-related head injuries in children: A population-based study. Pediatrics, 110, 5pp. 
Maring, W., \& Van Schagen, I. (1990). Age dependence of attitudes and knowledge in cyclists. Accident Analysis and Prevention 22(2), pp. 127-136.

Mayhew, D. R., Brown, S. W., \& Simpson, H. M. (2002). The Alcohol-Crash Problem in Canada: 2000. Report TP 11759 E. The Traffic Injury Research Foundation of Canada. Ottawa, Ontario, 177 pp.

Mayhew, D. R., Brown, S. W., and Simpson, H. M. (1999). Alcohol use among drivers and pedestrians fatally injured in motor vehicle accidents: Canada, 1997. Ottawa, Ontario, Canada: The Traffic Injury Research Foundation of Canada.

McCarthy, M., \& Gilbert, K. (1996). Cyclist road fatalities in London 1985-1992: drivers, vehicles, manoeuvres and injuries. Accident Analysis and Prevention 28(2), pp. 275-279

McMahon, P. J., Duncan, C., Stewart, J. R., Zegeer, C. V., \& Khattak, A. J. (1999). Analysis of factors contributing to "walking along roadway" crashes. Transportation Research Record, No. 1674, pp. 41-48.

Mercier-Guyon, C. (E. D. ), Clayton, A., Colgan, M., \& Tunbridge, R. (1997a). The drinking pedestrian a 20-year follow-up. Proceedings of the 14th International Conference on Alcohol, Drugs and Traffic Safety - T97, held Annecy, France, September 21-26, 1997, Vol. 1, pp. 149-54.

Mercier-Guyon, C. (E. D. ), Fodd, R. D., Harkey, D. L., Reinfurt, D. W., \& Marchetti, L. M. (1997b). High alcohol-involved pedestrian crash sites: driver and pedestrian behaviors. Proceedings of the 14th International Conference on Alcohol, Drugs and Traffic Safety - T97, held Annecy, France, September 21-26, 1997, Vol. 1, pp. 161-7.

Mercier-Guyon, C. (E. D. ), Fontaine, H., \& Gourlet, Y. (1997c). Alcohol involvement in pedestrian accidents in France. Proceedings of the 14th International Conference on Alcohol, Drugs and Traffic Safety - T97, held Annecy, France, September 21-26, 1997, Vol. 1, pp. 155-60.

Miles-Doan, R. (1996). Alcohol use among pedestrians and the odds of surviving an injury: evidence from Florida law enforcement data. Accident Analysis and Prevention 28(1), pp. 23-31.

Miller, J. A., Austin, J., \& Rohn, D. (2004). Teaching pedestrian safety skills to children. Environment and Behavior, 36, 368-385.

Miller, R., \& Sutaria, T. C. (1998). City of Santa Ana pedestrian safety study. Harmonizing Transportation and Community Goals - The Challenge for Today's Transportation Professional. ITE International Conference, Monterey, CA, March 1-4, 1998.

MMWR (1999). Pedestrian fatalities-Cobb, DeKalb, Fulton, and Gwinnett counties, Georgia, 1994-1998. Morb Mortal Wkly Rep 48(28), pp. 601-5.

Mock, C. N., Forjuoh, S. N., \& Rivara, F. P. (1999). Epidemiology of transport-related injuries in Ghana. Accident Analysis and Prevention 31(4), pp. 359-70.

Moe, P., Denney, C., Wilkinson, B., Beltz, M., \& Clarke, A. (1997). Bicycle and pedestrian planning under the Intermodal Surface Transportation Efficiency Act (ISTEA): a synthesis of the state of the practice. (Report No. FHWA-PD-97-053). Washington, DC: Federal Highway Administration.

Moritz, W. E. (1997). Survey of North American bicycle commuters: design and aggregate results. Transportation Research Record, No. 1578, pp. 91-101.

Moritz, W. E. (1998). Adult bicyclists in the United States: Characteristics and riding experience in 1996. Transportation Research Record, No. 1636, pp. 1-7. 
Morris, B. A., Trimble, N. E. (1991). Promotion of bicycle helmet use among schoolchildren: a randomized clinical trial. Can J Public Health 82(2), pp. 92-4.

Morris, B. A., Trimble, N. E., \& Fendley, S. J. (1994). Increasing bicycle helmet use in the community. Measuring response to a wide-scale, 2-year effort. Can Fam Physician 40, pp. 1126-31.

Moudon, A. V., Hess, P. M., Snyder, M. C., and Stanilov, K. (1997). Effects of site design on pedestrian travel in mixed-use, medium-density environments. Transportation Research Record, No. 1578, pp. 48-55.

Muttart, J. W. (1995). The cognitive ability and characteristics of children pedestrians involved in accidents. Accident Investigation Quarterly, No. 7, pp. 34, 47.

National Highway Traffic Safety Administration (1995). A pedestrian safety training program for elementary school bus riders. Traffic Tech, No. 98, Washington, DC: Author. Available at http://www. nhtsa.

gov/About+NHTSA/Traffic+Techs/current/A+Pedestrian+Safety+Training+Program+for+Eleme ntary+School+Bus+Riders.

NHTSA. (1998a). Field test of a safety zone program for older pedestrians. Traffic Tech, No. 174. Washington, DC: National Highway Traffic Safety Administration.

NHTSA. (1998b). Zone guide for pedestrian safety shows how to make systematic improvements. Traffic Tech, No. 181, (Report No. DOT HS 042 731, Washington, DC: National Highway Traffic Safety Administration. .

NHTSA. (1998c). 1998 Motor Vehicle Occupant Safety Survey, Data Preview VI: Bicycle Use. Washington, DC: National Highway Traffic Safety Administration.

NHTSA. (1999a). Traffic Safety Facts 1998. . (Report No. DOT HS 808-983). Washington, DC: National Highway Traffic Safety Administration.

NHTSA. (2010a). Traffic Safety Facts 2009 Data. Pedestrians. . (Report No. DOT HS 811-394). Washington, DC: National Highway Traffic Safety Administration. Available at http://www-nrd. nhtsa. dot. gov/Pubs/811394. pdf.

NHTSA. (2011b). Traffic Safety Facts 2009 Data. Bicyclists and other Cyclists. . (Report No. DOT HS 811 386. Washington, DC: National Highway Traffic Safety Administration. Available at http://www-nrd. nhtsa. dot. gov/Pubs/811386. pdf.

NHTSA. (2011c). Traffic Safety Facts 2009. Older Population. . (Report No. DOT HS 811-391. Washington, DC: National Highway Traffic Safety Administration.

NHTSA. (1999b). Walk alert: national pedestrian safety program guide. (Report No. DOT HS-042 769)., . Washington, DC: National Highway Traffic Safety Administration.

NHTSA. (1999c). Walking through the years: pedestrian safety for your child. (Report No. HS-808 818). Washington, DC: National Highway Traffic Safety Administration.

NHTSA. (2000a). NHTSA/FHWA Pedestrian and Bicycle Strategic Planning Research Workshops. Draft report. Washington, DC: National Highway Traffic Safety Administration.

NHTSA. (2000b). Pedestrian and bicycle crash analysis tool. Washington, DC: National Highway Traffic Safety Administration.

NHTSA. (2002). Bicycle Helmet Use Laws. State Legislative Fact Sheet. Washington, DC: National Highway Traffic Safety Administration. 
NHTSA. (2003). National Survey of Pedestrian and Bicyclist Attitudes and Behavior. Highlights Report. Washington, DC: National Highway Traffic Safety Administration.

NHTSA. (2004, April). Bicycle Helmet Use Laws. Traffic Safety Facts - Laws. Washington, DC: National Highway Traffic Safety Administration.

NHTSA. (2006a). Traffic Safety Facts 2005 Data. . (Report No. DOT HS810-624). Washington, DC: National Highway Traffic Safety Administration.

NHTSA. (2006b). Traffic Safety Facts 2005 Data. . (Report No. DOT HS810-617). Washington, DC: National Highway Traffic Safety Administration.

NHTSA. (2006c, January). Bicycle Helmet Use Laws. Traffic Safety Facts - Laws. Washington, DC: National Highway Traffic Safety Administration.

NHTSA. (2008a). Bicycle Helmet Use Laws. Traffic Safety Facts - Laws. (Report No. DOT HS 810 866). Washington, DC: National Highway Traffic Safety Administration.

NHTSA. (2008b). National Survey of Bicyclist and Pedestrian Attitudes and Behavior. Volume II: Findings Report. (Report No. DOT HS 810 972). Washington, DC: National Highway Traffic Safety Administration.

National Technical Information Service. (1994). Pedestrian movement and safety. NTIS Report No. PB94-883121/GAR. Springfield, VA: Author.

Nelson, A. C., \& Allen, D. (1997). If you build them, commuters will use them: association between bicycle facilities and bicycle commuting. Transportation Research Record, No. 1578, pp. 79-83.

Nelson, A. C. (1995). Private provision of public pedestrian and bicycle access ways: public policy rationale and the nature of public and private benefits. Transportation Research Record, No. 1502, pp. 96-104.

Negel, R., Hankenhof, B., Kimmel, S., \& Saxe, J. (2003). Educating grade school children using a structured bicycle safety program. Journal of Trauma. November; 55 (5). 920-3.

Niittymaki, J., \& Kikuchi, S. (1998). Application of fuzzy logic to the control of a pedestrian crossing signal. Transportation Research Record, No. 1651, pp. 30-38.

Nitzburg, M. S., \& Knoblauch, R. L. (2000). An evaluation of high visibility crosswalk treatments. Center for Applied Research. Inc., Great Falls, VA, Paper No. 00-1603. Paper presented at Transportation Research Board 79th Annual Meeting, January 9-13, 2000, Washington, DC.

Noland, R. B. (1996). Pedestrian travel times and motor vehicle traffic signals. Transportation Research Record, No. 1553, pp. 28-33.

O’Leary, A. A., Lockwood, P. B., \& Taylor, R. V. (1996). Evaluation of detectable warning surfaces for sidewalk curb ramps. Transportation Research Record, No. 1538, pp. 47-53.

O’Reilly, D. (1998). Developments in the understanding of child pedestrian safety training. Traffic Safety on Two Continents. Conference sponsored by: Swedish National Road and Transport Research Institute, Transportation Research Board, Forum of European Road Safety Research Institute, and Laboratorio Nacional de Engenharia Civil. Lisbon, Portugal, September 22-24, 1997. Report No. VTI konferens 9A part 3, pp. 69-82.

O’Sullivan, S., \& Morrall, J. (1996). Walking distances to and from light-rail transit stations. Transportation Research Record, No. 1538, pp. 19-26. 
Olkkonen, S., \& Honkanen, R. (1990). The role of alcohol in nonfatal bicycle injuries. Accident Analysis \& Prevention 22(1), pp. 89-96.

Osberg, J. S., Stiles, S. C., \& Asare, O. K. (1998). Bicycle safety behaviour in Paris and Boston. Accident Analysis and Prevention 30(5), pp. 679-687.

Otis, S. C., \& Machemehl, R. B. (1996). Predicting pedestrian safety at suburban signalized intersections. Conference Compendium of Technical Papers for the 66th ITE Annual Meeting. Sponsored by: Institute of Transportation Engineers, Minneapolis, MN, September 15-18, 1996, pp. 172-175.

Otis, S. C., Mahmassani, H. S., Machemehl, R. B., \& Palamarthy, S. (1994). Pedestrian signals: warrants and effectiveness. (Report No. FHWA/TX-95+1296-2F. Washington, DC: Federal Highway Administration.

Oxley, J., Fildes, B., Ihsen, E., Charlton, J., \& Day, R. (1997). Differences in traffic judgements between young and old adult pedestrians. Accident Analysis and Prevention 29(6), Report No. HS-042 579, pp. 839-847.

Oxley, J., Fildes, B., Ihsen, E., Charlton, J., \& Day, R. (1997). Simulation of the road crossing task for older and younger adult pedestrians: a validation study. Road Safety Research and Enforcement Conference, 1997, Hobart, Tasmania, Australia.

Palamarthy, S., Mahmassani, H. S., \& Machemehl, R. B. (1994). Models of pedestrian crossing behavior at signalized intersection. (Report No. FHWA/TX-94+1296-1).. Washington, DC: Federal Highway Administration.

Parkin, P. C., Hu, X., Spence, L. J., Kranz, K. E., Shortt, L. G., \& Wesson, D. E. (1995). Evaluation of a subsidy program to increase bicycle helmet use by children of low-income families. Pediatrics 96(2), pp. 283-287.

Patrick, D. A., Bensard, D. D., Moore, E. E., Partington, M. D., \& Karrer, F. M. (1998). Driveway crush injuries in young children: a highly lethal, devastating, and potentially preventable event. $J$ Pediatr Surg 33(11), pp. 1712-5.

Pein, W. (1997). Bicyclist performance on a multiuse trail. Transportation Research Record, No. 1578, pp. 127-131.

Peng, R. Y., \& Bongard, F. S. (1999). Pedestrian versus motor vehicle accidents: an analysis of 5,000 patients. J Am Coll Surg 189(4), pp. 343-8.

Petritsch, T. (2000). Importance of traffic enforcement in bicycle safety. Paper presented at Bicycle Safety 2000 Conference, National Highway Traffic Safety Administration, Washington, DC.

Porter, C., Suhrbier, J., \& Schwartz, W. L. (1999). Forecasting bicycle and pedestrian travel - state of the practice and research needs. Transportation Research Record, No. 1674, pp. 94-101.

Posner, J. C., Liao, E., Winston, F. K., Cnaan, A., Shaw, K. N., \& Durbin, D. R. (2002). Exposure to traffic among urban children injured as pedestrians. Injury Prevention, 8, 231-235.

Povey, L. J., Frith, W. J., \& Graham, P. G. (1999). Cycle helmet effectiveness in New Zealand. Accident Analysis and Prevention 31(6), pp. 763-770.

Powell, J., Wilkins, D., Leiper, J., \& Gillam, C. (2000). Stay on your feet safety walks group. Accident Analysis and Prevention 32(3), pp. 389-90.

Preston, B. (1995). Cost effective ways to make walking safer for children and adolescents. Injury Prevention 1(3), pp. 187-90. 
Preston, B. (1997). The safety of walking and cycling in different countries. In: R. Tolley, ed., The greening of urban transport, edition 2, chapter 4, , pp. 37-51. New York: John Wiley and Sons, Ltd.

Preusser Research Group, Inc. (2000). Laws and ordinances that promote pedestrian and bicycle safety. Task 2. Literature review. Draft. Project Memorandum, NHTSA Contract No. DTNH22-98-D45079, Task Order 02. Washington, DC: National Highway Traffic Safety Administration.

Preusser, D. F., \& Leaf, W. A. (2000). Pedestrian crash data. In: National Highway Traffic Safety Administration: NHTSA/FHWA Pedestrian and Bicycle Strategic Planning Research Workshops. Draft report.

Puder, D. R., Visintainer, P., Spitzer, D., \& Casal, D. (1999). A comparison of the effect of different bicycle helmet laws in 3 New York City suburbs. AJPH 89(11), pp. 1736-8.

Puranik, S., Long, J., \& Coffman, S. (1998). Profile of pediatric bicycle injuries. South Med J 91(11), pp. 1033-7.

Rajesh, K., \& Lovell, M. E. (2000). Pedestrian injuries sustained in negotiating traffic calming measures. J Accid Emerg Med 17(3), pp. 233-4.

Räsänen, M., \& Summala, H. (1998). Attention and expectation problems in bicycle-car collisions: an indepth study. Accident Analysis and Prevention 30(5), pp. 657-666.

Raymond, P. D., \& Knoblauch, R. L. (2000). The effect of crosswalk markings on vehicle speeds. Center for Applied Research. Inc., Great Falls, VA. Paper No. 00-1602. Paper presented at Transportation Research Board 79th Annual Meeting, January 9-13, 2000, Washington, DC.

Redmon, T. (2003). Assessing the attitudes and behaviors of pedestrians and drivers in traffic situations. Institute of Transportation Engineers Journal, April 2003.

Replogle, M. (1992). Bicycle and pedestrian policies and programs in Asia, Australia, and New Zealand. The national bicycling and walking study - Case Study No. 17.(Publication No. FHWA-PD-93016). Washington, DC: Federal Highway Administration, .

Replogle, M. (1992). Bicycles and cycle-rickshaws in Asian cities: issues and strategies. Transportation Research Record, No. 1372, pp. 76-84.

Retting, R. A., \& Van Houten, R. (1997). Safety benefits of advance stop lines at signalized intersections: results of a field evaluation. Arlington, VA: Insurance Institute for Highway Safety.

Retting, R. A. (1993). A review of fatal injuries to pedestrians induced by urban truck crashes. Association for the Advancement of Automotive Medicine, Proceedings, 37th Annual Conference, San Antonio, TX, November 4-6, 1993, 128p.

Retting, R. A. (1999). Traffic engineering approaches to improving pedestrian safety. Transportation Quarterly 53(2), pp. 87-99.

Retting, R. A., Ferguson, S. A., \& McCartt, A. T. (2003). A review of evidence-based traffic engineering measures designed to reduce pedestrian-motor vehicle crashes. American Journal of Public Health, 93, 1456 -1463.

Retting, R. A., Van Houten, R., Malenfant, L., Van Houten, J., \& Farmer, C. M. (1996). Special signs and pavement markings improve pedestrian safety. ITE Journal 66(12), p. 28.

Ribbens, H. (1996). Pedestrian facilities in South Africa: research and practice. Transportation Research Record, No. 1538, pp. 10-18. 
Richards, G. (1999). Crosswalks maybe becoming extinct in California. Transportation Builder 11(4), p. 27.

Rivara, F. P., Astley, S. J., Clarren, S. K., Thompson, D. C., \& Thompson, R. S. (1999). Fit of bicycle safety helmets and risk of head injuries in children. Injury Prevention 5(3), pp. 194-7.

Rivara, F. P., Thompson, D. C., Thompson, R. S., Rogers, L. W., Alexander, B., Felix, D., \& Bergman, A. B. (1994). The Seattle Children's Bicycle Helmet Campaign: Changes in helmet use and head injury admissions. Pediatrics 93(4), pp. 567-569.

Roads \& Traffic Authority. Sydney region (1994). Think before you cross: pedestrian safety campaign, Sydney region, November, 1994.

Roberts, I. and Crombie, I. (1995). Child pedestrian fatalities: sensitivity to traffic volume-evidence from the USA. Journal of Epidemiology and Community Health 49(2), pp. 186-188.

Roberts, I., Marshall, R., \& Lee, J. T. (1995). The urban traffic environment and the risk of child pedestrian injury: a case-crossover approach. Epidemiology 6(2), pp. 169-171.

Robinson, D. L. (1996). Head injuries and bicycle helmet laws. Accident Analysis and Prevention 28(4), pp. 463-475.

Robinson, D. L. (2007). Bicycle helmet legislation: Can we reach a consensus? Accident Analysis and Prevention, 39, 86-93.

Rodgers, G. B. (1994, June). Bicycle use and hazard patterns in the United States. Washington, DC : U.S. Consumer Product Safety Commission.

Rodgers, G. B. (1995). Bicyclist deaths and fatality risk patterns. Accident Analysis and Prevention 27(2), pp. 215-223.

Rodgers, G. B. (1997). Factors associated with the crash risk of adult bicyclists. Journal of Safety Research 28(4), Report No. HS-042 632, pp. 233-241.

Rodgers, G. B. (2002). Effect of State helmet laws on bicycle helmet use by children and adolescents. Injury Prevention, 8, 42-46.

Romer, R. T., \& Sathisan, S. K. (1997). Integrated systems methodology for pedestrian traffic flow analysis. Transportation Research Record, No. 1578, pp. 30-37.

Rothengatter, J. A., \& Sherborne, D. J. (1994). Responsive signal settings for pedestrians in urban areas. Towards an intelligent transport system. Proceedings of the first World Congress on Applications of Transport Telematics and Intelligent Vehicle-Highway Systems, November 30 -December 3, 1994, Paris. Volume 2, pp. 477-84.

Rouphail, N. M., \& Eads, B. S. (1997). Pedestrian impedance of turning-movement saturation flow rates: comparison of stimulation, analytical, and field observations. Transportation Research Record, No. 1578, pp. 56-63.

Safety Consulting Services (1997a). A compendium of traffic safety research projects in the bicyclist safety area, 1977-1997. Draft report. Washington, DC: National Highway Traffic Safety Administration.

Safety Consulting Services (1997b). A compendium of traffic safety research projects in the pedestrian safety area, 1969-1997. Draft report. Washington, DC: National Highway Traffic Safety Administration. 
Saibel, C., Salzberg, P., \& Thurston, R. (1996). Observational survey of driver compliance with the pedestrian crosswalk law, 1995. Olympia, WA: Washington Traffic Safety Commission.

Sakai, Y. (1995). Pedestrian waiting time indicator with voice guidance. Steps Forward. Intelligent Transport Systems World Congress, Yokohama, Japan, November 9-11, 1995. Sponsored by: VERTIS, ITS America, and ERTICO. Conference Proceedings Volume 3, p. 1398.

Sarkar, S. (1993). Determination of service levels for pedestrians, with European examples. Transportation Research Record, No. 1405, pp. 35-42.

Sarkar, S. (1995a). Evaluation of different types of pedestrian-vehicle separations. Transportation Research Record, No. 1502, pp. 83-95.

Sarkar, S. (1995b). Evaluation of safety for pedestrians at macro- and microlevels in urban areas. Transportation Research Record, No. 1502, pp. 105-118.

Sarkar, S., Nederveen, A. A. J., \& Pols, A. (1997). Renewed commitment to traffic calming for pedestrian safety. Transportation Research Record, No. 1578, pp. 11-19.

Sarkar, S., Van Houten, R., \& Moffatt, J. (1999). Using license manuals to increase awareness about pedestrian hazards at intersections - Missed opportunity for educating drivers. Transportation Research Record, No. 1674, pp. 49-56.

Sarker, M. J., Koike, H., \& Morimoto, A. (1999). Assessment of gap actuated push button signal by using traffic simulation model. Utsunomiya University, Dept. of Civil Engineering, Utsunomiya, Japan. Paper presented at Transportation Research Board 78th Annual Meeting, January 10-14, 1999, Washington, DC.

Sayer, J. R., \& Mefford, M. L. (2000). The Effect of Color Contrast on Daytime and Nighttime Conspicuity of Roadworker Vests. Report no. UMTRI-2000-35. Ann Arbor, MI: University of Michigan Industry Affiliation Program for Human Factors in Transportation Safety. Available at http://hdl. handle. net/2027. 42/49418.

Sayer, J. R., Mefford, M. L., Flannagan, M. J., Sivak, M., Traube, E., \& Kojima, S. (1998). Effects of retro-reflective marking color on pedestrian detection distance. (Report No. UMTRI-98-8). Ann Arbor, MI: University of Michigan Transportation Research Institute.

Scheib, B. A. (1998). Bicycle laws: a survey and comparison of regulations in Virginia and the nation. (Report No. VTRC 97-R34). Richmond, VA: Virginia Transportation Research Council.

Schewe, G., Knöss, H. -P., Ludwig, O., Schäufele, A., \& Schuster R. (1984). Experimental studies on the question of the marginal value of alcohol-induced unfitness to operate a vehicle in the case of bicyclists. Blutalkohol 21, pp. 97-109.

Schieber, R. A., Kresnow, M. J., Sacks, J. J., Pledger, E. E., O’Neil, J. M., \& Toomey, K. E. (1996). Effect of a state law on reported bicycle helmet ownership and use. Arch Pediatr Adolesc Med 150(7), pp. 707-12.

Schieber, RA, \& Vegega, ME (Eds). (2002). Reducing childhood pedestrian Injuries - Summary of a multidisciplinary conference. Injury Prevention, 8, 1-15.

Schlundt, D., Warren, R., \& Miller, S. (2004). Reducing unintentional injuries on the nation's highways: A literature review. Journal of Health Care for the Poor and Underserved, 15, 76-98.

Schwartz, W. L. (2000a). Bicycle research data needs. In NHTSA/FHWA Pedestrian and Bicycle Strategic Planning Research Workshops. Draft report. Washington, DC: National Highway Traffic Safety Administration. 
Schwartz, W. L. (2000b). Pedestrian safety data needs. In: NHTSA/FHWA Pedestrian and Bicycle Strategic Planning Research Workshops. Draft report. Washington, DC: National Highway Traffic Safety Administration.

Scuffham, P. A., \& Langley, J. D. (1997). Trends in cycle injury in New Zealand under voluntary helmet use. Accident Analysis and Prevention 29(1), pp. 1-12.

Scuffham, P. A., Alsop, J., Cryer, C., \& Langley, J. D. (2000). Head injuries to bicyclists and the New Zealand bicycle helmet law. Accident Analysis and Prevention 32(4), pp. 565-573.

Shafizadeh, K., \& Niemeier, D. (1997). Bicycle journey-to-work: travel behavior characteristics and spatial attributes. Transportation Research Record, No. 1578, pp. 84-90.

Shimazaki, T., \& Yang, D. (1992). Bicycle use in urban areas in China. Transportation Research Record, No. 1372, pp. 26-30.

Shriver, K. (1997). Influence of environmental design on pedestrian travel behavior in four Austin neighborhoods. Transportation Research Record, No. 1578, pp. 64-75.

Silcock, D., Selby, T., Walker, R., \& Packham, D. (1998). Measurement of pedestrians' exposure to risk. Traffic Safety on Two Continents. Conference sponsored by: Swedish National Road and Transport Research Institute, Transportation Research Board, Forum of European Road Safety Research Institute, and Laboratorio Nacional de Engenharia Civil. Lisbon, Portugal, September 22- 24, 1997. Report No. VTI konferens 9A part 3, pp. 27-40.

Simpson, B. (1998). Road speed limits. Papers from Road Speed Limits conference held March 11,1998. Birmingham, UK: Aston University.

Sisiopiku, V. P., \& Akin, D. (2000). Assessment of pedestrian crossing options. Department of Civil and Environmental Engineering, East Lansing, MI, Paper No. 00-1494. Paper presented at Transportation Research Board 79th Annual Meeting, January 9-13, 2000, Washington, DC.

Snell Memorial Foundation (2002). Circumstances and Severity of Bicycle Iinjuries: Summary Report of Harborview Helmet Studies. 10p.

Snyder, M. B., \& Knoblauch, R. L. (1971, January). Pedestrian safety: The identification of precipitating factors and possible countermeasures, Volume I.(Report No. DOT HS 800 403). Washington, DC: National Highway Traffic Safety Administration.

Snyder, M. B., \& Knoblauch, R. L. (1971, January). Pedestrian safety: The identification of precipitating factors and possible countermeasures, Volume II, Appendices. (Report No. DOT HS 800 404). Washington, DC: National Highway Traffic Safety Administration.

Solomon, H. L. (1997). Pedestrian information plaques. ITE Journal 67(10), p. 22.

Sorton, A., \& Walsh, T. (1994). Bicycle stress level as a tool to evaluate urban and suburban bicycle compatibility. Transportation Research Record, No. 1438, pp. 17-24.

Sosin, D. M., Sacks, J. J., \& Webb, K. W. (1996). Pediatric head injuries and deaths from bicycling in the United States. Pediatrics 98(5), pp. 868-870.

Spaite, D. W., Criss, E. A., Weist, D. J., Valenzuela, T. D., Judkins, D., \& Meislin, H. W. (1995). A prospective investigation of the impact of alcohol consumption on helmet use, injury severity, medical resource utilization, and health care costs in bicycle-related trauma. Journal of TraumaInjury Infection \& Critical Care 38(2), pp. 287-90. 
Steinberg, G., Freedman, M., \& Fogash, M. (2000). Literature review on pedestrian/bicyclist conspicuity. Draft Final Report. Washington, DC: National Highway Traffic Administration.

Stevens, M. M., Olson, A. L., Gaffney, C. A., Tosteson, T. D., Mott, L. A., \& Starr, P. (2002). A pediatric, practiced-based, randomized trial of drinking and smoking prevention and bicycle helmet, gun, and seatbelt safety promotion. Pediatrics, 109, 490-497.

Stevenson, M., Iredell, H., Howat, P., Cross, D., Hall, M. (1999). Measuring community/environmental interventions: the Child Pedestrian Injury Prevention Project. Injury Prevention 5(1), pp. 26-30.

Stevenson, M. R. (1996). The validity of children's self-reported exposure to traffic. Accident Analysis and Prevention 28(5), pp. 599-605.

Stutts, J. C. (1997). Injuries to pedestrians and bicyclists: a look at non-motor vehicle and non-roadway events. 41st Annual Association for the Advancement of Automotive Medicine, Orlando, FL, November 10 11, 1997, pp. 139-156.

Stutts, J. C., \& Hunter, W. W. (1998). Police reporting of pedestrians and bicyclists treated in hospital emergency rooms. Transportation Research Record, No. 1635, pp. 88-92.

Stutts, J. C., \& Hunter, W. W. (1999). Motor vehicle and roadway factors in pedestrian and bicyclist injuries: an examination based on emergency department data. Accident Analysis and Prevention 31(5), pp. 505-14.

Stutts, J. C., Hunter W. W., Tracy, L., \& Wilkinson, W. C., III (1992, March). Pedestrian and bicyclist safety: a review of key program and countermeasure development during the 1980's. (Report No. DOT HS 808 108). Washington, DC: National Highway Traffic Administration. Available at http://isddc.dot.gov/OLPFiles/NHTSA/007442.pdf.

Stutts, J. C., Hunter, W. W., \& Pein, W. E. (1996). Pedestrian-vehicle crash types: an update. Transportation Research Record, No. 1538, pp. 68-74.

Subramanian, R. (2005, March). Alcohol Involvement in Fatal Motor Vehicle Traffic Crashes, 2003. (Report No. DOT HS 809 822). National Highway Traffic Safety Administration. Available at http://www-nrd.nhtsa.dot.gov/Pubs/809822.pdf.

Summala, H., Pasanen, E., Räsänen, M., \& Sievänen, J. (1996). Bicycle accidents and drivers’ visual search at left and right turns. Accident Analysis and Prevention 28(2), pp. 147-153.

Svanström, L., Welander, G., Ekman, R., \& Schelp, L. (2002). Development of a Swedish bicycle helmet promotion programme - one decade of experiences. Health Promotion International, 17, 161169.

Taillaur, A. (1997). Traffic calming experience in the UK. XIIIth World Meeting of the International Road Federation, Toronto, Canada, June 16-20, 1997.

Takamiya, S., \& Hamada, S. (1998). Information used by visually impaired people while walking. Transportation Research Record, No. 1636, pp. 104-109.

Tan, C. H., \& Zegeer, C. V. (1995). European practices and innovations for pedestrian crossings. ITE Journal 65(11), p. 24.

Tanaboriboon, Y., Agustin, T., \& Minfang, Y. (1995). Experiences in developing countries with impact of exclusive lanes for nonmotorized transportation: case studies of China and Indonesia. Transportation Research Record, No. 1487, pp. 84-89. 
Taylor, D., \& Davis, W. J. (1999). Review of basic research in bicycle traffic science, traffic operations, and facility design. Transportation Research Record, No. 1674, pp. 102-110.

Taylor, D. B., \& Mahmassani, H. S. (1998). Behavioral models and characteristics of bicycle-automobile mixed-traffic: planning and engineering implications. (Report No. SWUTC/98/60056-1). Austin, Texas: Center for Transportation Research, University of Texas.

Taylor, D. B. (1993). Analysis of traffic signal clearance interval requirements for bicycle-automobile mixed traffic. Transportation Research Record, No. 1405, pp. 13-20.

Thom, R. G., \& Clayton, A. M. (1992). Low-cost opportunity for making cities bicycle-friendly based on a case study analysis of cyclist behavior and accidents. Transportation Research Record, No. 1372, pp. 90-101.

Thom, R. G., \& Clayton, A. M. (1993). Accident data requirements for improving cycling safety. Transportation Research Record, No. 1405, pp. 1-6.

Thomas, S., Acton, C., Nixon, J., Battistutta, D., Pitt, W. R., \& Clark, R. (1994). Effectiveness of bicycle helmets in preventing head injury in children: case-control study. British Medical Journal 308(6922), pp. 173-176.

Thompson, D. C., Nunn, M. E., Thompson, R. S., \& Rivara, F. P. (1996). Effectiveness of bicycle safety helmets in preventing serious facial injury. JAMA 276(24), pp. 1974-75.

Thompson, D. C., Rivara, F. P., \& Thompson, R. (2000). Helmets for preventing head and facial injuries in bicyclists. Cochrane Database Syst Rev 2:CD001855.

Thompson, D. C., Rivara, F. P., \& Thompson, R. S. (1996). Effectiveness of bicycle safety helmets in preventing head injuries. JAMA 276(24), pp. 1968-73.

Thompson, D. C., Thompson, R. S., \& Rivara, F. P. (1990). Incidence of bicycle-related injuries in a defined population. AJPH 80(11), pp. 1388-90.

Thompson, L. (1996). Pedestrian road crossing safety. Cpl. Bibliography 331/332/333. Journal of Planning Literature 11(2), pp. 263-300.

Thompson, R. S., Rivara, F. P., \& Thompson, D. C. (1989). A case-control study of the effectiveness of bicycle safety helmets. $N$ Engl J Med 320(21), pp. 1361-7.

Thompson, R. S., Thompson, D. C., Rivara, F. P., \& Salazar, A. A. (1993). Cost-effectiveness analysis of bicycle helmet subsidies in a defined population. Pediatrics 91(5), pp. 902-907.

Thomson, J. A., Ampofo-Boateng, K., Lee, D. N., Grieve, R., Pitcairn, T. K., \& Demetre, J. D. (1998). The effectiveness of parents in promoting the development of road crossing skills in young children. British Journal of Educational Psychology 68(4), pp. 475-491.

Thornton, S., Pearson, A., Andree, K., \& Rodgers, N. (1999). Taking the child's perspective seriously. Psychologist 12(8), pp. 393-394.

Tidwell, J. E., \& Doyle, D. P. (1995). Driver and pedestrian comprehension of pedestrian law and traffic control devices. Transportation Research Record, No. 1502, pp. 119-128.

Towner, E., Dowswell, T., Burkes, M., Dickinson, H., Towner, J., \& Hayes, M. (2002). Bicycle helmets: Review of effectiveness. Road Safety Research Report, 30, 94p. Department of Transport, UK.

Tracy, L. (1992, September). Procedures and resource guide for bicycle helmet promotions: a review of bicycle helmet promotions in the United States., (Report No. DOT HS 807 963). Washington, 
DC: National Highway Traffic Safety Administration Available at http://ntl.bts.gov/lib/25000/25800/25840/DOT-HS-807-963.pdf.

TranSafety, Inc (1994). Measuring bicycle stress level. Transafety Reporter 12(9), pp. 5-6.

Transport Research Laboratory (1996). Pedestrian accident studies update (1993 - 1996). Current Topics in Transport CT 47. 1, 36p.

Transport Research Laboratory (1997). Safety helmets (cycle and motorcycle) update (1994-1997). Current Topics in Transport, ct 83. 1, 35p. Transportation Research Board (1998). Managing speed: review of current practice for setting and enforcing speed limits. (Special report 254). Washington, DC: National Academy Press.

Turner, D., Nitzburg, M., \& Knoblauch, R. (1998). Ultraviolet headlamp technology for nighttime enhancement of roadway markings and pedestrians. Transportation Research Record, No. 1636, pp. 124-131.

Tyree, P. (2000). Bicycle safety education. Paper presented at Bicycle Safety 2000 Conference, National Highway Traffic Safety Administration, Washington, DC.

Tyrrell, R. A., \& Patton, C. W. (1998). The effectiveness of educating pedestrians about their own nighttime visibility. Human Factors and Ergonomics Society 42nd Annual Meeting, Chicago IL, October 5-9, 1998, Proceedings, Volume 2, pp. 1205-09.

Tyrrell, R. A., Patton, C. W., \& Brooks, J. O. (2004). Educational interventions successfully reduce pedestrians' overestimates of their own nighttime visibility. Human Factors, 46, pp. 170-182.

Tyrrell RA, Wood JM, Carberry TP. (2004) On-road measures of pedestrians' estimates of their own nighttime conspicuity. Journal of Safety Research, 2004; 35(5): 483-90.

University of North Carolina, Highway Safety Research Center. (1996). Florida pedestrian planning and design guidelines. Chapel Hill, NC: Author.

UNC-HSRC. (1994). A compendium of available bicycle and pedestrian trip generation data in the United States. A supplement to the national bicycling and walking study. (Publication No. FHWA-PD95-009). Washington, DC: Federal Highway Administration,Van Houten, R., \& Malenfant, J. E. L. (1999). Canadian research on pedestrian safety. (Report No. FHWA-RD-99-090). Washington, DC: Federal Highway Administration,

Van Houten, R., Healey, K., Malenfant, J. E. L., \& Retting, R. (1998). Use of signs and symbols to increase the efficacy of pedestrian-activated flashing beacons at crosswalks. Transportation Research Record, No. 1636, pp. 92-95.

Van Houten, R., Malenfant, J. E. L., Van Houten, J., \& Retting, R. A. (1997a). Using auditory pedestrian signals to reduce pedestrian and vehicle conflicts. Transportation Research Record, No. 1578, pp. 20-22.

Van Houten, R., Retting, R. A., Farmer, C. M., \& Van Houten, J. (1997b). Field evaluation of a leading pedestrian interval signal phase at three urban intersections. Arlington, VA: Insurance Institute for Highway Safety.

Van Houten, R., Retting, R. A., Van Houten, J., Farmer, C. M., \& Malenfant, J. E. L. (1999). Use of animation in led pedestrian signals to improve pedestrian safety. ITE Journal 69(2), pp. 30-38 (6p. ). 
Van Houten, R., Van Houten, J., Malenfant, J. E. L., \& Andrus, D. (1999). Use of animated “eyes” so that motorists leaving an indoor parking garage look for pedestrians. Transportation Research Record, No. 1674, pp. 57-60.

Van Houten, R., Van Houten, J., Malenfant, J. E. L., \& Retting, R. (1998). Use of animation in led pedestrian signals to improve pedestrian safety. International Municipal Signal Association (IMSA). Journal 36(2), pp. 47-53.

Van Schagen I. N. L. G., \& Brookhuis, K. A. (1994). Training young cyclists to cope with dynamic traffic situations. Accident Analysis and Prevention 26(2), pp. 223-230.

Varhelyi, A. (1996). Drivers’ speed behaviour at a zebra crossing., \(Report No. LUTVDG/1-55-1996). Lund, Sweden: Lund University of Technology

Varhelyi, A. (1998). Drivers' speed behaviour at a zebra crossing: a case study. Accident Analysis and Prevention 30(6), pp. 731-743.

Virkler, M. R., \& Balasubramanian, R. (1998). Flow characteristics on shared hiking/biking/jogging trails. Transportation Research Record, No. 1636, pp. 43-46.

Virkler, M. R., \& Elayadath, S. (1994). Pedestrian speed-flow-density relationships. Transportation Research Record, No. 1438, pp. 51-58.

Virkler, M. R. (1998a). Prediction and measurement of travel time along pedestrian routes. Transportation Research Record, No. 1636, pp. 37-42.

Virkler, M. R. (1998b). Signal coordination benefits for pedestrians. Transportation Research Record, No. 1636, pp. 77-82.

Virkler, M. R. (1998c). Scramble and crosswalk signal timing. Transportation Research Record, No. 1636, pp. 83-87.

Virkler, M. R. (1998d). Pedestrian compliance effects on signal delay. Transportation Research Record, No. 1636, pp. 88-91.

Virkler, M. R., Elayadath, S., \& Saranathan, G. (1995). High-volume pedestrian crosswalk time requirements. Transportation Research Record, No. 1495, pp. 41-48.

Wachtel, A., \& Lewiston, D. (1994). Risk factors for bicycle-motor vehicle collisions at intersections. ITE Journal 64(9), pp. 30-35.

Walker, I. (2007). Drivers overtaking bicyclists: Objective data on the effects of riding position, helmet use, vehicle type and apparent gender. Accident Analysis and Prevention, 39, 417-425.

Waller, J. A. (1995). Bicycle ownership, use, and injury patterns among elementary schoolchildren. Injury Prevention 1(4), pp. 256-61.

Warren, D. (2000). Speed management and the non-motorist. In: NHTSA/FHWA Pedestrian and Bicycle Strategic Planning Research Workshops. Draft report.

Weber, J. E., Maio, R. F., Blow, F. C., Hill, E. M., Barry, K. L., \& Waller, P. F. (2002) Alcohol and/or other drug use among adult non-occupant motor vehicle crash victims. Alcohol \& Alcoholism, 37, 468-471.

Weinberger, S. J. (1997). Experimental crosswalk warning device testing in California. Institute of Transportation Engineers 67th Annual Meeting, Boston, MA, August 3-7, 1997. 
Welander, G., Ekman, R., \& Schelp, L. (1995). Effectiveness of systematic helmet information. Head injuries connected with bicycle accidents among children 0-14 years and other age groups in Skaraborg county, 1978-1989, compared with four other counties and Sweden. Road Safety in Europe and Strategic Highway Research Program (SHRP), Lille, France, September 26-28, 1994 (VTI Konferens), No. 2A:2, pp. 85-102.

Welander, G., Ekman, R., Svanstrom, L., Schelp, L., \& Karlsson, A. (1999). Bicycle injuries in Western Sweden: a comparison between counties. Accident Analysis and Prevention 31(1-2), pp. 13-19.

Wellar, B. (E. D. ). (1996). Proceedings of the 1996 Ottawa-Carleton pedestrian safety conference: Perspectives on Pedestrian Safety.

Wessels, R., Limotti, B., Davis, D., \& Dornfeld, M. (1995). Bicycle collision data in Washington state, 1988 to 1993. Olympia, WA: Washington State Department of Transportation.

Wessels, R., Limotti, B., Davis, D., Riner, I., Hartsell, R., \& Dornfeld, M. (1997). Washington state bicycle collision data, 1994 to 1996. Olympia, WA: Washington State Department of Transportation.

Wessels, R. L. (1996). Bicycle collisions in Washington State: a six-year perspective, 1988-1993. Transportation Research Record, No. 1538, pp. 81-90.

West, R., Train, H., Junger, M., West, A., \& Pickering, A. (1999). Accidents and problem behaviour. Psychologist 12(8), pp. 395-397.

Whitebread, D., \& Neilson, K. (1999). Learning to cross the road: Cognition in action. Psychologist 12(8), pp. 403-405.

Wierda, M., \& Brookhuis, K. A. (1991). Analysis of cycling skill: A cognitive approach. Applied Cognitive Psychology 5(2), pp. 113-122.

Wigan, M. (1995). Treatment of walking as a mode of transportation. Transportation Research Record, No. 1487, pp. 7-13.

Wilkinson III, W. C. (1993). Trading off among the needs of motor vehicle users, pedestrians, \& bicyclists. The national bicycling \& walking study - Case Study No. 10. (Publication No. FHWA-PD-94-012). Washington, DC: Federal Highway Administration.

Wilkinson III, W. C., Clarke, A., Epperson, B., \& Knoblauch, R. (1994). Selecting roadway design treatments to accommodate bicycles. (Report No. FHWA-RD-92-073). Washington, DC: Federal Highway Administration.

Williams, J., McLaughlin, K., \& Clarke, A. (1993). Balancing engineering, education, law enforcement, and encouragement. The national bicycling and walking study - Case Study No. 11. (Publication No. FHWA-PD-93-009). Washington, DC: Federal Highway Administration.

Wilson, J., Fang, M., \& LeBrun, D. (2003). Locations for collisions involving alcohol and drug impaired pedestrians in urban areas. 2003 International Cooperation on Theories and Concepts in Road Safety - Extra Workshop :Proceedings. Vienna, Austria.

Wilson, J., Fang, M., \& LeBrun, D. (2003). Locations for collisions involving alcohol and drug impaired pedestrians in urban areas. 2003 International Cooperation on Theories and Concepts in Road Safety - Extra Workshop :Proceedings. Vienna, Austria.

Womack, K. N. (1996). Bicycle-helmet use evaluation using comparison-site observation. Transportation Research Record, No. 1538, pp. 91-95. 
Wood JM, Tyrrell RA, Carberry TP. (2005). Limitations in drivers' ability to recognize pedestrians at night. Human Factors, 47(3): 644-53.

Wynne, G. G. (1992). A study of bicycle and pedestrian programs in European countries. The national bicycling and walking study - Case Study No. 16. (Publication No. FHWA-PD-92-037). Washington, DC: Federal Highway Administration.

Yamori, K. (1998). Going with the flow: Micro-macro dynamics in the macrobehavioral patterns of pedestrian crowds. Psychological Review 105(3), pp. 530-557.

Yelon, J. A., Harrigan, N., \& Evans, J. T. (1995). Bicycle trauma: a five-year experience. American Surgeon 61(3), pp. 202-5.

Young, S. B. (1999). Evaluation of pedestrian walking speeds in airport terminals. Transportation Research Record, No. 1674, pp. 20-26.

Zacharias, J. (1999). The Amsterdam experiment in mixing pedestrians, trams and bicycles. ITE Journal 69(8), 6p.

Zavoski, R., Lapidus, G., Lerer, T., \& Banco, L. (1995). Bicycle injury in Connecticut. Connecticut Medicine 59(1), pp. 3-9.

Zeedyk, M. S., \& Kelly, L. (2003). Behavioural observations of adult-child pairs at pedestrian crossings. Accident Analysis and Prevention, 35, 771-776.

Zegeer, C. V. (1991, August). Synthesis of safety research - pedestrians. (Report No. FHWA-SA-91034), Federal Highway Administration, Washington, DC. No..

Zegeer, C. V. (1994). FHWA study tour for pedestrian and bicyclist safety in England, Germany, and The Netherlands. (Report No. FHWA-PL-95-006). Washington, DC: Federal Highway Administration.

Zegeer, C. V. (2000a). Engineering countermeasures research for bicycling. In: NHTSA/FHWA Pedestrian and Bicycle Strategic Planning Research Workshops. Draft report. Washington, DC: National Highway Traffic Safety Administration.

Zegeer, C. V. (2000b). Pedestrian facilities research. In: NHTSA/FHWA Pedestrian and Bicycle Strategic Planning Research Workshops. Draft report. Washington, DC: National Highway Traffic Safety Administration.

Zegeer, C. V., \& Feske, D. (1994). National bicycling and walking study: Transportation choices for a changing America. Report to Congress. (Report No. HEP-50-3-94(225M)E FHWA-PD-94-023). Washington, DC: Federal Highway Administration.

Zegeer, C. V., \& Seiderman C. B. (1999). Designing for pedestrians. In: The Traffic Safety Toolbox, Institute of Transportation Engineers.

Zegeer, C. V., Cynecki, M., Fegan, J., Gilleran, B., Lagerwey, P., Tan, C., \& Works, R. (1994a). Summary report on FHWA study tour for pedestrian and bicyclist safety in England, Germany, and the Netherlands. (Report No. FHWA-PL-95-006). Washington, DC: Federal Highway Administration.

Zegeer, C. V., Stewart, J. R., \& Huang, H. (2000). Safety effects of marked vs unmarked crosswalks at uncontrolled locations. Washingtoin, DC: Federal Highway Administration. 
Zegeer, C. V., Stutts, J., Hunter, B., \& Pein, W. (1994). The national bicycling and walking study Transportation choices for a changing America. (Publication No. FHWA-PD-94-023). Washington, DC: Federal Highway Administration.

Zegeer, C. V., Stutts, J. C., Huang, H., Zhou, M., \& Rodgman, E. (1993). Analysis of elderly pedestrian accidents and recommended countermeasures. Transportation Research Record, No. 1405, pp. 56-63.

Zehnpfennig, G. H., Cromar, J., \& Maclennan, S. J. (1993). Measures to overcome impediments to bicycling and walking. The national bicycling and walking study - Case Study No. 4. (Publication No. FHWA-PD-93-031). Washington, DC: Federal Highway Administration.

Zein, S. R., Geddes, E., Hemsing, S., \& Johnson, M. (1997). Safety benefits of traffic calming. Transportation Research Record, No. 1578, pp. 3-10. 

DOT HS 811614

June 2012

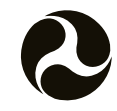

U.S. Department of Transportation

National Highway

Traffic Safety

Administration

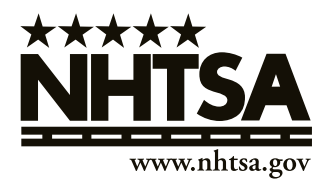

8474-060512-v3 